\title{
Atomic Spectrometry Update - A review of advances in environmental analysis
}

Owen T. Butler, ${ }^{\mathrm{a} *}$ Warren R.L. Cairns, ${ }^{\mathrm{b}}$ Jennifer M. Cook,${ }^{\mathrm{c}}$ Christine M Davidson, ${ }^{\mathrm{d}}$ and Regina Mertz-Kraus. ${ }^{\mathrm{e}}$

${ }^{a}$ Health and Safety Laboratory, Harpur Hill, Buxton, UK SK17 9JN

owen.butler@hsl.gsi.gov.uk

* review coordinator

${ }^{\mathrm{b}} \mathrm{CNR}$-IDPA, Universita Ca' Foscari, 30123 Venezia, Italy

${ }^{\mathrm{c} B r i t i s h}$ Geological Survey, Keyworth, Nottingham, UK NG12 5GG

dUniversity of Strathclyde, Cathedral Street, Glasgow, UK G1 1XL

'Institut für Geowissenschaften, Johannes Gutenberg-Universität, Becher-Weg 21, 55099 Mainz, Germany

This is the $33^{\text {th }}$ annual review of the application of atomic spectrometry to the chemical analysis of environmental samples. This Update refers to papers published approximately between August 2016 and June 2017 and continues the series of Atomic Spectrometry Updates (ASUS) in Environmental Analysis ${ }^{1}$ that should be read in conjunction with other related ASUs in the series, namely: clinical and biological materials, foods and beverages ${ }^{2}$; advances in atomic spectrometry and related techniques ${ }^{3}$; elemental speciation $^{4}$; X-ray spectrometry ${ }^{5}$; and metals, chemicals and functional materials ${ }^{6}$.

In the field of air analysis, highlights within this review period included the fabrication of new air samplers using 3D printer technology, development of a portable aerosol concentrator unit based upon electrostatic precipitation and instrumental developments such as a prototype portable spark emission spectrometer to quantify metal particles in workplace air. The advent of ICP-MS/MS systems has enabled analysts to develop improved methods for the determination of PGEs and radioactive elements present in airborne particles. With such instruments, the capacity to eliminate or minimise many isobaric interferences now enables analysts to forego the use of many onerous sample clean-up procedures. Improvements in the 
capabilities of aerosol mass spectometers were noted as were developments in other complimentary measurement techniques such as Raman.

In the arena of water analysis there are growing concerns regarding engineered NPs e.g. Ag NPs, entering water courses resulting in the development and optimisation of new methods based upon FFF and sp-ICP-MS techniques to measure such inputs. Similar concerns exist for MRI contrasting agents e.g. Gd-based compounds and here improved methodologies that involve the use of sample preconcentration using chelating columns and ICP-MS analysis have been proposed.

In the field of plant and soil analysis, similar to developments in the water sector, there has been increased interest in the measurement of NPs. Many comparisons of sample digestion or extraction methods have been reported but a key issue rarely addressed is transferability, i.e. whether methods preferred by one group of researchers using particular apparatus are also optimal in a different laboratory using different apparatus. New sample preconcentration methods continued to appear although - as in previous years - the CRMs selected for method validation often failed to reflect the nature of the intended sample(s). A noteworthy advance is the use of HR-CS-ETMAS for elemental analysis. Developments in LIBS included greater use of TEA $\mathrm{CO}_{2}$ lasers in place of Nd:YAG lasers and increased use of stand-off measurement. The past year has also seen a rise in proximal sensing using LIBS and pXRFS.

In the field of geological analysis, the quest continues for well-characterised matrixmatched materials suitable for the calibration of elemental and, particularly, isotopic measurements by microanalytical techniques. Increasing interest in stable isotope analysis by SIMS is reflected by the number of matrix-matched RMs developed specifically for this technique. Much work continues on ways of improving isotope ratio measurements by ICPMS and TIMS for a wide range of different isotope systems relevant to geochemical studies. High spatial resolution analysis by LIBS, LA-ICP-MS and SIMS to obtain data on chemical and isotopic variations in minerals and biogenic materials in two and three dimensions are the foundation for many new insights in geoscientific research. In XRFS and LIBS, the advantages and limitations of portable instrumentation continue to be major focus of activity. 
$1.1 \quad$ Review papers

$1.2 \quad$ Sampling techniques

$1.3 \quad$ Reference materials and calibrants

$1.4 \quad$ Sample preparation

$1.5 \quad$ Instrumental analysis

1.5.1 Atomic absorption, emission and fluorescence spectrometry

1.5.2 Mass spectrometry

1.5.2.1 Inductively coupled plasma mass spectrometry

1.5.2.2 Other mass spectrometry techniques

1.5.3 X-ray spectrometry

1.5.4 Other instrumental techniques

$2 \quad$ Water analysis

$2.1 \quad$ Review papers

$2.2 \quad$ Reference materials

2.3 Sample preconcentration and extraction

$2.4 \quad$ Speciation and nanomaterial analysis

2.4.1 Review papers

2.4.2 Elemental speciation

2.4.3 Characterisation and determination of nanomaterials

$2.5 \quad$ Instrumental analysis

2.5.1 Atomic absorption spectrometry

2.5.2 Vapour generation techniques

2.5.3 Inductively coupled plasma mass spectrometry

2.5.4 Laser induced breakdown spectroscopy

2.5.5 X-ray spectrometry

Analysis of soils, plants and related materials

$3.1 \quad$ Review papers

$3.2 \quad$ Reference materials

3.3 Sample preparation

3.3.1 Sample dissolution and extraction

3.3.2 Sample preconcentration

$3.4 \quad$ Instrumental analysis

3.4.1 Atomic absorption spectrometry

3.4.2 Atomic emission spectrometry 
3.4.3 Atomic fluorescence spectrometry

3.4.4 Inductively coupled plasma mass spectrometry

3.4.5 Laser induced breakdown spectroscopy

3.4.6 X-ray spectrometry

Analysis of geological materials

4.1 Reference materials and data quality

4.2 Sample preparation, dissolution, separation and preconcentration

4.3 Instrumental analysis

4.3.1 Review papers

4.3.2 Atomic absorption and atomic emission spectrometry

4.3.3 Laser induced breakdown spectroscopy and related techniques

4.3.4 Inductively coupled plasma mass spectrometry

4.3.4.1 Instrumentation

4.3.4.2 Trace element determinations by solution-based ICP-MS

4.3.4.3 Trace element determinations by laser ablation ICP-MS

4.3.4.4 Isotope ratio determinations

4.3.5 Thermal ionisation mass spectrometry

4.3.6 Secondary ion mass spectrometry

4.3.7 Other mass spectrometric techniques

4.3.8 X-ray spectrometry

4.3.8.1 Laboratory-based XRFS

4.3.8.2 Portable XRFS

4.4 Data reduction software

5 Glossary of terms

$6 \quad$ References 


\subsection{Review papers}

Several review papers summarised developments in the detection, preparation and characterisation of engineered nanoparticles. Useful sample preparation procedures ${ }^{7}$ (254 references) for the subsequent analysis of metallic and metal oxide NPs found in biological, customer product and environmental samples were tabulated and promising future directions discussed. The developments in FFF applications in biomedical, food and environmental studies considered in a review ${ }^{8}$ (141 references) were drawn mostly from papers published in the last four years. A review ${ }^{9}$ (82 references) on the analytical capabilities of different MSbased techniques for the interrogation of engineered inorganic nanomaterials considered future developments in elemental analysis as well as developments in hyphenated techniques for molecular analysis. Developments ${ }^{10}$ (130 references) in $\mathrm{Hg}^{0}$ measurements employing solidstate sensors and approaches such as quartz-crystal microbalance, resistitive measurements and surface acoustic wave were reviewed.

\subsection{Sampling techniques}

Developments in sampler technologies for workplace air monitoring included a new personal sampler ${ }^{11}$ for the measurement of respirable quartz particles. This sampler, fabricated using 3D printing, was designed to collect particulate matter onto a small filter spot of ca. $9 \mathrm{~mm}$ diameter for subsequent analysis using portable FTIR instrumentation. It was anticipated that this approach will enable faster exposure assessments to be conducted on site. Sampling mixed-phased atmospheres remains challenging. It was interesting to note the development ${ }^{12}$ of a new personal sampler for the concurrent sampling of $\mathrm{H}_{2} \mathrm{SO}_{4}$ acid mist and $\mathrm{SO}_{2}$ gas. This device employed an impactor to collect the thoracic size fraction of the aerosol and a porous membrane denuder to collect the $\mathrm{SO}_{2}$. The performance of this prototype, constructed in PTFE, was evaluated both in laboratory and field settings. A new low-cost, disposable personal sampler ${ }^{13}$, designed to operate at a nominal $10 \mathrm{~L} \mathrm{~min}^{-1}$ rather than a more conventional $2 \mathrm{~L}$ $\min ^{-1}$, enabled a five-fold increase in sample mass to be collected per unit time. This is most welcome as reductions in workplace air exposure limits for many metals are anticipated and will bring other other challenges, such as the need to reassess the potential for sample contamination. The presence of metal contamination in the filter media can be of concern. Blanks levels ${ }^{14}$ in cotton-based textile materials were lower than those in a nylon mesh material currently used in the nanoparticle respiratory deposition sampler (Zeflon International). Experience gained by researchers at NIOSH in characterising exposure to airborne nanomaterials in the workplace enabled them to refine their assessment strategy ${ }^{15}$. This 
approach, termed NEAT 2.0 (Nanomaterial Exposure Assessment Technique), placed a stronger emphasis on time-averaged, filter-based sampling for future worker exposure assessments compared to the protocols in the original NEAT 1.0 document.

New approaches for assessing occupational exposure to airborne pollutants are most interesting to read. A small wearable aerosol microconcentrator developed by NIOSH researchers ${ }^{16}$ employed corona discharge to ionise sampled particles which were subsequently precipitated onto an electrode. It was considered that this approach could potentially be superior to alternatives such as filtration, focused impaction using aerodynamic lens or spot collection using condensational growth. They envisaged that this unit could form the basis of a new generation of compact hand-held aerosol analysers offering real-time in-situ measurements. Analysis of exhaled breath condensate (EBC) offers a potential for a noninvasive method for detecting inhaled NPs. A study ${ }^{17}$ of methodologies for the preservation of inhaled welding fume in EBC concluded that flash-freezing was preferable to storing samples at room temperature for maintaining the original particle morphology. Spanish researchers ${ }^{18}$ provided evidence of the direct adsorption of $\mathrm{Hg}$ in human hair after analysing samples from individuals who were occupationally exposed.

The Beta Attenuation Monitor is a widely used ambient air particulate sampler which provides $\mathrm{PM}_{2.5}$ mass concentration data in real time, often at hourly intervals. Particles are collected and deposited as a spot on a filter tape and the attenuation of a radiation beam passed through this spot is exponentially dependent on the mass of particles deposited. Once a reading is taken, the filter spool is wound on to present a fresh surface for the next sampling interval. Researchers based in the US ${ }^{19}$ investigated whether it was possible to recover and analyse filter spots to provide additional time-resolved chemical data. The glass-fibre filter tapes currently used contain elemental impurities which limit the successful determination of many metals of potential interest. Another limitation was the inability to determine elemental $\mathrm{C}$, a marker widely used for monitoring diesel engine emissions. The authors suggested that replacement with a cleaner Teflon filter tape could well be beneficial. Coincidentally, a new sampler incorporating a XRFS unit is now commercially available.

German researchers ${ }^{20}$ evaluated techniques for sampling volatile As species $\left(\mathrm{AsH}_{3}\right.$ and methylated species) present in fumarolic gases and emitted from volcanoes. They noted that previously reported sampling techniques, such as needle trap devices and cryotrapping, did not perform well due to either poor collection efficiency or artifact formation during storage. Tedlar $^{\mathrm{TM}}$ gas bags performed well as samplers, although 60 to $90 \%$ losses of methylated species remained possible if test items were stored for extended periods prior to analysis. The dominant 
species found in a study of Italian fumaroles was $\mathrm{AsH}_{3}$ suggesting that microbially catalysed methylation was of minor importance.

Sampling atmospheric trace species can be challenging. An investigation ${ }^{21}$ into memory effects of gold-coated sorbent tubes, typically used for sampling trace levels of atmospheric $\mathrm{Hg}^{0}$, concluded that repetitive thermal cleaning of the sampling tubes to remove stubborn adsorbed traces of $\mathrm{Hg}$ and hydrocarbons resulted in a two-fold improvement in LOD. The AirCore sampler is a balloon-mounted air sampler which collects a continuous air profile during descent through the stratosphere. A new sub-sampler, dubbed the SAS (Stratospheric Air Sub-sampler) was developed ${ }^{22}$ to extract aliquots of collected air from this AirCore device, for subsequent determination of ${ }^{14} \mathrm{CO}_{2}$ by IRMS, whilst maintaining vertical height profile information.

\subsection{Reference materials and calibrants}

The source matter for two new NIST certified reference materials ${ }^{23}$ was dust collected from the air intake facility at a large city-centre exhibition hall. Uniquely, these materials were certified for both organic and inorganic measurands including $\mathrm{Cd}$ and $\mathrm{Pb}$ (by ID-ICP-MS), $\mathrm{Hg}$ (by ID-CV-ICP-MS) and Cr, Mn and V (by ICP-AES and INAA). Both materials are now available as NIST SRM 2786 (fine atmospheric particulate matter (mean particle diameter $<10$ $\mu \mathrm{m}$ ) and NIST SRM 2787 (fine atmospheric particulate matter (mean particle diameter $<2.5 \mu \mathrm{m})$. The status of $\mathrm{Pu}$ and $\mathrm{U}$ isotopic particulate standards available from NBL was reviewed ${ }^{24}$ and suggestions made for future requirements. Such CRMs are a prerequisite for ensuring the quality of measurements in key areas such as nuclear forensics, safeguarding and nonproliferation operations, but improvements in accuracy and precision now attainable with modern MC-ICP-MS cannot be fully exploited because of the large uncertainties associated with some existing NBL materials.

A suite of isotopic $\mathrm{CH}_{4}$ reference gases in air $^{25}$ was developed and certified with uncertainities of $<1.5 \%$ and $<0.2 \%$ for $\delta^{2} \mathrm{H}$ and $\delta^{13} \mathrm{C}$. Aliquots of these reference gases were diluted to provide $\mathrm{CH}_{4}$ standards with typical atmospheric concentrations and branded as JRAS-M16 (Jena Reference Air Set-Methane 2016). Calibration of Hg monitoring instruments typically relies upon gas standards prepared from the saturated head-space above a pool of liquid $\mathrm{Hg}$ kept at a constant temperature. New SI-traceable results ${ }^{26}$ for the $\mathrm{Hg}^{0}$ concentration at saturation in air between 15 and $30^{\circ} \mathrm{C}$, are welcome. An innovative automated temperaturecontrolled sampling system, constructed for this purpose, enabled defined aliquots of $\mathrm{Hg}$ enriched head-space air to be collected at different temperatures. These were collected into a 
liquid medium, mixed with defined volumes of an isotopically enriched $\mathrm{Hg}$ solution and presented for ID-ICP-MS analysis.

\subsection{Sample preparation}

Recovery of useful elements from waste is of growing interest. A two-step microwave-assisted digestion procedure ${ }^{27}$ was recommended for the extraction of REEs from coal fly ash. Ash samples were heated in a $\mathrm{H}_{2} \mathrm{SO}_{4}: \mathrm{HF}$ acid mixture $(4+1)$ on a hotplate and then subjected to attack with dilute $\mathrm{HCl}$ in the microwave oven. Recoveries for $\mathrm{Ce}, \mathrm{Dy}, \mathrm{Er}, \mathrm{Eu}, \mathrm{Gd}, \mathrm{Ho}, \mathrm{La}, \mathrm{Lu}$, $\mathrm{Nd}, \mathrm{Pr}, \mathrm{Sc}, \mathrm{Sm}, \mathrm{Tb}, \mathrm{Tm}, \mathrm{Y}$ and $\mathrm{Yb}$ were $>95 \%$ when NIST SRM 1633b (coal fly ash) was analysed by ICP-AES. An analytical procedure ${ }^{28}$ for the determination of total $\mathrm{Cr}$ and $\delta^{53} \mathrm{Cr}$ in lichens and mosses by SF-ICP-MS and MC-ICP-MS employed a high pressure/temperature acid digestion in conjunction with a sample clean-up step using an anion-exchange resin. This approach was deemed robust as the reproducibility of isotope ratio measurements, performed by different operators on different occasions over a period of two months, was $c a$. $0.11 \%$ (2SD). The strong negative correlation between $\delta^{53} \mathrm{Cr}$ and total $\mathrm{Cr}$ in lichen and moss samples indicated that $\mathrm{Cr}$ deposited from local emission source(s) was depleted in heavy isotopes.

Bioaccessibility measurements are conducted to ascertain what fractions of metals can potentially be solubilised within humans once inhaled or injested. The SBET (simplified bioaccessibility extraction test) and the stomach phase of the UBM (unified bioaccessibility method), originally developed for contamination land studies procedures, have been miniaturised $^{29}$ for air filter applications. This was geared towards the analysis of filters employed in the TEOM air sampler, widely used within the UK and other air monitoring networks. This air sampler measures $\mathrm{PM}_{10 / 2.5}$ mass in real-time but filters are often then discarded so their further use was welcome. Bioaccessibility measurements of $\mathrm{As}, \mathrm{Cd}, \mathrm{Cr}, \mathrm{Fe}$, $\mathrm{Mn}, \mathrm{Ni}, \mathrm{Pb}$ and $\mathrm{Zn}$ in small $\mathrm{mg}$ quantities of particulate matter were undertaken. Contamination issues were overcome by prewashing syringe filters in dilute acid. Rasmussen and coworkers ${ }^{30}$ investigated the effect of $\mathrm{pH}$, particle size and crystal form on the dissolution behaviour of $\mathrm{Zn}$, $\mathrm{ZnO}$ and $\mathrm{TiO}_{2}$ engineered-nanomaterials in simulated body-fluids. They concluded that experimental $\mathrm{pH}$ and temperature conditions should be reported in all future studies so as to facilitate the comparability of published data.

Radionuclide measurements often require laborious and complex sample manipulation, separation, clean-up and preconcentration steps prior to analysis. Following the Fukushima Dai-ichi nuclear power plant incident, a Japanese consortium developed ${ }^{31}$ an ICP-MS/MS procedure for the simultaneous determination of ${ }^{135} \mathrm{Cs},{ }^{137} \mathrm{Cs},{ }^{239} \mathrm{Pu}$ and ${ }^{240} \mathrm{Pu}$ isotopes in 
suspended particles. Radiocesium and $\mathrm{Pu}$ were sequentially preconcentrated using ammonium molydophosphate and ferric hydroxide precipitation and then separated from matrix elements using a two-stage ion-exchange chromatographic procedure. Limbeck and his team ${ }^{32}$ improved the manipulation of radioactive particles by upgrading and automating a fission track method. They incorporated a laser micro-dissection system to facilitate the isolation of these particles of interest and developed a harvester unit to enable the collection and transfer of identified particles to other micro-analytical techniques. This new capability enabled $U$ isotopic signatures in nuclear materials to be determined within a turn-around of 12 days. Researchers at the University of Erlangen ${ }^{33}$ evaluated various methods for sampling carbonyls in air for subsequent ${ }^{14} \mathrm{C}$ dating using AMS. Two of these procedures utilised the Strecker synthetic method to form amino acids from carbonyls using either sodium cyanide or trimethylsilylcyanide and the third semicarbazide to form crystalline carbazones. All resultant adducts were separated and purified using TLC. The performance of these procedures compared favourably against the more conventional carbonyl sampling approach employing derivatisation with 2,4-dinitrophenylhydrazine and separation of adducts using HPLC.

A wide-ranging review paper $^{34}$ (112 references) both outlined the various approaches used to speciate or fractionate $\mathrm{Mn}$ in a diverse range of matrices such as air, animals, plants and waters and summarised a number of useful extraction procedures.

\subsection{Instrumental analysis}

\subsubsection{Atomic absorption, emission and fluorescence spectrometry}

The determination ${ }^{35}$ of $\mathrm{S}$ in airborne particles collected on a filter using high resolution continuum source AAS exploited the characteristic molecular absorption of the CS molecule at $258.056 \mathrm{~nm}$ and results obtained on a range of CRMs were within their certified uncertainity limits. The same authors exploited a solid sampling capability ${ }^{36}$ for the direct and rapid determination of $\mathrm{Hg}$ in airborne particles by placing filter aliquots directly into the graphite furnace, not employing a pyrolysis step and by using Ag and Au NPs as novel matrix modifiers.

A portable system ${ }^{37}$ for the on-line determination of $\mathrm{Hg}$ speciation in flue and process gases consisted of two AAS detectors in parallel, each hyphenated to a gas sampling system which used impingers to trap $\mathrm{Hg}$ species. In the first system, total $\mathrm{Hg}$ was measured by reducing all $\mathrm{Hg}$ species in the sampled gas stream to $\mathrm{Hg}^{0}$ using $\mathrm{SnCl}_{2}$ as reducant. In the second system, sampled flue gas was initially passed through a $\mathrm{KCl}$ solution to remove $\mathrm{Hg}^{\mathrm{II}}$ and thereby allowing only $\mathrm{Hg}^{0}$ to be detected. The $\mathrm{Hg}^{\mathrm{II}}$ species concentration in the sampled flue gas was 
calculated from the difference between the two results. Usefully, calibration units, that produced $\mathrm{Hg}^{0}$ and $\mathrm{Hg}^{\mathrm{II}}$ gas standards, were also developed.

On-line measurements are most useful when attempting to elucidate the kinetics of chemical processes. In one example ${ }^{38}$, an SMPS was coupled to an ICP-AES system for the real-time measurement of the elemental composition of size-resolved NP aggregrates synthesised within a diffusion flame reactor. There was a correlation between precursor molar ratios and elemental ratio in magnetite and $\mathrm{SiO}_{2}$ particles in the size range 50-140 $\mathrm{nm}$. In a second example ${ }^{39}$, an automated ICP-AES system for the continuous leaching of air filter samples to assess the bioaccessability of $\mathrm{Al}, \mathrm{Ba}, \mathrm{Cu}, \mathrm{Fe}$ and $\mathrm{Mn}$ in $\mathrm{PM}_{10}$ particles was developed.

Work developing new prototype instruments for in situ measurements continues. Reseachers at the University of Miami deployed ${ }^{40}$ their LIF instrument, designed for in situ trace $\mathrm{Hg}$ measurement in ambient air, during a recent instrumental comparison exercise held in Reno. At a temporal resolution of $c a$. 5 minutes, their $\mathrm{Hg}^{0}$ measurements were within $10-25 \%$ of measurements obtained by two, more conventional, AFS instruments equipped with goldtrap concentrator units. Comparative oxidised $\mathrm{Hg}$ measurements were also performed using $\mathrm{KCl}$-coated annular denuders to preconcentrate air samples. The resultant $\mathrm{Hg}^{0}$ was determined following a thermal reduction step. Although results agreed with those measured by AFS instruments also equipped with $\mathrm{KCl}$-denuders, measurement uncertantities were large. This was attributed to the challenges of quantifying a measurand at the $\mathrm{pg} \mathrm{m}^{-3}$ level. Researchers ${ }^{41}$ at NIOSH developed a field-portable microplasma instrument for the real-time determination of carbon nanomaterials in workplace air. Their approach involved the preconcentration of aerosols on a microelectrode tip (see also section 1.2) for analysis by spark emission spectrometry (SES) at the characteristic C line of $247.856 \mathrm{~nm}$. The absolute LOD was $1.6 \mathrm{ng}$, equivalent to $c a .240 \mathrm{ng} \mathrm{m}^{-3}$ for a nominal 7.5 L air sample. This study demonstrated that SES could form the basis of a new type of portable aerosol analyser for in-situ elemental analysis in the workplace.

\subsubsection{Mass spectrometry}

1.5.2.1 Inductively coupled plasma mass spectrometry. Two improved biomonitoring applications have been reported. In one ${ }^{42}$, ICP-MS/MS was used to determine Pd, Pt and Rh in particulates deposited on moss samples. Reliable measurements were obtained, either on-mass $\left({ }^{103} \mathrm{Rh}\right)$ or by employing a mass-shift approach using $\mathrm{NH}_{3}$ as a reaction gas (measurements performed at masses 159 for $\mathrm{Pd}, 171$ for $\mathrm{Rh}$ and 229 for $\mathrm{Pt}$ ). Elemental recoveries were 
quantitative, within stated certified ranges, when test portions of IRMM CRM BCR 723 (road dust) were analysed. Furthermore, results for moss samples were in agreement with data derived from a more laborious preparatory procedure involving CPE and measurement by quadrupole ICP-MS. In an ETV-DRC-ICP-MS method ${ }^{43}$ for the determination of $\mathrm{Cd}, \mathrm{Cr}, \mathrm{Hg}$ and $\mathrm{Pb}$ in honey, homogenates were prepared by simply diluting samples in dilute $\mathrm{HNO}_{3}$ and adding ascorbic acid as a modifier. Due to matrix mismatch between samples and aqueous standards, both ID and standard addition calibration protocols were required for quantification. The method LODs were $0.4,0.1,0.6$ and $0.5 \mathrm{ng} \mathrm{g}^{-1}$ for these four elements.

An intriguing but perhaps complicated and not very portable approach ${ }^{44}$ for the direct analysis of mercury in air involved coupling a gas-to-particle conversion unit to an ICPMS instrument. The process involved sampling air containing traces of $\mathrm{Hg}^{0}$ which were converted to $\mathrm{HgO}$ and subsequently agglomerated with $\mathrm{NH}_{4} \mathrm{NO}_{3}$ particles. These agglomerates were then introduced into the ICP-MS instrument through a gas-exchange device in which the matrix air was replaced with Ar sufficient to sustain the plasma. The method LOD of $0.12 \mathrm{ng}$ $\mathrm{m}^{-3}$ was considered sufficient to measure airborne $\mathrm{Hg}$ concentrations of $c a .2 \mathrm{ng} \mathrm{m}^{-3}$ with a high temporal resolution without recourse to sample preconcentration. The usefulness of isotopes for elucidating the biogeochemical cycle of mercury is attracting widespread interest. In a study from Beijing ${ }^{45}$, the $\mathrm{Hg}$ isotopic composition was determined both for particles from 30 potential industrial source materials and for those collected on $23 \mathrm{PM}_{2.5}$ filter samples. The results were influenced by seasonal variations in both mass-dependent fractionation (represented by the ratio ${ }^{202} \mathrm{Hg} /{ }^{198} \mathrm{Hg}, \delta^{202} \mathrm{Hg}$ ) and mass-independent fractionation of isotopes with odd and even mass numbers (represented by $\Delta^{199} \mathrm{Hg}$ and $\Delta^{202} \mathrm{Hg}$ ). All filter samples were highly enriched in $\mathrm{Hg}$ and displayed wide ranges of both $\delta^{202} \mathrm{Hg}(-2.18$ to $0.51 \%)$ and $\Delta^{199} \mathrm{Hg}$ $(-0.53$ to $0.57 \%$ o $)$ as well as small positive $\Delta^{202} \mathrm{Hg}(0.02$ to $0.17 \%)$. Such variations were attributed to all-year-round anthropogenic emission sources such as smelting and cement production, as well as seasonal variations dominated by coal combustion in winter and biomass burning in autumn. The more positive $\Delta^{199} \mathrm{Hg}$ values, noted in air samples collected in the spring and early summer, were attributed long-range $\mathrm{Hg}$ emissions that had undergone extensive photochemical reduction. In another China-based study ${ }^{46}$, the fractionation of $\mathrm{Hg}$ isotopes in particles arising from coal combustion and seawater flue gas desulfurisation (SFGD) processes was examined. Researchers employed MC-ICP-MS with a precombustion step for the elegant liberation of $\mathrm{Hg}$ from solid matrices. It was demonstrated that whilst stack emissions were enriched with lighter Hg isotopes, the SFGD end-product was enriched with heavier $\mathrm{Hg}$ isotopes. The authors concluded that this information could be most useful in 
tracing $\mathrm{Hg}$ emissions from such power plants. An interesting and more theoretical paper ${ }^{47}$ described the first measurements of isotope fractionation during the oxidation of $\mathrm{Hg}^{0}$ by halogen atoms. The study used a laboratory gas chamber to simulate photochemical reactions that occur in the atmosphere. A more experimental study ${ }^{48}$ was of the applicability of $\mathrm{Tl}$ as IS for mass bias corrections in the determination of $\mathrm{Hg}$ isotopes by MC-ICP-MS.

The ${ }^{240} \mathrm{Pu} /{ }^{239} \mathrm{Pu} ;{ }^{241} \mathrm{Pu} /{ }^{239} \mathrm{Pu}$ and ${ }^{242} \mathrm{Pu} /{ }^{239} \mathrm{Pu}$ isotope ratios in mixed-oxide particles were measured ${ }^{49}$ by ICP-MS following sample dissolution and separation of $\mathrm{Pu}$ from matrix using UTEVA ${ }^{\mathrm{TM}}$ resins. The ${ }^{238} \mathrm{Pu} /{ }^{239} \mathrm{Pu}$ ratio was calculated from the ${ }^{238} \mathrm{Pu} /\left({ }^{239} \mathrm{Pu}+{ }^{240} \mathrm{Pu}\right)$ activity ratio measured by $\alpha$-spectrometry and the ${ }^{240} \mathrm{Pu} /{ }^{239} \mathrm{Pu}$ ratio measured by ICP-MS. A method ${ }^{50}$ for the continuous determination of ${ }^{239} \mathrm{Pu}$ in ice cores coupled both a SF-ICP-MS instrument and a continuous-flow ion analyser to an ice core melter. Advantages of this approach included less sample preparation and reduced analysis time. A simple, sensitive and robust method ${ }^{51}$ employed GC-MC-ICP-MS to determine ${ }^{32} \mathrm{~S} /{ }^{34} \mathrm{~S}$ isotopes in trace organic sulfur compounds (OSCs) found in sour $\mathrm{CH}_{4}$ gas streams. The GC system was equipped with a thermal conductivity detector to determine $\mathrm{H}_{2} \mathrm{~S}$ and a fast valve switching system to enable a precise chromatographic heart cut to be taken, thereby preventing saturation of the ICP-MS system. Any matrix effects arising from high concentrations of $\mathrm{CH}_{4}$ (up to $95 \% v / v$ ) and $\mathrm{H}_{2} \mathrm{~S}$ (up to $10 \% \mathrm{v} / \mathrm{v}$ ) in gases produced by the pyrolysis of sulfur-rich kerogen were minimised The accuracy of this approach was better than $0.3 \%$ for OSCs at a concentration of 25 pmol (1.4 ppm).

The scanning mobility particle sizer (SMPS) provides size distribution and concentration of nanoparticles in air with a temporal resolution of a few minutes or less. As reported in last year's Update ${ }^{1}$, there is ongoing interest in the benefits of coupling SMPS to ICP-MS systems so that complementary elemental data can be gathered. Swiss-based researchers $^{52}$ determined the $\mathrm{Cu}, \mathrm{K}$ and $\mathrm{Na}$ concentrations in aerosol particles (13 to $340 \mathrm{~nm}$ ) released by the combustion of wood samples that had been impregnated with different metal salts. Use of a rotating disk diluter allowed the controlled dilution of particulate-laden air in order not to extinquish the plasma. A widely-used instrument for collecting size-segregated airborne particles is the micro-orifice uniform deposit impactor (MOUDI). Laser ablation ${ }^{53}$ was key to providing a fast and sensitive method for the direct elemental analysis of MOUDI filter samples of urban air. Filter sections were ablated and elemental image maps, created with ImageJ software, converted to concentration values using results from the parallel ablation of a calibrant filter (NIST SRM 2783 (air particulate on filter media)). For a nominal $4.32 \mathrm{~m}^{3}$ air 
sample (30 $\mathrm{L} \mathrm{min}^{-1}$ over a $24 \mathrm{~h}$ period) the LODs (3SD) ranged between $0.003 \mathrm{ng} \mathrm{m}^{-3}$ for $\mathrm{V}$ to $0.370 \mathrm{ng} \mathrm{m}^{-3}$ for Fe. Agreements were $\operatorname{good}\left(\mathrm{R}^{2}=0.94\right.$ to 0.99 , slope $=0.83$ to 1.52$)$ between data obtained for $\mathrm{As}, \mathrm{Fe}, \mathrm{Mn}, \mathrm{Pb}, \mathrm{V}$ and $\mathrm{Zn}$ using this new $\mathrm{LA}$ approach and data generated using a more conventional acid leach procedure with analysis by ICP-MS. The poorer agreement noted for $\mathrm{Cu}, \mathrm{Ni}$ and $\mathrm{Sb}$ which was attributed to their low concentrations in air and hence greater uncertainities in the resultant measurements. The determination of isotopic ratios of elements within single particles by the interrogation of transient signals from LA-ICP-MS analysis can be time consuming as integration parameters need to be set manually on a peakby-peak basis. A new approach ${ }^{54}$, which relied on a point-to-point data reduction process and applied robust statistical estimator methods, was claimed to be a simple but robust alternative that did not require supervision.

Two review papers ${ }^{55,56}$ (20 and 146 references) usefully described advances in the application of sp-ICP-MS for the characterisation of nanomaterials.

1.5.2.2 Other mass spectrometry techniques. The Aerodyne aerosol mass spectrometer is a commercially available and frequently used instrument for the on-line in-situ measurement of sub- $\mu \mathrm{m}$ ambient aerosols. A review $\operatorname{paper}^{57}$ (24 references) detailed instrumental developments and various air quality monitoring applications. A summary ${ }^{58}$ of recent instrumental refinements included the redesign of the sampling inlet, development of a new aerodynamic lens and refinements in the particle vaporiser unit. Particles at the upper end of the $\mathrm{PM}_{2.5}$ size distribution could now be interrogated so as a result $89 \%$ of the non-refractory chemical mass of $\mathrm{PM}_{2.5}$ was detected. This was an improvement over the previous design in which only $65 \%$ could be detected. Complementary papers described, in more detail, the development, validation and performance of this new lens system ${ }^{59}$ and the enhanced particle vaporiser unit ${ }^{60}$. A soft ionisation approach ${ }^{61}$ employed a NIR laser to desorb and ionise molecules deposited on an aluminium target within the sampling inlet of an aerosol mass spectrometer. This resulted in minimal analyte fragmentation, producing characteristic ions at $[\mathrm{M}-\mathrm{H}]^{-}$for acidic organic aerosol molecules and $[\mathrm{M}+\mathrm{H}]^{-}$for basic organic analytes. Single particle aerosol mass spectrometers can produce copious amounts of mass spectral data so data mining techniques, such as fuzzy c-means clustering, are invaluable. A new approach ${ }^{62}$ applied OPTICS (ordered points to identify the clustering structure) in combination with fuzzy c-means clustering to get a faster and more detailed interpretation of mass spectral data.

A combination ${ }^{63}$ of TOF and SF SIMS techniques was used for the determination of both elemental and isotopic composition of particles in nuclear forensic samples. Qualitative 
elemental scans obtained by TOF-SIMS were useful for assessing isobaric overlaps on U isotopes. The U isotope analysis was performed using SF-SIMS in a molecular shift mode. Measuring $\mathrm{UO}_{2}{ }^{+}$species rather than $\mathrm{U}^{+}$minimised the isobaric overlaps identified previously. A new algorithm ${ }^{64}$ enabled better identification of isotopically unique U-containing particles than possible with the image data processing techniques currently used in SIMS analysis. Images from test samples (composites of NIST SRMs) were successfully evaluated. Fusion ${ }^{65}$ of SIMS images with elemental maps from EDS facilitated, for the first time, the location of isotopically unique U-bearing particles in powdered samples. A simulant sample, consisting of NIST SRMs (U particles) dispersed in a river sediment (NIST SRM 8704 (Buffalo River sediment)), was used to evaluate the utility of this approach. The Cameca NanoSIMS 50 ion probe $^{66}$ was capable of measuring accurately species-specific, stable $\mathrm{N}$-isotope ratios in bulk $\mathrm{NaNO}_{3}$ and $\mathrm{KNO}_{3}$ powders deposited on a gold substrate. Typical within-run precision was $\pm 1.3 \%$ and the accuracy for long-term measurements on an in-house $\mathrm{NaNO}_{3}$ standard was $\pm 1.9 \%$ for a raster size of $5 \times 5 \mathrm{~m}^{2}$. The authors suggested that this approach would be useful for determining the isotopic composition in single $\mu \mathrm{m}$-sized nitrate particles in order to understand better the fractionation processes that can occur when NO molecules react on the surfaces of sea-salt and dust particles.

A method ${ }^{67}$ for the simultaneous determination of both concentration and isotopic composition of $U$ in individual micro-particles by ID-TIMS was validated by the successful analysis of NIST SRM U030, either as particles or as digests. Results were in good agreement with certified ${ }^{235} \mathrm{U} /{ }^{238} \mathrm{U}$ and ${ }^{236} \mathrm{U} /{ }^{238} \mathrm{U}$ values. An automated particle-screening software package ${ }^{68}$, originally developed for SIMS analysis, was applied to highly precise TIMS data to identify specific U particles. The advantage of TIMS analysis was that molecular- and hydridederived isobaric inferences were minimised.

Improved isotope ratio mass spectrometry instrumentation included the new automated system $^{69}$ for the simultaneous determination of both $\delta^{2} \mathrm{H}$ and $\delta^{13} \mathrm{C}$ and $\delta^{13} \mathrm{C}$ and $\delta^{18} \mathrm{O}$ in atmospheric $\mathrm{CH}_{4}$ and $\mathrm{CO}_{2}$ gas samples, respectively. Air samples collected in flasks or cylinders were split into two streams and introduced simultaneously into two IRMS instruments. Analysis of 16 samples which included 4 reference and 1 QC air sample took 36 h. Long-term precisions, derived from the repeated analysis of a QC air sample since 2012, were: $0.04 \%$ o $\left(\delta^{13} \mathrm{C}\right.$ of $\left.\mathrm{CO}_{2}\right) ; 0.07 \%$ o $\left(\delta^{18} \mathrm{O}_{\text {of }} \mathrm{CO}_{2}\right) ; 0.11 \%$ o $\left(\delta^{13} \mathrm{C}_{\text {of }} \mathrm{CH}_{4}\right)$ and $1.0 \%$ o $\left(\delta^{2} \mathrm{H}\right.$ of $\mathrm{CH}_{4}$ ). Within a single day, the system exhibited a typical methane $\delta^{13} \mathrm{C}$ repeatability standard deviation $(1 \sigma)$ of $0.06 \%$. The high throughput and reliability of operation were important for 
coping with the large number of air samples anticipated from ongoing atmospheric green-house gas monitoring programmes. An improved HR-MC-IRMS method ${ }^{70}$ for measuring six singlyor doubly- substituted isotopic variants of $\mathrm{N}_{2} \mathrm{O}$ required only $10 \mu \mathrm{M}$ of sample, took only 8-10 $\mathrm{h}$ per sample and offered a powerful new analytical capability for identifying the environmental sources and sinks for this important atmospheric molecule. A new instrumental setup ${ }^{71}$ combining LA nano-combustion-GC with IRMS enabled $\delta^{13} \mathrm{C}$ measurements to be performed on samples such as pollen that contained only ng quantities of C. Analysis of the IAEA CH-7 polyethylene standard had good accuracy and precision of $<0.5 \%$ on sample masses as low as $42 \mathrm{ng} \mathrm{C}$. This level of performance was sufficient to discriminate between pollen species.

\subsubsection{X-ray spectrometry}

Analysis of particles on filters using EDXRFS is typically carried out under vacuum for optimal performance, particularly for low $\mathrm{Z}$ elements, but this can result in loss of volatile species so hindering further analysis of filter samples by other techniques, e.g. ion

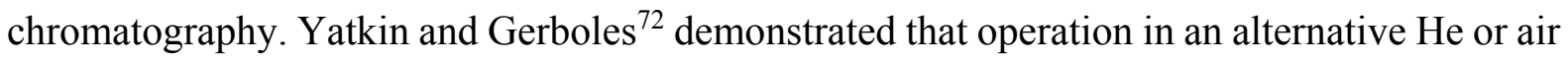
mode gave generally comparable data and that method performance met the data quality objectives of the European Directive for Air Quality for the determination of As and $\mathrm{Pb}$ but not of $\mathrm{Cd}$ or $\mathrm{Ni}$. This was most likely due to the low loadings of these elements in typical $\mathrm{PM}_{10}$ filter samples and the insensitivity of XRFS for measuring Cd. Analysis of size-segregated metal-containing aerosols involved sampling ${ }^{73}$ using a nano-MOUDI (see also section 1.5.2.1) and pXRFS analysis of the particles collected on the impaction targets. Test aerosols were created from stainless steel substrates using a spark discharge system and impaction targets analysed both directly and quickly using pXRFS and by ICP-MS following digestion. Data correlated well for the two elements studied, $\mathrm{Cr}\left(\mathrm{R}^{2}=0.84\right)$ and $\mathrm{Fe}\left(\mathrm{R}^{2}=0.91\right)$. This XRFS approach was deemed useful for mass loadings on targets of $>2.5 \mu \mathrm{g}$. The performance of a commercially available XRFS system ${ }^{74}$ for in-situ measurement of elements in $\mathrm{PM}_{10}$ particles was compared to analysing filter samples in the laboratory by ICP-AES and ICP-MS. Filter samples were collected over $24 \mathrm{~h}$ using a $\mathrm{PM}_{10}$ air sampler located alongside this instrument at the sampling site. To allow direct comparison, the hourly XRFS data were aggregated to $24 \mathrm{~h}$ averages. Regression analysis for $\mathrm{Ba}, \mathrm{Ca}, \mathrm{Cu}, \mathrm{Fe}, \mathrm{K}, \mathrm{Mn}, \mathrm{Pb}, \mathrm{S}$, Ti and $\mathrm{Zn}$ had excellent correlation $\left(\mathrm{R}^{2}>0.95\right)$ although slope values ranged between 0.97 and 1.8 (average 1.28). The authors suggested that the differences were due to factors such as: different PM10 sampler inlet characteristics; XRF beam attenuation due to particle size effects; the relative effectiveness of 
the filter digestion method for different elements and perhaps micro-spatial sampling heterogeneity i.e. distance between the two sampling inlets.

A round-up of X-ray applications included the assessment ${ }^{75}$ of trace metals (20 elements) in Parisian air through the analysis of dust deposited on moss samples growing in cemeteries. Use of a slurry suspension-TXRFS methodology avoided a digestion step, reduced the risk of sample contamination and worked well with small sample quantities. Work focused on utilising Grimmia pulvinata, a moss species common in the 21 cemeteries studied and commonly found across Europe. The oxidation state of $\mathrm{S}$ in atmospheric particulate matter ${ }^{76}$ was investigated using a combination of NEXFS and XRF microscopy. Study of oxidation states $\mathrm{S}^{0}$ and $\mathrm{S}^{\mathrm{VI}}$ led to the finding that the source of the $\mathrm{S}^{\mathrm{VI}}$ species was either ammonium sulfate from the reaction of $\mathrm{NH}_{3}$ with $\mathrm{SO}_{2}$ or metal sulfates from industrial emissions. The $\mathrm{S}^{0}$ species most likely originated from primary emission sources such as bacteria or incomplete combustion. An assessment of worker exposure ${ }^{77}$, conducted for the first time at a nuclear fuel fabrication plant, involved the sampling of U-containing particles using a cascade impactor and elemental characterisation using SEM-EDS. An eight-stage Marple impactor, with particle cutoff points of 21.3, 14.8, 9.8, 6.0, 3.5, 1.6, 0.9 and $0.5 \mu \mathrm{m}$, was used. Carbon tape was employed as an impaction substrate as its conductivity was necessary for SEM analysis. The extent of any bias in the EDS measurements was assessed by analysing standard test samples, prepared by depositing aliquots of NIST SRM U-010 (high purity $\mathrm{U}_{3} \mathrm{O}_{8}$ particles) onto this carbon substrate. A bias in $U$ mass measurements of up to $15 \%$ was attributed to beam interactions with oxygen in this substrate material which resulted in an over-estimation of the oxygen content in the uranyl particles interrogated. The performance of a Rietveld XRD procedure $^{78}$ for the quantification of crystalline phases in fly ash was optimised after careful assessment of various experimental conditions: internal standards $\left(\mathrm{SiO}_{2}\right.$ or $\mathrm{TiO}_{2}$, spike dosages in the range $10-50 \% \mathrm{~m} / \mathrm{m}$ ); incident X-rays (laboratory or synchrotron sources) and software (GSAS or TOPAS programmes). The procedure gave good reproducibility with arithmetric mean errors and the standard errors of identified main phases as low as $c a .1 \%$.

\subsubsection{Other instrumental techniques}

Agrawal et al. ${ }^{79}$ improved a spectrophotometric method for the determination of ultra-trace levels of Be in air filter and wipe samples from a workplace setting. Sampled particles were treated with a $\mathrm{NH}_{4} \cdot \mathrm{HF}_{2}$ solution and the liberated Be complexed with a hydroxybenzoquinoline sulfate to form a highly sensitive fluorophore. Method LODs of $<0.01 \mathrm{ng} \mathrm{L}^{-1}$, equating to $<0.1$ ng per sample, compared favourably with those obtainable by ICP-MS. It is now possible to 
perform rapid in-situ field measurements. A prototype atmospheric aerosol monitor ${ }^{80}$, developed for the on-line measurement of $\mathrm{Cr}$, Fe and $\mathrm{Mn}$ in $\mathrm{PM}_{2.5}$, consisted of: a particle-intoliquid collector; acid leaching of suspended particles; complexation with an appropriate chromophore and detection using a flow-through UV/VIS detector. The LODs, based upon a nominal $24 \mathrm{~m}^{3}$ air sample, were $0.25,0.17$ and $0.17 \mathrm{ng} \mathrm{m}^{-3}$ for $\mathrm{Cr}, \mathrm{Fe}$ and $\mathrm{Mn}$ respectively. It was suggested that future configurations could be adapted to measure water-soluble metals as well as metals in certain oxidation states which would require the use of specific chromogenic ligands.

Thermal-optical analysis for the determination of carbonaceous content of atmospheric particles is well established but differences in protocols have led to discrepancies in reported elemental C data. Researchers in Hong Kong ${ }^{81}$ used the same instrument to analyse 1398 filter samples by both the NIOSH TOT (thermal optical transmittance) and the IMPROVE (Interagency Monitoring of Protected Visual Protected Environments)TOR (thermal optical reflectance) protocols. About $80 \%$ of this discrepancy was attributable to a difference in the peak inert mode temperature employed and the remaining $c a .20 \%$ to a difference in the optical method (TOT vs TOR). Fuller et al. ${ }^{82}$ compared light absorption of $\mathrm{PM}_{10}$ particles collected on four different filter substrates $\left(E^{2} \mathrm{mab}^{\mathrm{TM}}\right.$ filters (Teflon-coated glass-fibre filter), mixed cellulose ester filters, quartz fibre filters and Teflon filters) by both reflectrometry and transmissometry techniques. They established relationships between these absorption measurements and elemental $\mathrm{C}$ concentrations derived from thermal-optical analysis. There were strong linear relationships between reflectrometry and transmissometry data for each filter type but absorption characteristics differed. This illustrated the complexity of light scattering and the loading effects of particles collected on various filter media. The relationship between elemental carbon values and light absorption was non-linear regardless of filter type. Real-time optical black carbon instruments, used for regulatory measurements of particle matter emissions from aircraft turbine engines, require calibration against elemental $\mathrm{C}$ mass measurements derived from thermo-optical analysis. An international consortium ${ }^{83}$ evaluated the response of two black carbon instruments to surrogate soot particles generated using a miniCAST soot generator. A key finding of this study was that, in addition to defining the elemental $\mathrm{C}$ content as currently undertaken, there is a need going forward to define the particle size distribution of any challenge soot used.

A feasibility study ${ }^{84}$ demonstrated that Raman microscopy could quantify $<1 \mu \mathrm{g}$ of respirable-size crystalline silica collected on an air filter sample. The LOD of $c a .0 .2 \mu \mathrm{g}$ for both quartz and cristobalite forms was $c a$. 10-fold lower that that currently achievable using 
FTIR or XRD techniques. Signal attenuation due to matrix species such as haematite, as found in foundry dusts, remains an issue however and this ne new approach may well therefore be best suited for measuring low concentration of silica in air in those workplaces where other matrix species are not present to any significant extent. As the global production of carbon nanotubes (CNTs) increases, concerns grow about their safe handling during production and use. Raman spectroscopy ${ }^{85}$ unequivocally identified that airborne particles settled on a work surface contained CNTs. Furthermore, the technique could be used to ascertain whether the CNTs were synthesised by an electric-arc method or by a chemical vapour deposition method.

A round-up of instrumental developments and applications included a new IMS-TOF instrument ${ }^{86}$ for the determination of water-soluble organic $\mathrm{C}$ and organosulfate species in aerosol samples and a review paper $^{87}$ (112 references) detailing the current status and application of IMS for the detection of chemical warfare agents. Cavity ring-down spectroscopy offers a growing potential for the ultra-sensitive and real-time detection of trace gas species, as exemplified by studies ${ }^{88}$ which measured $\mathrm{NO}_{2}$ at a concentration of 38 pptv and measured ${ }^{89}{ }^{14} \mathrm{CO}_{2}$ at $<10$ ppqv!

\section{Water Analysis}

\subsection{Review papers}

Three reviews published in the current review period focussed on the analysis of trace elements in water. Kallithrakas-Kontos and Foteinis ${ }^{90}$ (122 references) concentrated on recent advances in the determination of $\mathrm{Hg}$ in waters whilst Gworek et al. ${ }^{91}$ (144 references) narrowed the field further to $\mathrm{Hg}$ in saline waters. coastal and oceanic waters. Sample separation and preconcentration procedures as well as direct methods for the determination of REEs in natural waters were also covered ${ }^{92}$ (156 references).

\section{$2.2 \quad$ Reference materials}


A new coastal seawater reference material (NMIA CRM MX014) was spiked ${ }^{93}$ with As, Cd, $\mathrm{Co}, \mathrm{Cr}, \mathrm{Cu}, \mathrm{Fe}, \mathrm{Hg}, \mathrm{Mn}, \mathrm{Ni}, \mathrm{Pb}, \mathrm{Se}$ and $\mathrm{V}$ at concentrations relevant to Australian environmental regulations. Use of optimised sample preparation methods together with reference analytical methods that included IDA or standard addition with ICP-MS allowed certified values to be assigned. Mercury was stable at a concentration of $0.4 \mu \mathrm{g} \mathrm{kg}^{-1}$ in the acidified sea water matrix for at least 4 years.

\subsection{Sample preconcentration and extraction}

A large number of methods are available for the preconcentration of trace elements from water samples and other matrices so several review papers appear each year. One particularly useful review ${ }^{94}(114$ references) covered the use of microsampling techniques for the analysis of the final small volume preconcentrate using atomic spectrometric instrumentation. The use of biological substrates and their immobilisation on nanomaterials has been reviewed ${ }^{95}$ (108 references) as has the use of chitosan and chitosan composites ${ }^{96}$ (98 references). A more specific review ${ }^{97}$ (116 references) covered the application of nanomaterials to the preconcentration of $\mathrm{Hg}$ in environmental and drinking waters. In a review ${ }^{98}$ (217 references) of liquid phase microextraction methods coupled with ETAAS for a wide range of matrices, it was noted that water analysis was the most common due to the simplicity of the matrix.

The most significant advances in analyte preconcentration for water analysis are summarised in Tables 1, 2 and 3. It should be noted that the last entry in Table $1^{99}$ is for a passive sampler and the figures of merit are dependent on deployment time.

\subsection{Speciation and nanomaterial analysis}

\subsubsection{Review papers}

Papers on multielemental speciation are rare so reviews are particularly welcome, such as the one on HPLC-ICP-MS methods ${ }^{100}$ (99 references) for environmental, food and clinical samples which covered both sample pretreatment and separation methods. Another review ${ }^{101}$ (41 references) focussed on green methods employing ICP-MS detection.

All the single element speciation papers covered waters as well as other matrices. A review of antimony speciation in environmental samples ${ }^{102}$ (41 references) discussed how the redox chemistry of Sb plays an important role in the chromatographic separation of its species 
and how complex formation can cause artefacts during extraction procedures. The challenges and significance of Mn speciation in various matrices was reviewed ${ }^{34}$ (112 references) with a focus on the determination of the bioavailability or bioactivity of $\mathrm{Mn}$ in the environment. A review ${ }^{103}$ (65 references) of extraction methods for either $\mathrm{Cr}^{\mathrm{III}}$ or $\mathrm{Cr}^{\mathrm{VI}}$ reflected the abundance of methods in the literature. The flow and miniaturisation systems used to automate the analyses were also covered.

Nanomaterials are now being exploited as stationary phases for speciation analysis such as the elemental speciation of environmental, food and biological samples covered in a 162-reference review ${ }^{104}$. 
Table 1 Preconcentration methods using solid phase extraction for the analysis of waters

\begin{tabular}{|c|c|c|c|c|c|c|c|}
\hline Analytes & Matrix & Substrate & Coating or modifier & Detector & $\begin{array}{l}\text { LOD (in } \mu \mathrm{L}^{-} \\
\text {1) unless } \\
\text { stated } \\
\text { otherwise }\end{array}$ & Validation & Reference \\
\hline $\begin{array}{l}\mathrm{Al}^{\mathrm{III}}, \mathrm{Cu}^{\mathrm{II}}, \\
\mathrm{Fe}^{\mathrm{III}}, \mathrm{Mn}^{\mathrm{II}} \\
\mathrm{Pb}^{\mathrm{II}}, \mathrm{Zn}^{\mathrm{II}}\end{array}$ & Natural waters & Silica & $\begin{array}{l}\text { polyhexamethylene } \\
\text { guanidine and 4,5- } \\
\text { dihydroxy-1,3- } \\
\text { benzenedisulfonic acid }\end{array}$ & ICP-AES & $\begin{array}{c}0.02\left(\mathrm{Cu}^{\mathrm{II}},\right. \\
\mathrm{Fe}^{\mathrm{III}}, \mathrm{Mn}^{\mathrm{II}}, \\
\left.\mathrm{Pb}^{\mathrm{II}}, \mathrm{Zn}^{\mathrm{II}}\right) \\
\text { and } 0.15 \\
\text { (Al). }\end{array}$ & $\begin{array}{c}\text { Spike } \\
\text { recovery }\end{array}$ & 105 \\
\hline $\mathrm{Au}$ & $\begin{array}{l}\text { Environmental } \\
\text { water }\end{array}$ & Magnetite & Graphene oxide & MP-AES & 0.005 & $\begin{array}{c}\text { Spike } \\
\text { recovery }\end{array}$ & 106 \\
\hline $\mathrm{Bi}$ & $\begin{array}{l}\text { Sea, lake, } \\
\text { river, stream } \\
\text { and rain } \\
\text { waters }\end{array}$ & $\begin{array}{l}\text { Halloysite } \\
\text { nanotubes }\end{array}$ & & $\begin{array}{l}\text { HR-CS- } \\
\text { ETAAS }\end{array}$ & 0.005 & $\begin{array}{c}\text { NIST SRM } \\
\text { 1643e (trace } \\
\text { elements in } \\
\text { water) and } \\
\text { NWRI CRM } \\
\text { TMDA-54.5 } \\
\text { (A high level } \\
\text { fortified } \\
\text { sample for } \\
\text { trace } \\
\text { elements) }\end{array}$ & 107 \\
\hline $\begin{array}{c}\mathrm{Cd}^{\mathrm{II}}, \mathrm{Co}^{\mathrm{II}} \mathrm{Cu}^{\mathrm{II}}, \\
\mathrm{Fe}^{\mathrm{II}}, \mathrm{Ni}^{\mathrm{II}}, \\
\mathrm{Mn}^{\mathrm{II}} \mathrm{Zn}^{\mathrm{II}}\end{array}$ & $\begin{array}{c}\text { Tap and } \\
\text { mineral waters }\end{array}$ & $\begin{array}{c}\text { Amberlite }{ }^{\circledR} \\
\text { XAD-16 }\end{array}$ & $\begin{array}{c}2-(2- \\
\text { benzothiazolylazo)-5- } \\
\text { dimethyl aminobenzoic } \\
\text { acid }\end{array}$ & FAAS & $\begin{array}{c}0.71(\mathrm{Cu}) \text { to } \\
3.55(\mathrm{Cd})\end{array}$ & $\begin{array}{l}\text { NIST SRM } \\
1643 \mathrm{e} \text { (trace } \\
\text { elements in } \\
\text { water) and } \\
\text { spike } \\
\text { recovery }\end{array}$ & 108 \\
\hline
\end{tabular}




\begin{tabular}{|c|c|c|c|c|c|c|c|}
\hline $\mathrm{Cr}, \mathrm{Cu}, \mathrm{Zn}$ & Water & $\begin{array}{l}\text { Graphene } \\
\text { oxide }\end{array}$ & Glycine & ED-XRFS & $\begin{array}{c}0.07(\mathrm{Zn}) \text { to } \\
0.15(\mathrm{Cr}) \mathrm{ng} \\
\mathrm{mL}^{-1}\end{array}$ & $\begin{array}{l}\text { Spike } \\
\text { recovery }\end{array}$ & 109 \\
\hline $\begin{array}{l}\text { Ce, Dy, Gd, } \\
\text { La, Nd, Sm, Y }\end{array}$ & Well water & $\begin{array}{l}\text { MWCNTs } \\
\text { coated } \\
\text { cellulose } \\
\text { acetate } \\
\text { membrane }\end{array}$ & $\begin{array}{c}\text { 1-(2-pyridylazo)-2- } \\
\text { naphthol }\end{array}$ & ICP-AES & $\begin{array}{c}0.05(\mathrm{La}) \text { to } \\
0.3(\mathrm{Nd} \text { and } \\
\mathrm{Ce})\end{array}$ & $\begin{array}{c}\text { Spike } \\
\text { recovery }\end{array}$ & 110 \\
\hline REEs, U & $\begin{array}{l}\text { Lake, well and } \\
\text { tap waters }\end{array}$ & Cotton roll & $\begin{array}{c}1,2,5,8- \\
\text { tetrahydroxyanthraquinone }\end{array}$ & ICP-AES & $\begin{array}{c}0.002(\mathrm{La}) \text { to } \\
0.420(\mathrm{U})\end{array}$ & $\begin{array}{c}\text { Spike } \\
\text { recovery }\end{array}$ & 111 \\
\hline $\begin{array}{l}\mathrm{Sb} \text { (total), } \\
\mathrm{Sb}^{\mathrm{III}}\end{array}$ & Bottled water & $\begin{array}{c}\mathrm{Fe}_{3} \mathrm{O}_{4} \mathrm{NPs} \\
\text { coated with } \\
\mathrm{Ag}^{0}\end{array}$ & $\begin{array}{l}\text { sodium 2-mercaptoethane- } \\
\text { sulphonate }\end{array}$ & $\begin{array}{l}\text { HR-CS- } \\
\text { ETAAS }\end{array}$ & 0.02 & $\begin{array}{c}\text { NIST SRM } \\
\text { 1640a (trace } \\
\text { elements in } \\
\text { water), NWRI } \\
\text { CRM CRM } \\
\text { TMRain-04 } \\
\text { (Simulated } \\
\text { rain water) }\end{array}$ & 112 \\
\hline $\begin{array}{c}\mathrm{Ag} \\
\text { nanoparticles }\end{array}$ & Lake water & $\begin{array}{l}\text { MWCNT } \\
\text { passive } \\
\text { sampler } \\
\end{array}$ & & ICP-MS & $\begin{array}{c}45 \mathrm{~nm} \text { (LOD } \\
\text { for Ag not } \\
\text { reported) }\end{array}$ & $\begin{array}{c}\text { Spike } \\
\text { recovery }\end{array}$ & 99 \\
\hline
\end{tabular}


Table 2 Preconcentration methods using liquid phase extraction for the analysis of water

\begin{tabular}{|c|c|c|c|c|c|c|c|}
\hline Analytes & Matrix & Method & Reagents & Detector & $\begin{array}{l}\text { LOD in } \mu g \mathrm{~L}^{-} \\
1 \text { (unless } \\
\text { stated } \\
\text { otherwise) }\end{array}$ & $\begin{array}{c}\text { Method } \\
\text { validation }\end{array}$ & Reference \\
\hline $\begin{array}{l}\mathrm{Ag}, \mathrm{Cd}, \mathrm{Ir}, \\
\text { Os, Pd, Pt, } \\
\text { Re, Ta }\end{array}$ & Water & DLLME & $\begin{array}{c}\text { Chloroform and Aliquat } \AA \\
336 \\
\text { (tricaprylmethylammonium } \\
\text { chloride) }\end{array}$ & ICP-MS & $\begin{array}{c}0.04(\mathrm{Pt}) \text { to } \\
0.3(\mathrm{Ag})\end{array}$ & $\begin{array}{c}\text { Spike } \\
\text { recovery of } \\
\text { Inorganic } \\
\text { Ventures } \\
\text { CMS-2 } \\
\text { (certified } \\
\text { precious } \\
\text { metal } \\
\text { standard) and } \\
\text { comparison } \\
\text { with SF-ICP- } \\
\text { MS results. }\end{array}$ & 113 \\
\hline $\begin{array}{c}\mathrm{Be}, \mathrm{Cd}, \mathrm{Cr}, \\
\mathrm{Hg}, \mathrm{Pb}, \mathrm{Tl}\end{array}$ & $\begin{array}{l}\text { Natural and } \\
\text { waste water }\end{array}$ & CPE & $\begin{array}{l}\text { Aliquat巴-336 (N-methyl- } \\
\text { N,N,N-trioctylammonium } \\
\text { chloride) and nonionic, } \\
\text { Triton }{ }^{\mathrm{TM}} \mathrm{X}-114\end{array}$ & CS-ETAAS & $\begin{array}{c}0.01(\mathrm{Be}) \text { to } \\
0.3(\mathrm{Hg})\end{array}$ & $\begin{array}{l}\text { NIST SRM } \\
\text { 1640a (natural } \\
\text { water), } \\
\text { IRMM CRM } \\
\text { BCR-713 } \\
\text { (final } \\
\text { effluent) and } \\
\text { IRMM CRM } \\
\text { BCR-715 } \\
\text { (industrial } \\
\text { effluent) and }\end{array}$ & 114 \\
\hline
\end{tabular}




\begin{tabular}{|c|c|c|c|c|c|c|c|}
\hline & & & & & & $\begin{array}{c}\text { spike } \\
\text { recovery }\end{array}$ & \\
\hline $\begin{array}{l}\mathrm{Cd}, \mathrm{Co}, \mathrm{Cu} \\
\mathrm{Ni}, \mathrm{Pb}, \mathrm{Zn}\end{array}$ & Water & CPE & $\begin{array}{c}\text { 1,5-di-phenylthiocarbazone } \\
\text { (dithizone) and Triton } \\
\text { X-114 }\end{array}$ & $\begin{array}{l}\text { USN-ICP- } \\
\text { AES }\end{array}$ & $\begin{array}{l}0.009(\mathrm{Cd}) \text { to } \\
0.02(\mathrm{Zn})\end{array}$ & $\begin{array}{l}\text { Spike } \\
\text { recovery }\end{array}$ & 115 \\
\hline $\mathrm{Cr}^{\mathrm{VI}}$ & $\begin{array}{c}\text { Tap, waste } \\
\text { and mineral } \\
\text { waters, air, } \\
\text { blood and } \\
\text { urine }\end{array}$ & $\begin{array}{l}\text { SFOD- } \\
\text { LLME }\end{array}$ & $\begin{array}{c}\text { Sodium dodecyl sulfate, } \\
\text { 1,5 diphenylcarbazide, and } \\
\text { 1-undecanol }\end{array}$ & ETAAS & 0.003 & $\begin{array}{l}\text { NIST SRM } \\
\text { 1640a } \\
\text { (Natural } \\
\text { water) }\end{array}$ & 116 \\
\hline In & water & DLLME & $\begin{array}{l}\text { 1-(2-pyridylazo)-2- } \\
\text { naphthol, undecanol }\end{array}$ & ETAAS & $55.6 \mathrm{ng} \mathrm{L}^{-1}$ & $\begin{array}{c}\text { Spike } \\
\text { recovery }\end{array}$ & 117 \\
\hline
\end{tabular}




\begin{tabular}{|c|c|c|c|c|c|c|c|c|}
\hline Analytes & Matrix & Method & Substrate & Reagents & Detector & $\begin{array}{c}\text { LOD in } \mu g \\
L^{-1} \text { (unless } \\
\text { stated } \\
\text { otherwise) }\end{array}$ & $\begin{array}{c}\text { Method } \\
\text { validation }\end{array}$ & Reference \\
\hline $\mathrm{Ag}$ & Seawater & SBME & $\begin{array}{c}\text { Capillary } \\
\text { hollow fibre stir } \\
\text { bar }\end{array}$ & $\begin{array}{l}\text { Aliquat }{ }^{\circledR} 336 \text { in } \\
\text { kerosene solution } \\
\text { and dodecan-1-ol }\end{array}$ & ETAAS & $0.09 \mathrm{ng} \mathrm{L}^{-1}$ & $\begin{array}{c}\text { Spike } \\
\text { recovery } \\
\text { and } \\
\text { comparison } \\
\text { with } \\
\text { DLLME } \\
\text { method }\end{array}$ & 118 \\
\hline As & Water & DME & MWCNT & diethylenetriamine & HG-AAS & $3.05 \mathrm{ng} \mathrm{L}^{-1}$ & $\begin{array}{c}\text { NRCC } \\
\text { CRM } \\
\text { SLRS-5 } \\
\text { (River } \\
\text { water) and } \\
\text { NWRI } \\
\text { CRM TM- } \\
\text { 28.3 (Lake } \\
\text { Ontario } \\
\text { water) }\end{array}$ & 119 \\
\hline
\end{tabular}




\begin{tabular}{|c|c|c|c|c|c|c|c|c|}
\hline $\mathrm{Ni}$ & $\begin{array}{c}\text { Sea and } \\
\text { river } \\
\text { waters }\end{array}$ & $\begin{array}{c}\text { Magnetic } \\
\text { SLME }\end{array}$ & Graphene oxide & $\begin{array}{c}\text { 1-hexadecyl-3- } \\
\text { methylimidazolium } \\
\text { chloride }\end{array}$ & FAAS & 0.16 & $\begin{array}{c}\text { Spike } \\
\text { recovery }\end{array}$ & 120 \\
\hline
\end{tabular}




\subsubsection{Elemental speciation}

Although little progress has been made in improving chromatographic conditions, a new solid phase for the preconcentration of both organic and inorganic arsenic species has been developed $^{121}$. Phosphine-modified polymer microspheres $(435 \mathrm{mg})$ were packed into a $50 \times$ 4.6 mm stainless steel minicolumn, which was mounted directly onto the injection valve in place of the sample loop. In this configuration, up to $25 \mathrm{~mL}$ of sample at $\mathrm{pH} 7.0$ could be loaded onto the column at $1 \mathrm{~mL} \mathrm{~min}^{-1}$. All the analytes ( $\mathrm{As}^{\mathrm{III}}$, DMA, MMA and $\mathrm{As}{ }^{\mathrm{V}}$ ) were retained. The As species were then eluted with the HPLC mobile phase $\left(20 \mathrm{mM} \mathrm{NH}_{4} \mathrm{NO}_{3}, 20 \mathrm{mM}\right.$ $\mathrm{NH}_{4} \mathrm{H}_{2} \mathrm{PO}_{4}, \mathrm{pH} 8.8$ ) onto a standard Hamilton PRPX100 (250 mm x $4.6 \mathrm{~mm}$ ) analytical column on which separation was achieved within 10 minutes at a flow rate of $1 \mathrm{~mL} \mathrm{~min}^{-1}$. Under these conditions and with ICP-MS detection, the LODs were in the range 0.82 (MMA) to 1.2 (As ${ }^{\mathrm{III}}$ ) ng $\mathrm{L}^{-1}$ and the precision (RSD) 3.2 (MMA) to $5.6 \%$ (DMA) $(\mathrm{n}=10)$. The method was tested against the NRCCRM GSBZ07-3171-2014 (water) for which the sum of the $\mathrm{As}^{\mathrm{III}}$ and $\mathrm{As}{ }^{\mathrm{V}}$ concentrations $\left(41.8 \pm 2.5 \mathrm{ng} \mathrm{mL}^{-1}\right)$ was in good agreement with the certified value of $43.9 \pm 3.5$ ng $\mathrm{mL}^{-1}$.

Methods for non-chromatographic elemental speciation abound. Those methods in which only one form of an analyte is preconcentrated and the concentration of another deduced by difference are included in Tables 1 to 3. This section covers methods in which more than one form of an analyte was speciated. In one such paper ${ }^{122}, \mathrm{As}^{\mathrm{III}}$ and $\mathrm{As}^{\mathrm{V}}$ were preconcentrated simultaneously on $40 \mathrm{mg}$ of metallic iron NPs that had been coated with $\mathrm{SiO}_{2}$ and functionalised with polyethyleneimine. The As species were preconcentrated from $300 \mathrm{~mL}$ of sample with a recovery $>80 \%$. The NPs were separated magnetically from the sample and the analytes extracted with $4 \mathrm{~mL}$ of a solution containing $1 \% \mathrm{~m} / \mathrm{v}$ thiourea and $5 \% \mathrm{v} / \mathrm{v} \mathrm{HCl}$ prior to detection by HG-AFS. The LOD was $0.002 \mu \mathrm{g} \mathrm{L}^{-1}$ as As and the precision for each species was $1.95 \%$ RSD for $\mathrm{As}^{\mathrm{III}}$ and $2.55 \%$ RSD for $\mathrm{As}^{\mathrm{V}}(\mathrm{n}=6)$. Mixed micelle DLLME ${ }^{123}$ was used to extract $\mathrm{Cr}^{\mathrm{VI}}$ and $\mathrm{Cr}^{\mathrm{III}}$ sequentially from natural waters and effluents. Samples of 1-10 mL were adjusted to $\mathrm{pH} 2$ and $\mathrm{Cr}^{\mathrm{VI}}$ extracted with $1 \mathrm{~mL}$ of a $10 \% \mathrm{~m} / \mathrm{v}$ solution of the cationic surfactant Aliquat-336 with $0.6 \mathrm{~mL}$ of trichloroethylene added as the dispersive solvent. The organic-rich upper layer was removed and dissolved in $0.2 \mathrm{~mL}$ of methanol containing $2 \% v / v \mathrm{HNO}_{3}$. The $\mathrm{pH}$ of the remaining sample was readjusted to $\mathrm{pH} 2$ if necessary and the $\mathrm{Cr}{ }^{\mathrm{III}}$ extracted with 2 $\mathrm{mL}$ of a $10 \% \mathrm{~m} / \mathrm{v}$ sodium dioctyl sulfosuccinate solution after the addition of trichloroethylene. The trichloroethylene-rich layer that formed was treated in the same way as the first extract. Both extracts were analysed directly by ETAAS. The LODs were $0.5 \mathrm{pg} \mathrm{mL}^{-1}$ for $\mathrm{Cr}^{\mathrm{III}}, 0.6 \mathrm{pg}$ $\mathrm{mL}^{-1}$ for $\mathrm{Cr}^{\mathrm{VI}}$ and $0.7 \mathrm{pg} \mathrm{mL}^{-1}$ for total $\mathrm{Cr}$ with a maximum $\mathrm{RSD}$ of $6 \%$ for 10 replicates within 
the linear range of 0.02 to $1 \mathrm{ng} \mathrm{mL} \mathrm{mL}^{-1}$. The method was validated against the IRMM CRMs BCR 714 and 715 (industrial effluent) and the NIST SRM 1640a (natural water). The total Cr values and the sum of the concentrations for the two species agreed with the certified values for the total $\mathrm{Cr}$ concentration. A field method for trapping $\mathrm{V}^{\mathrm{IV}}$ and $\mathrm{V}^{\mathrm{V}}$ involved ${ }^{124}$ the use of Agilent Bond Elut (500 mg bed) strong anion-exchange cartridges preconditioned with $0.2 \mathrm{M}$ $\mathrm{Na}_{2}$ EDTA to trap $\mathrm{V}^{\mathrm{IV}}$ and $\mathrm{V}^{\mathrm{V}}$ from $10 \mathrm{~mL}$ filtered water samples. Subsequently $\mathrm{V}^{\mathrm{IV}}$ was eluted in the laboratory with $15 \mathrm{~mL}$ of a solution of $5 \mathrm{mM} \mathrm{Na}{ }_{2}$ EDTA, $2 \mathrm{mM}$ tetrabutylammonium hydroxide and $4 \% v / v$ methanol at $\mathrm{pH} 4$. The cartridge was dried by passing air through then $\mathrm{V}^{\mathrm{v}}$ eluted with $15 \mathrm{~mL}$ of $80 \mathrm{mM}$ dihydrogen ammonium phosphate. The $\mathrm{V}$ content of the eluents was determined by ICP-MS with a method LOD of $0.05 \mu \mathrm{g} \mathrm{L}^{-1}$ for $\mathrm{V}$. In the absence of suitable speciation RMs, the total V values in the NIST SRM 1640a (natural water) and the NWRI CRM TMDA-54.2 (trace metal fortified water) were compared with those obtained using HPLC-ICP-MS. The species could be preserved on the column for up to 15 days. Comparison of results obtained by this in-situ trapping method with those obtained for water samples taken and analysed back in the laboratory revealed that the vanadyl species was probably converted into a vanadate species during transport.

\subsubsection{Characterisation and determination of nanomaterials}

A review ${ }^{125}$ (57 references) of analytical methods used for "monitoring the fate and transformation of silver nanoparticles in natural waters" covered the main fractionation methods, including sp-ICP-MS, asymmetric flow FFF-ICP-MS and CPE, and discussed the fate of silver NPs in aquatic environments.

One of the most widely used methods for NP counting and sizing at environmentally relevant concentrations is the use of single particle counting ICP-MS. An attempt was made ${ }^{126}$ to formalise a systematic and reproducible approach for the determination of NPs in environmental samples, since they are more complex than mixtures of pure water and NPs. For a soil extract spiked with $30 \mathrm{~nm} \mathrm{Ag} \mathrm{NPs} \mathrm{at} \mathrm{a} \mathrm{concentration} \mathrm{of} 5.05 \mu \mathrm{g} \mathrm{L} \mathrm{L}^{-1}$, the mean particle size was measured as $68.2 \mathrm{~nm}$, but diluting the sample to near the method LOD $\left(0.05 \mu \mathrm{g} \mathrm{L}^{-1}\right)$ resulted in a measured mean particle size of $37.4 \mathrm{~nm}$. A further two-fold dilution was used to confirm the result. It has been suggested ${ }^{127}$ that dilution followed by analysis may not be suitable for seawater samples as the behaviour of NPs in dilute seawater is different to that in undiluted seawater. An alternative approach was the use of FI sample introduction with on-line dilution to lessen matrix problems as well as to reduce the time for which the sample remained diluted prior to analysis to $<100 \mathrm{~ms}$. Using a $20 \mu \mathrm{L}$ sample loop, a carrier flow rate of 10-50 
$\mu \mathrm{L} \min ^{-1}$ and a capillary inserted into the nebuliser, introduction of a sample at $0.8 \mathrm{~mL} \mathrm{~min}{ }^{-1}$ and $5 \mathrm{~mm}$ from the tip of the nebuliser was possible. Matrix effects were reduced to the point where the intensity for NPs in seawater was up to $80 \%$ of that in deionised water. The size LOD of $18 \mathrm{~nm}$ in deionised water and $25 \mathrm{~nm}$ in seawater was sufficient to follow the dissolution dynamics of engineered NPs spiked into seawater at a concentration of $200 \mathrm{ng} \mathrm{Ag} \mathrm{L}{ }^{-1}$, the equivalent of 1.7-2.1 x $10^{5}$ particles per $\mathrm{mL}$ for $60 \mathrm{~nm} \mathrm{Ag} \mathrm{NPs.} \mathrm{Another} \mathrm{advantage} \mathrm{of} \mathrm{using}$ FI-sp-ICP-MS ${ }^{128}$ was that the calculation steps were less complicated as known volumes were injected and so the peak area was directly proportional to the mass of NPs injected if the instrument had been previously calibrated against a NP standard. Therefore it was not necessary to maintain a constant sample uptake rate, so the flow fluctuations caused by the matrix were less important. The size LOD was $20 \mathrm{~nm}$ for an instrument dwell time of $5 \mathrm{~ms}$ and a $200 \mu$ s settle time. This was the same LOD as obtained using sp-ICP-MS.

Despite the flexibility of sp-ICP-MS, coupled techniques are still used, some even with detection in sp mode. The coupling of asymmetric flow FFF with sp-ICP-MS overcame ${ }^{129}$ some of the shortcomings of the two techniques. The limitations of sp-ICP-MS in the presence of a concentrated dissolved fraction were removed because the dissolved fraction was eliminated to waste in the asymmetric flow. Using a $1.5 \mathrm{~mL} \mathrm{~min}^{-1}$ channel flow rate, the FFF separated a mixture of $\mathrm{Ag}$ NPs and $\mathrm{Ag}-\mathrm{SiO}_{2}$ by their hydrodynamic diameters within 30 minutes. A limitation of asymmetric flow FFF analysis is that the mass concentration is based upon the peak height but the particle number concentration is calculated by assuming all the NPs detected are spherical and of the same composition. This assumption breaks down when the sample content is a mix of coated and uncoated samples. With sp-ICP-MS as the detection method, each particle was an integration event so the particle number concentration was counted. From the difference in individual signal heights it was possible to distinguish between $\mathrm{Ag}$ and $\mathrm{Ag}-\mathrm{SiO}_{2} \mathrm{NPs}$ in deionised water with a background $\mathrm{Ag}^{+}$concentration as high as 9.65 $\mu \mathrm{g} \mathrm{L}^{-1}$. To determine $\mathrm{TiO}_{2}$ NPs in lake water ${ }^{130}$, sedimentation field FFF combined with ICPMS/MS was used to overcome the interferences that affect Ti determination by ICP-MS. The separation was optimised using two $\mathrm{TiO}_{2}$ standards $(21$ and $50 \mathrm{~nm})$ at a flow rate of $0.5 \mathrm{~mL}$ $\min ^{-1}$ and with a sedimentation field of $1000 \mathrm{rpm}$. The instrumental LOD for $\mathrm{Ti}^{+}$was $10 \mathrm{ng} \mathrm{L}^{-}$ ${ }^{1}$ using $\mathrm{NH}_{3} / \mathrm{He}$ as the collision/reaction gas at $2 \mathrm{~mL} \mathrm{~min}^{-1}$. The method LOD for Ti NPs when using sedimentation flow FFF-ICP-MS/MS was $6.8 \mu \mathrm{g} \mathrm{L}^{-1}$. This was sufficient to detect Ti NPs in lake water. Analysis of a $500 \mathrm{~mL}$ lake water sample before and after preconcentration by centrifugation at $10000 \mathrm{rpm}$ for $2 \mathrm{~h}$ gave very similar size distributions $(75-400 \mathrm{~nm})$. Sunscreens or remobilised lake sediments were considered to be potential sources of the Ti 
NPs detected. Unfortunately, neither the mass of Ti found nor the particle count per mL was reported so comparisons with other methods was not possible.

\section{$2.5 \quad$ Instrumental analysis}

\subsubsection{Atomic absorption spectrometry}

A semi-continuous method for the determination of dissolved elemental mercury ${ }^{131}$ used an adapted CV-AAS system as detector. The sample was introduced using a peristaltic pump at a flow rate of up to $15 \mathrm{~mL} \mathrm{~min}{ }^{-1}$ and mixed with a mercury-free $\mathrm{N}_{2}$ flow of $75 \mathrm{~mL} \mathrm{~min}^{-1}$. The $\mathrm{Hg}^{0}$ released was collected on a gold trap for a minimum of 3 minutes (high concentration flue gas scrubber samples) and a maximum of 4-6 minutes (seawater samples). During thermal desorption, an additional flow of mercury-free air was introduced in order to reach the optimum flow rate through the AAS detector of $0.3 \mathrm{~L} \mathrm{~min}^{-1}$. The calibration was linear over the expected concentration range (0-30 ng L L $\left.\mathrm{L}^{-1}\right)$ and the LOD was 0.004 to $0.014 \mathrm{ng} \mathrm{L}^{-1}$ depending on amalgamation time. The results obtained agreed well with those obtained using the standard discreet purge and trap AFS method.

The selective detection of $\mathrm{Cr}^{\mathrm{VI}}$ in water used ${ }^{132}$ in situ selective thermal separation and ETAAS analysis. The $\mathrm{Cr}^{\mathrm{III}}$ present in the sample was complexed with 2-thenoyltrifluoracetone and the resulting product vapourised at $400^{\circ} \mathrm{C}$ during the ashing step. This left only $\mathrm{Cr}^{\mathrm{VI}}$ present at the $1200^{\circ} \mathrm{C}$ atomisation step. The $\mathrm{Cr}^{\mathrm{III}}$ concentration was determined by difference between the total $\mathrm{Cr}$ and $\mathrm{Cr}^{\mathrm{VI}}$ values. The LOD was $0.046 \mu \mathrm{g} \mathrm{L}^{-1}$ for $\mathrm{Cr}^{\mathrm{VI}}$ and the analytical precision $3.1 \% \operatorname{RSD}(\mathrm{n}=5)$ at a concentration of $1 \mu \mathrm{g} \mathrm{L} \mathrm{L}^{-1}$. The method was validated with the Chinese CRMs GBW(E)080403a and GBW(E)080404b (chromium in simulated water) and results for bottled water samples compared with those obtained by IC-ICP-MS analysis.

\subsubsection{Vapour generation techniques}

A simple selective hydride generation method for $\mathrm{Sb}$ in waters ${ }^{133}$ with ICP-MS detection has been developed. A $9 \mathrm{~mL}$ aliquot was taken from an $18 \mathrm{~mL}$ sample, acidified to $2 \% v / v$ with $\mathrm{HCl}$, and $1.0 \mathrm{~mL}$ of a $10 \% \mathrm{~m} / \mathrm{v}$ citric acid solution added as a masking agent. Unlike the citric acid complex formed with $\mathrm{Sb}^{\mathrm{III}}\left(\left[\mathrm{Sb}\left(\mathrm{C}_{6} \mathrm{O}_{7} \mathrm{H}_{6}\right)_{2}\right]^{-}\right)$, that formed with $\mathrm{Sb}^{\mathrm{v}}\left(\left[\mathrm{Sb}(\mathrm{OH})_{3}\left(\mathrm{C}_{6} \mathrm{O}_{7} \mathrm{H}_{5}\right)\right]^{-}\right)$ cannot be reduced with $\mathrm{NaBH}_{4}$. To reduce the $\mathrm{Sb}^{\mathrm{V}}$ to $\mathrm{Sb}^{\mathrm{III}}, 1 \mathrm{~mL}$ of $30 \% \mathrm{~m} / v$ KI solution was added to the remaining $9 \mathrm{~mL}$. To improve the instrumental $\mathrm{Sb}$ response, a $2 \mathrm{~mL} \mathrm{~min}^{-1} \mathrm{CH}_{4}$ flow was introduced to the Ar sample gas flow of the ICP-MS between the gas liquid separator and the torch. Under the optimised conditions, the LODs were $4.0\left(\mathrm{Sb}^{\mathrm{III}}\right)$ and $6.0 \mathrm{ng} \mathrm{\textrm {L } ^ { - 1 }}$ (total $\mathrm{Sb}$ ) 
and the precision $2 \% \operatorname{RSD}(\mathrm{n}=3)$ at a concentration of $1.0 \mu \mathrm{g} \mathrm{L}^{-1}$. Spike recoveries of $\mathrm{Sb}^{\mathrm{III}}$ and total $\mathrm{Sb}$ varied between 98 and $103 \%$ at the 1 and $10 \mu \mathrm{g} \mathrm{L}^{-1}$ levels. The mean $\mathrm{Sb}^{\mathrm{III}}$ concentration in 10 bottled water samples was $0.032 \mu \mathrm{g} \mathrm{L}^{-1}$ but unfortunately the $\mathrm{SD}$ on this measurement was not reported.

A photochemical vapour generation method using ICP-MS as detector ${ }^{134}$ was developed for the determination of Os in natural waters. When the sample was acidified to $5 \%$ $v / v \mathrm{HNO}_{3}$, volatile $\mathrm{OsO}_{4}$ was easily produced under $\mathrm{UV}$ irradiation. To improve sensitivity without increasing the blank, the irradiation time was increased by using a stopped-flow FI system. The optimum irradiation time of $150 \mathrm{~s}$ had the added advantage that the irradiation photo-reduced the sample matrix and heated the sample to $90{ }^{\circ} \mathrm{C}$, thereby improving the separation of $\mathrm{OsO}_{4}$ from the sample in the GLS. Memory effects from residual $\mathrm{OsO}_{4}$ were almost eliminated by using a $5 \% v / v \mathrm{NH}_{4} \mathrm{OH}$ solution as the carrier. This was a big improvement over the use of $5 \% \mathrm{HNO}_{3}$ as carrier when the signal from the preceding sample dropped by only $80 \%$ in the wash out time of $60 \mathrm{~s}$. The LOD was $0.8 \mathrm{pg} \mathrm{mL}^{-1}$, the precision $3.2 \% \operatorname{RSD}(\mathrm{n}=5)$ at a spike concentration of $1 \mathrm{ng} \mathrm{mL}^{-1}$ and the recoveries $97 \%$ (river water) to $109 \%$ (seawater). The swift and quantitative liberation ${ }^{135}$ of $\mathrm{Hg}$ from water samples (from a water purification plant and with concentrations of up to $\left.100 \mu \mathrm{gL}^{-1}\right)$ ina GLS was made possible by the addition of $10 \% v / v$ formic acid and use of a short $10 \mathrm{~s}$ UV irradiation pulse. An AFS system was then used to determine $\mathrm{Hg}$ with analytical LOD of $0.003 \mu \mathrm{g} \mathrm{L} \mathrm{L}^{-1}$. The LOD for $\mathrm{Hg}$ with ICP-AES detection was reduced ${ }^{136}$ to $90 \mathrm{pg} \mathrm{mL}^{-1}$ by adding $15 \% \mathrm{v} / \mathrm{v}$ formic acid to the sample and irradiating with an $11 \mathrm{~W}$ UV-C lamp prior to pneumatic nebulisation. All the $\mathrm{Hg}$ was converted to $\mathrm{Hg}^{\circ}$ in a spray chamber held at $40{ }^{\circ} \mathrm{C}$ and no negative effects were seen for the simultaneous detection of the non-volatile analytes $(\mathrm{Cu}, \mathrm{Fe}$ and $\mathrm{Mn})$. The method was validated with the IRMM CRMs ERMCA713 (waste water) and ERCCC580 (estuarine sediment).

\subsubsection{Inductively Coupled Plasma Mass Spectrometry.}

A review on the analysis of water by $I C P-M S$ covered ${ }^{137}$ (81 references) the typical problems with water analysis (matrix effects, sampling and spectral interferences) and discussed the robust conditions and higher matrix tolerances that new instruments can achieve.

The problems associated with $B$ analysis in water have been rediscovered ${ }^{138}$. Preservation of samples and immediate analysis (within $24 \mathrm{~h}$ ) after sampling were essential. In the ICP-AES analysis, the Fe and $\mathrm{Cr}$ emission lines close to the main $\mathrm{B}$ emission line could present problems. Filtration would reduce the measured B concentrations at low actual 
concentrations but increase them at high actual concentrations. When appropriate care was taken, results within $5 \%$ of the assigned values of proficiency scheme samples could be obtained. Strangely, no mention was made of known B memory effects within sample introduction systems, or of any attempts to reduce them.

A commercially available system with FI and preconcentration on an IDA column resin was used off-line to prepare seawater samples for REE analysis ${ }^{139}$. Using ID-ICP-MS analysis, REEs were successfully determined in only $11 \mathrm{~mL}$ of seawater with a procedural long-term error of $\leq 3.9 \% 2 \sigma$ RSD $(n=16)$ for all REEs except Ce and Gd. Results for measured REE concentrations in the samples from an international intercalibration (Geotraces) were within $7 \%(2 \sigma \mathrm{RSD})$ of the consensus values except for Ce (71\%), Gd (14\%) and $\mathrm{Lu}(12 \%)$. The REE concentrations in Brazilian rivers were determined ${ }^{140}$ in filtered samples, with and without preconcentration by SPE with bis-(2-ethyl-hexyl)-phosphate. This preconcentration approach was unable to retain $\mathrm{Gd}$ complexes, suspected to be present in discharges from hospitals that use MRI contrasting agents. Such complexes only dissociate slowly in acidic water to produce the free ion which is retained by the phosphate ester. Strong correlations with parameters indicative of industrial effluents and recycled water $\left(\mathrm{B}, \mathrm{NH}_{4} \mathrm{OH}\right.$ and $\left.\mathrm{DOC}\right)$ seemed to confirm the finding that this Gd source was indeed anthropogenic in origin. A anthropogenic input was also observed in seawater samples from San Francisco Bay ${ }^{141}$. The Gd levels in the southern part of the Bay had risen more than 13-fold from $8.27 \mathrm{pmol} \mathrm{kg}^{-1}$ in 1993 to $112 \mathrm{pmol} \mathrm{kg}^{-1}$ in 2013. It was suggested that preconcentration with the NOBIAS PA-1® 20 resin followed by SF-ICP-MS detection could be used to monitor increases in the environmental concentrations of Gd and other exotic trace elements in waste streams from hospitals and technological industries.

The quantification and fractionation of fine particulate carbon in stream water was achieved by coupling asymmetric flow FFF with SF and quadrupole ICP-MS ${ }^{142}$. Using an optical carbon detector as a reference method, recoveries were $122 \pm 22 \%$ and the LOD $0.3 \mathrm{mg}$ $\mathrm{L}^{-1}$. The latter was poorer than that $\left(0.04 \mathrm{mg} \mathrm{L}^{-1}\right)$ achievable with a dedicated carbon detector. The particulate carbon concentrations in a fresh water sample and a bovine serum albumin candidate RM were determined. If FFF-quadrupole-ICP-MS were used with FI sample introduction, recoveries could be improved to $90-113 \%$.

Accurate isotope ratio measurements by ICP-MS typically require laborious preconcentration and matrix separation steps before analysis. To overcome these problems, ICMC-ICP-MS was investigated for $\mathrm{Mg}^{143}$ and $\mathrm{Sr}^{144}$ isotope ratio analyses. Using an IonPac CS16 cation-exchange column $(5 \times 250 \mathrm{~mm}, 5 \mu \mathrm{m}$ particle size $)$ with corresponding guard 
column and suppressor unit at a flow rate of $1 \mathrm{~mL} \mathrm{~min}^{-1}$, the $\mathrm{Sr}$ was isolated from the matrix and determined within 14 minutes with a precision that was worse than that of traditional offline methods but within the uncertainty of the certified value of the NIST SRM 987 (strontium carbonate isotopic standard). For $\mathrm{Mg}$, a narrower ( $3 \mathrm{~mm}$ id) version of the same column was used so that the flow rate $\left(0.36 \mathrm{~mL} \mathrm{~min}^{-1}\right)$ was compatible with the desolvation system. A good precision of $\pm 0.15 \%$ o (2SD) on ${ }^{26} \mathrm{Mg} /{ }^{24} \mathrm{Mg}$ isotope ratios in matrix-rich natural waters was achieved with an analysis time of 18 minutes per replicate, comparable to the precision obtainable with off-line matrix separation methods. The use of DGT samplers, typically used to obtain time-weighted average concentration in bodies of water, was tested ${ }^{145}$ under controlled conditions in a clean room to ascertain whether accurate $\mathrm{Pb}$ and $\mathrm{Zn}$ isotope ratios could be obtained. Use of Chelex ${ }^{\circledR}-100$ resin as the accumulation layer introduced no fractionation of $\mathrm{Pb}$ isotopes but fractionation of $\mathrm{Zn}$ isotopes did occur. A correction factor was applied to account for the exposure time and thickness of the diffusion layer. Photographic black and white film was used ${ }^{146}$ as a DGT analogue for in situ sampling of S in sediment pore water in order to obtain a $2 \mathrm{D}(22 \times 3.5 \mathrm{~mm})$ map of the $\delta^{34} \mathrm{~S}$ distribution. Photographic film disturbed the sediments less and had a $10^{3}$ superior binding affinity for $\mathrm{S}$ than typically used DGT binding matrices. Interrogating the film with a LA-MC-ICP-MS instrument allowed a high spatial resolution $\left(10^{2} \mu \mathrm{m}\right)$ map of $\delta^{34} \mathrm{~S}$ in the pore waters to be obtained with a reasonable accuracy $(<0.9 \%$ o, $2 \sigma)$ and external precision $(<0.8 \%$ o, $2 \sigma)$ across an environmentally relevant concentration range $(0.01-20 \mathrm{mM})$.

\subsubsection{Laser induced breakdown spectroscopy.}

A LIBS procedure for the direct determination of $\mathrm{Sr}$ in seawater and mineral water ${ }^{147}$ employed the Sr II $407.77 \mathrm{~nm}$ ion emission line. An LOD of $25 \mu \mathrm{g} \mathrm{L}^{-1}$ could be achieved for fresh water samples but was as poor as $200 \mu \mathrm{g} \mathrm{L}^{-1}$ for salty waters due to matrix effects. For $\mathrm{Sr}$ concentrations in the $1-20 \mathrm{mg} \mathrm{L}^{-1}$ range, no dilution or preconcentration was necessary and measurements could be carried out a frequency of 1 sample $\min ^{-1}$. Measurement repeatability was $12 \% \operatorname{RSD}(\mathrm{n}=10)$ for a $1 \mathrm{mg} \mathrm{L}^{-1}$ standard prepared in deionised water but was poorer at $41 \% \operatorname{RSD}(\mathrm{n}=10)$, when the same standard was prepared using a seawater matrix.

Typically, trace elements in water need to be preconcentrated onto or into a solid matrix before LIBS analysis. One method ${ }^{148}$ used a magnesium alloy to trap $\mathrm{Cd}, \mathrm{Cr}, \mathrm{Cu}$, and $\mathrm{Pb}$ into a thin surface layer. The linear working range was $0-7 \mu \mathrm{g} \mathrm{mL}^{-1}$ for a mixed element standard (except for $\mathrm{Cu}$ which gave a curved response at all concentrations) and the LODs were between $0.025(\mathrm{Cr})$ and $0.420(\mathrm{Cd}) \mu \mathrm{g} \mathrm{mL}^{-1}$. Alternatively ${ }^{149}$, the target trace elements could 
be incorporated into a poly(vinyl alcohol)(PVA) membrane. The PVA solution was cast into a petri dish with $10 \mathrm{~mL}$ of the sample or standard so that the elements were incorporated directly into a $0.34 \mathrm{~mm}$ thick polymer film once dried. The LODs were $1 \mathrm{ng} \mathrm{mL}^{-1}$ (Ag) to $5 \mu \mathrm{g} \mathrm{mL} \mathrm{m}^{-1}$ (Cd) when using a series of "differently linear" calibration curves. A sample preparation time of 90 minutes for the curing and drying of the polymer is a limitation on the utility of this method for the moment and work on improvements continues.

\subsubsection{X-ray fluorescence spectrometry.}

A big advantage that XRFS has over other atomic spectrometry techniques is the availability of portable hand-held analysers which allow measurements in the field to be undertaken. Use of a suitable preconcentration method allowed some metals to be detected in water samples. The Purolite ${ }^{\circledR} \mathrm{S} 930$ resin was used ${ }^{150}$ to determine $\mathrm{Cu}, \mathrm{Fe}, \mathrm{Mn}, \mathrm{Ni}, \mathrm{Pb}$ and $\mathrm{Zn}$ concentrations in river and groundwater samples. The method LOD was 5-18 $\mu \mathrm{g} \mathrm{L}^{-1}$ and the precision $<15 \%$ RSD ( $n=10)$. The results were lower than those obtained using ICP-MS, probably because ICPMS measured elements within fine suspended particles as well as dissolved elements. Solid phase extraction disks with iminodiacetate functional groups were investigated ${ }^{151}$ as a means of preconcentrating $\mathrm{Cd}, \mathrm{Cu}, \mathrm{Fe}, \mathrm{Hg}, \mathrm{Mn}, \mathrm{Pb}$ and $\mathrm{Zn}$ from water samples. Elemental recoveries from $50 \mathrm{ml}$ spiked water samples were between $89 \%(\mathrm{Cu})$ and $110 \%(\mathrm{Hg})$ and the resultant method LODs were between $3.2(\mathrm{~Pb})$ and $9.4(\mathrm{Fe}) \mu \mathrm{g} \mathrm{L} \mathrm{L}^{-1}$.

At the other end of the portability scale, a sensitive TXRFS method was developed ${ }^{152}$ at the Shanghai synchrotron facility. Using a $100 \mathrm{~s}$ read time, the LODs were $0.03(\mathrm{Zn})$ to 0.11 (Cr) pg for a $10 \mu \mathrm{L}$ sample deposited as a $100 \mu \mathrm{m}$ diameter spot size on a conditioned Si wafer. Results for waters spiked with 100 and $500 \mu \mathrm{g} \mathrm{L}^{-1} \mathrm{Co}, \mathrm{Cr}, \mathrm{Cu}, \mathrm{Mn}$, and Ni agreed within 10\% of results obtained by ICP-MS. 


\section{$3 \quad$ Analysis of soils, plants and related materials}

\subsection{Review papers}

Notable element-specific reviews were that on fractionation and speciation analysis of $\mathrm{Mn}^{34}$ (2016) (113 references) in numerous matrices, including soils, sediments and plants and that on sources, distribution and analytical methods for the determination of $\mathrm{Tl}^{153}$ (129 references).

Two review articles concerning the determination of radionuclides were of interest. The first ${ }^{154}$ (109 references) focussed on the fission products ${ }^{135} \mathrm{Cs},{ }^{137} \mathrm{Cs}$ and ${ }^{90} \mathrm{Sr}$, with particular reference to analyses using AMS, ICP-MS and TIMS. The second ${ }^{155}$ (155 references) provided a comprehensive overview of the status of radiochemical analysis in Nordic countries.

Other notable reviews discussed: the use of elemental and molecular mass spectrometry in rhizosphere research ${ }^{156}$ (118 references); techniques and strategies for quantifying and mapping chemical elements in single cells ${ }^{157}$ (103 references); methods for separation and characterisation of environmental NPs and sub- $\mu \mathrm{m}$ particles ${ }^{158}$ (97 references); and progress and challenges in the application of (predominantly atomic-spectrometry-based) analytical techniques in archaeological soil analysis ${ }^{159}$ (81 references).

\subsection{Reference materials}

Useful supplementary information on popular CRMs has been published since our last Update. Concentrations of 49 elements - including 21 not characterised by NIST - were reported ${ }^{160}$ for SRMs 2709a (San Joaquin soil), 2710a (Montana I soil), 2711a (Montana II soil), 2586 and 2587 (both trace elements in soil - containing $\mathrm{Pb}$ from paint). Another study ${ }^{161}$ measured 46 elements in five RMs - one soil (NCS DC 77302/GBW 07410) and five sediments (Analytika Metranal-1, IAEA-405, NRCC MESS-3, NCS DC 73309/GBW 07311 and NCS DC 75301/GBW 07314). A ${ }^{99 m}$ Tc activity concentration of $600 \pm 40 \mathrm{mBq} \mathrm{kg}^{-1}$ was determined ${ }^{162}$ for IAEA 315 (radionuclides in marine sediment) by ICP-MS. Two groups developed and applied MC-ICP-MS methods to obtain new isotopic information on CRMs: workers in Brazil ${ }^{163}$ reported ${ }^{66} \mathrm{Zn} /{ }^{64} \mathrm{Zn}$ values for NIST SRMs 2709 (San Joaquin soil), 1646a (estuarine sediment) and 1573a (tomato leaves); while researchers in Canada and China ${ }^{164}$ provided ${ }^{71} \mathrm{Ga} /{ }^{69} \mathrm{Ga}$ ratios in IGGE GSS-1 (soil), GSS-5 (soil) and GSD-13 (sediment), and in NRCC PACS-2 (sediment).

Articles featuring the development of analytical procedures specifically for use in the 
certification of new CRMs included a detailed description ${ }^{165}$ of an ID-ICP-MS procedure that contributed $\mathrm{Cd}, \mathrm{Cu}, \mathrm{Hg}, \mathrm{Pb}$ and $\mathrm{Zn}$ mass fraction values for IAEA 458 (marine sediment). The evaluation $^{166}$ of CV-AAS and ICP-MS methods included application to four candidate INCT CRMs, one of which was a sediment.

\subsection{Sample preparation}

\subsubsection{Sample dissolution and extraction}

A key challenge relating to the extraction of NPs from environmental media for analysis by sp$I C P-M S$ is differentiation between the dissolved analyte and the analyte associated with the NPs, especially when the dissolved concentration is high. A serial dilution method ${ }^{126}$ developed to overcome this used extracts of Ag NP-contaminated soil. The sample was first analysed to determine the dissolved Ag concentration and then diluted so that only transient signals from individual Ag NPs were recorded. The same research group assessed the utility of an ion-exchange procedure ${ }^{167}$ to quantify dissolved Ag ions in soil extracts containing Ag NPs, validating their results by comparison with those obtained with an ISE. They also investigated $^{168}$ the efficiency of a variety of reagents for extraction of Ag NPs from soils amended with biosolids. Sonication in $2.5 \mathrm{mM}$ tetrasodium pyrophosphate at a soil:solution ratio of 1:100 $(\mathrm{m} / \mathrm{v})$ followed by sedimentation to remove soil colloids gave the optimal suspension for analysis by sp-ICP-MS, with minimal NP dissolution and agglomeration. A CPE method ${ }^{169}$ was optimised for recovery of Au NPs with different surface coatings and size that had been spiked into an agricultural soil extract. The original particle size distribution was preserved when TX-114 with or without $2 \mathrm{mM} \mathrm{NaCl}$ was used as extractant. Enzymatic digestion with Macerozyme R-10 successfully recovered both $\mathrm{CeO}_{2} \mathrm{NPs}^{170}$ and $\mathrm{Pt} \mathrm{NPs}^{171}$ from plants that had been grown hydroponically in NP-contaminated nutrient.

Several improved methods for radionuclides were reported. Researchers in Japan ${ }^{172}$ recommended $\mathrm{CaF}_{2} / \mathrm{LaF}_{3}$ co-precipitation followed by sequential application of three commercial resins - TEVA, UTEVA, DGA - for removal of interfering elements in their method for determination of $\mathrm{Pu}$ in soils and sediments by SF-ICP-MS. Members of the same team developed a method ${ }^{173}$ for ultratrace determination of ${ }^{241} \mathrm{Am}$ in soil and made a detailed study $^{174}$ of TRU and DGA resins for interference removal. Other authors ${ }^{175}$ reported an improved version of their automated anion-exchange procedure for sequential separation of $\mathrm{La}$, $\mathrm{Pb}, \mathrm{Pu}, \mathrm{Th}$ and $\mathrm{U}$ and its application to tree ring samples. A novel multi-step procedure ${ }^{176}$ to study the distribution of ${ }^{99 \mathrm{~m}} \mathrm{Tc}$ in seaweed by ICP-MS separated the total content into eight 
fractions. The majority of $\mathrm{Tc}$ was found as $\mathrm{TcO}_{4}{ }^{-}$or in water-, acid- and alkali-soluble forms $(15 \%, 29 \%, 14 \%$ and $25 \%$ of the total content, respectively) with the remainder bound to pigment $(3 \%)$, algin $(11 \%)$ and cellulose $(3 \%)$. No Tc bound to water-soluble protein was detected. Extraction procedures specifically designed for use with ICP-MS/MS included a simple method ${ }^{177}$ for purification of soil digest prior to measurement of $U$ and ${ }^{236} U /{ }^{238} U$ ratios and a procedure ${ }^{178}$ for ultratrace determination of ${ }^{135} \mathrm{Cs} /{ }^{137} \mathrm{Cs}$ in environmental samples at global fallout levels. The latter procedure may have the potential to rival analysis using TIMS.

Losses due to venting during microwave-assisted extraction with hot mineral acids did not always affect ${ }^{179}$ the accuracy of concentrations measured by ICP-AES or ICP-MS, even for relatively volatile analytes such as As. The authors suggested that condensation promoted by the temperature gradient between the bottom and top of the (tall) digestion vessels aided analyte recovery. A MAE with aqua regia followed by addition of $0.1 \mathrm{M} \mathrm{NH} 4 \mathrm{SCN}$ prevented the loss of I both during mineralisation and in the spray chamber when analysing biota (including seaweed ) by ICP-MS ${ }^{180}$. A hotplate digestion ${ }^{181}$ with $\mathrm{HCl}\left(2 \mathrm{~h}\right.$ at $\left.150{ }^{\circ} \mathrm{C}\right)$ avoided formation of insoluble precipitates that led to inaccuracies when MAE with HCl-HNO3-HF was applied to carbonate-rich sediment prior to analysis by ICP-MS.

The feasibility of microwave-induced combustion to digest soil with high inorganic matter content for determination of halogens was demonstrated ${ }^{182}$ for the first time. A $100 \mathrm{mg}$ sample was mixed with $400 \mathrm{mg}$ of microcrystalline cellulose to aid combustion, placed in a quartz cell filled with 20 bar of $\mathrm{O}_{2}$ and ignited. The liberated halogens were trapped in $6 \mathrm{~mL}$ of $100 \mathrm{mM} \mathrm{NH}_{4} \mathrm{OH}$ solution. Following dilution, $\mathrm{Cl}$ and $\mathrm{F}$ were measured by $\mathrm{IC}$ and $\mathrm{Br}$ and I by ICP-MS. Spike recoveries were 94-103\%.

An ultrasound assisted extraction $^{183}$ for measurement of I in food by ICP-AES involved sonication of $0.1 \mathrm{~g}$ samples in $10 \mathrm{~mL}$ of deionised water for 5 minutes and gave a recovery of $98 \%$ for analysis of NIST SRM 1573 a (tomato leaves). A UAE for soil ${ }^{184}$ using a deep eutectic solvent (choline chloride/oxalic acid in a 1:2 molar ratio) was optimised by two-level full factorial design using NIST SRM 2709 (San Joaquin soil). When sonication of $0.1 \mathrm{~g}$ test samples for 10 minutes in $10 \mathrm{~mL}$ solvent was followed by a 5 minute period of further heating in a block digestor at $120^{\circ} \mathrm{C}$, recoveries by ICP-AES were similar to certified and indicative values for As, Cd, Mo, Sb, Se and V. Sonication in a mixture ${ }^{185}$ of $5 \mathrm{mM}$ 1-butyl-3-methylimidazolium tetrafluoroborate ionic liquid, $0.005 \mathrm{M}$ EDTA and $0.1 \mathrm{M} \mathrm{NaHCO}_{3}$ for 7 minutes gave performance similar to that obtained with $6 \mathrm{~h}$ conventional shaking in $0.05 \mathrm{M}$ EDTA solution for determination of available $\mathrm{Cd}, \mathrm{Cu}, \mathrm{Ni}, \mathrm{Pb}$ and $\mathrm{Zn}$ in sediment by FAAS. In another sediment study ${ }^{186}$ sonication in $4 \mathrm{M} \mathrm{HCl}$ and $0.75 \%(\mathrm{~m} / \mathrm{v})$ thiourea for 20 minutes were optimal 
for extraction of $\mathrm{Hg}$, giving results close to target values for analysis of IRMM CRM BCR 320 R (channel sediment) and NIST SRM 2709a (San Joaquin soil) by CV-AAS.

Comparisons of extraction methods for soil and sediments included a study ${ }^{187}$ of the effects of soil properties on the efficiency of extraction of roxarsone and its metabolites by different reagents for determination by HPLC-ICP-MS. Soil pH, CEC and Fe content all affected the extraction of As species but satisfactory performance was obtained with 9:1 $(\mathrm{v} / \mathrm{v})$ $0.1 \mathrm{M} \mathrm{NaH}_{2} \mathrm{PO}_{4}+0.1 \mathrm{M} \mathrm{H}_{3} \mathrm{PO}_{4}$. To improve understanding of total $\mathrm{P}$ content in agricultural runoff, a comparison ${ }^{188}$ was made of acid persulfate, USGS and alkaline persulfate methods for measuring $\mathrm{P}$ in suspended sediment by ICP-AES. Use of the acid persulfate method was recommended. Dilute $\mathrm{HNO}_{3}(0.75-1.0 \mathrm{M})$ was ${ }^{189}$ more efficient than chelating agents for extraction of 20 elements from NRCC CRM MESS-3 (marine sediment). However, whether it could "provide a better assessment of potentially bioavailable metals" is open to debate since the true bioavailable concentration was unknown. A valuable study ${ }^{190}$ used ID to compare the selectivity of $0.43 \mathrm{M} \mathrm{HNO}, 0.43 \mathrm{M} \mathrm{CH} \mathrm{CH}_{3} \mathrm{COOH}, 0.05 \mathrm{M} \mathrm{Na}_{2} \mathrm{H}_{2} \mathrm{EDTA}$ and $1 \mathrm{M} \mathrm{CaCl}_{2}$ for extraction of labile $\mathrm{Cd}, \mathrm{Cu}, \mathrm{Ni}, \mathrm{Pb}$ and $\mathrm{Zn}$ from four soils with varying characteristics. Whilst $\mathrm{CH}_{3} \mathrm{COOH}$ and $\mathrm{CaCl}_{2}$ failed to recover the labile pool quantitatively, $\mathrm{HNO}_{3}$ and EDTA solubilised additional, non-labile analyte. It was suggested that a lower concentration of EDTA might represent the optimal extractant for estimating the labile PTE fraction in soils.

Comparisons of methods for extraction of plants included a study ${ }^{191}$ on CRMs amongst them NIST SRM 1571 (orchard leaves) - that found MAE in $4 \mathrm{~mL}$ of $\mathrm{HNO}_{3}+2 \mathrm{~mL}$ of $\mathrm{H}_{2} \mathrm{O}_{2}$ gave best recoveries for the determination of $\mathrm{Cu}, \mathrm{Fe}$ and $\mathrm{Zn}$ by FAAS. The extraction of As species was studied ${ }^{192}$ using NRCCRM GBW 10049 (green onion) with determination by HPLC-ICP-MS. Three common extraction methods (shaking at $90{ }^{\circ} \mathrm{C}$ in a water bath, UAE and MAE) and three extractants (water, ammonium phosphate and $\mathrm{HNO}_{3}$ ) were assessed by summing the concentrations of As species released and comparing the sum with the certified total As concentration. Best recovery (94\%) was obtained by MAE in $1 \% \mathrm{HNO}_{3}$. A method ${ }^{193}$ for measuring $\mathrm{As}, \mathrm{Cd}, \mathrm{Cu}, \mathrm{Ni}, \mathrm{Pb}$ and $\mathrm{Zn}$ in artichoke involved extraction of $0.5 \mathrm{~g}$ sample in $10 \mathrm{~mL} 25 \% \mathrm{HNO}_{3}$ at room temperature with passage of ozone through the extractant, followed by centrifugation to isolate the supernatant for analysis by AAS. Recoveries were similar to those obtained using UAE, those for NIST SRM 1570a (spinach leaves) were 98-101\%. The same SRM featured in a comparison ${ }^{194}$ of dry ashing, hotplate digestion $\left(5+1 \mathrm{HNO}_{3}: \mathrm{H}_{2} \mathrm{O}_{2}\right)$ and MAE digestion $\left(7+1 \mathrm{HNO}_{3}: \mathrm{H}_{2} \mathrm{O}_{2}\right)$. All of the procedures gave results close to target values but the microwave procedure was the most accurate. Dry ashing at $480{ }^{\circ} \mathrm{C}$ followed by dissolution of the ash in $\mathrm{HNO}_{3}$ gave recoveries superior to those obtained using hot acid 
digestion in 1:2 $(v / v) \mathrm{HNO}_{3}+\mathrm{H}_{2} \mathrm{O}_{2}$ for the determination of REEs in plants by ICP-MS ${ }^{195}$. Hotplate digestion ${ }^{196}$ with mixtures of $\mathrm{HCl}$ and $\mathrm{HNO}_{3}$ was however preferred to dry ashing for extraction of $\mathrm{Cu}$ and $\mathrm{Fe}$ from orange peel and leaves for determination by FAAS. Four digestion methods ${ }^{197}$ were compared for the determination of 19 elements in samples of wood by ICP-AES and CV-AAS: MAE according to method EN 15290; wet digestion using USEPA Method 3050B; and dry ashing (again according to EN 15290), both with and without a subsequent $\mathrm{LiBO}_{2}$ fusion. Through analysis of IRMM CRM BCR 100 (beech leaves) and BCR 62 (olive leaves) it was shown that wet digestion was the most fit for purpose, giving results close to certified values. Wet digestion also allowed a relatively large sample mass $(5 \mathrm{~g})$ to be taken in order to have analyte concentrations above LOD values.

Studies involving DGT and related devices for estimating the available fraction of analytes in soil and sediments included a comparison ${ }^{198}$ of high resolution (precipitated zirconia and ferrihydrite) and conventional (ferrihydrite slurry) gels for measurement and mapping of $\mathrm{W}$ in soils and sediments by LA-ICP-MS. All gave comparable $\mathrm{W}$ concentrations but the high resolution approach was better at identifying hotspots. A novel sampling device that incorporated a strong basic anion-exchange resin was developed and tested by a research group in Austria for the ICP-MS determination ${ }^{199}$ and MC-ICP-MS isotopic analysis ${ }^{200}$ of labile sulfate in soil. A further innovation ${ }^{201}$ from the same group was the combination of DGT and a planar optode for $\mathrm{pH}$ sensing in the same device. Detailed images of $\mathrm{pH}$ and trace element distribution in soil around a plant root were obtained using LA-ICP-MS for elemental information and a ratiometric method to map the $\mathrm{pH}$-sensitive luminophore, $2^{\prime}, 7^{\prime}$-dichloro5(6)- $N$-octadecyl-carboxamidofluorescein. Black-and-white photographic film ${ }^{146}$ was used to obtain a high-resolution 2D map of $\delta^{34} \mathrm{~S}$ in sediment pore waters by LA-MC-ICP-MS. The advantages of this substrate over those commonly used in DGT devices are that it is readily available and requires minimal preparation before deployment.

In bioaccessibility testing, a dynamic version of the unified bioaccessibility test ${ }^{202}$ was successfully developed and coupled with ICP-AES for on-line determination of $\mathrm{Cu}, \mathrm{Fe}$ and $\mathrm{Mn}$ in soybeans.

An eight-step sequential extraction protocol for fractionation of $\mathrm{V}$ in soil ${ }^{203}$ was proposed to overcome poor recoveries obtained using previous methods. A five-step procedure for the extraction of As from soils and sediments ${ }^{204}$ was updated and shown, by spike recovery tests, to preserve $\mathrm{As}^{\mathrm{III}}$ and $\mathrm{As}^{\mathrm{V}}$ speciation during extraction. A variant ${ }^{205}$ on the ultrasound 
assisted version of the BCR protocol mentioned in last year's Update ${ }^{1}$ was shown to be applicable to $\mathrm{Cd}, \mathrm{Ni}$ and $\mathrm{Pb}$.

\subsubsection{Preconcentration procedures}

Numerous preconcentration procedures for specific analytes have been reported. Methods for the analysis of soils, plants or related materials, or those developed for other sample matrices that used soil or plant CRMs for validation, are summarised in Tables 4 to 6 . 
Table 4. Preconcentration methods involving coprecipitation used in the analysis of soils, plants and related materials

\begin{tabular}{|c|c|c|c|c|c|c|}
\hline Analyte(s) & Matrix & Coprecipitating agent & Detector & $\operatorname{LOD}\left(\mu \mathrm{g} \mathrm{L}^{-1}\right)$ & $\begin{array}{l}\text { CRMs or other } \\
\text { validation }\end{array}$ & Reference \\
\hline $\mathrm{Ag}$ & Plant, water & $\begin{array}{l}\text { 1,6-diamino-4-(4-chlorophenyl)-2- } \\
\text { oxo-1,2-dihydropyridine-3,5- } \\
\text { dicarbonitrile }\end{array}$ & FAAS & 1.60 & $\begin{array}{l}\text { NKK CRMs } 916 \\
\text { and } 920 \text { (Al alloy) }\end{array}$ & 206 \\
\hline $\mathrm{Cd}, \mathrm{Pb}$ & $\begin{array}{l}\text { Tea, tobacco, } \\
\text { water }\end{array}$ & $\begin{array}{c}\text { 3-(4-tert-butylphenyl)-5-phenyl-4-(2- } \\
\text { hydroxy-5-methoxybenzylamino) - } \\
\text { 4H-1,2,4-triazole }\end{array}$ & FAAS & $\begin{array}{c}2.0 \text { for } \mathrm{Pb}, 0.2 \text { for } \\
\mathrm{Cd}\end{array}$ & $\begin{array}{l}\text { HPS CRM SA-C } \\
\text { (sandy soil C) }\end{array}$ & 207 \\
\hline
\end{tabular}


Table 5. Preconcentration methods involving liquid-phase microextraction used in the analysis of soils, plants and related materials

\begin{tabular}{|c|c|c|c|c|c|c|c|}
\hline Analyte(s) & $\begin{array}{l}\text { Sample } \\
\text { matrix }\end{array}$ & Method & Reagent(s) & Detector & $\begin{array}{l}\text { LOD }\left(\mu \mathrm{g} \mathrm{L} \mathrm{L}^{-}\right. \\
\text {1) (unless } \\
\text { otherwise } \\
\text { stated) }\end{array}$ & CRMs or other validation & Reference \\
\hline $\mathrm{Ag}, \mathrm{Cd}$ & $\begin{array}{c}\text { Nuts, } \\
\text { vegetables }\end{array}$ & UA-CPE & $\begin{array}{l}\text { 3,7-diamino-2,8- dimethyl-5- } \\
\text { phenyl-phenaziniumchlorid, } \\
\text { poly(ethyleneglycol-mono-p- } \\
\text { nonylphenylether) }\end{array}$ & FAAS & $\begin{array}{c}0.02 \text { for } \mathrm{Ag} \\
0.9 \text { for } \mathrm{Cd}\end{array}$ & $\begin{array}{c}\text { NIST SRM 1573a (tomato } \\
\text { leaves) and SRM 1643e (trace } \\
\text { elements in waters) }\end{array}$ & 208 \\
\hline As & $\begin{array}{l}\text { Sediment, } \\
\text { soil, water }\end{array}$ & $\begin{array}{c}\text { MIL- } \\
\text { AALLME }\end{array}$ & $\begin{array}{l}\text { magnetic ionic liquid 1-butyl-3- } \\
\text { methylimidazolium tetrachloroferrate }\end{array}$ & ETAAS & $\begin{array}{l}0.029 \text { for } \\
\mathrm{As}^{\text {III }}\end{array}$ & $\begin{array}{c}\text { NRCCRM GBW } 080231 \\
\text { (seawater), } 08605 \text { (water), } \\
07402 \text { (soil), } 070008 \text { (soil), } \\
07309 \text { (sediment) }\end{array}$ & 209 \\
\hline $\mathrm{Cd}$ & $\begin{array}{l}\text { Sediment, } \\
\text { water }\end{array}$ & $\begin{array}{c}\text { UA- } \\
\text { DLLME }\end{array}$ & $\begin{array}{l}\text { 5-(4-dimethylaminobenzylidene) } \\
\text { Rhodanine }\end{array}$ & FAAS & 0.23 & $\begin{array}{l}\text { AR APS } 1071 \text { (drinking water), } \\
\text { RTC } 016 \text { (freshwater sediment } \\
\text { 3), NIST SRM 1566b (oyster } \\
\text { tissue), SRM 1573a (tomato } \\
\text { leaves) }\end{array}$ & 210 \\
\hline $\mathrm{Cd}$ & Herbs & SFODME & 1-(2-pyridylazo)-2-naphthol & ETAAS & 0.0052 & $\begin{array}{c}\text { NIST SRM 1573a (tomato } \\
\text { leaves) }\end{array}$ & 211 \\
\hline $\mathrm{Cd}, \mathrm{Cu}$ & Tea, water & DLLME & $\begin{array}{l}\text { N,N'-bis(2-hydroxy-5-bromo- } \\
\text { benzyl)1,2 diaminopropane, carbon } \\
\text { tetrachloride }\end{array}$ & FAAS & $\begin{array}{l}0.69 \text { for } \mathrm{Cd} \\
2.0 \text { for } \mathrm{Cu}\end{array}$ & $\begin{array}{c}\text { NRCC SLRS-5 (river water), } \\
\text { NIST SRM 1573a (tomato } \\
\text { leaves) }\end{array}$ & 212 \\
\hline $\mathrm{Co}$ & $\begin{array}{l}\text { Spinach, } \\
\text { water }\end{array}$ & DLLME & $\begin{array}{c}\text { thiocyanate, cetylpyridinium } \\
\text { chloride, acetone, carbon } \\
\text { tetrachloride }\end{array}$ & ETAAS & 0.02 & $\begin{array}{l}\text { NWRI CRM-TMDW (drinking } \\
\text { water) }\end{array}$ & 213 \\
\hline $\mathrm{Cr}$ & Soil & LLME & $\begin{array}{l}\text { methyltrioctylammonium chloride, } \\
\text { xylene }\end{array}$ & $\begin{array}{l}\text { FAAS, } \\
\text { ETAAS }\end{array}$ & $\begin{array}{c}2 \mathrm{mg} \mathrm{kg}^{-1} \\
(\text { FAAS), } 25 \\
\mu \mathrm{g} \mathrm{kg}^{-1} \\
\text { (ETAAS) }\end{array}$ & $\begin{array}{c}\text { RTC CRM041-30G Chromium } \\
\text { VI-Soil }\end{array}$ & 214 \\
\hline $\mathrm{Hg}$ & $\begin{array}{l}\text { Coal, rock, } \\
\text { soil }\end{array}$ & LLME & $\begin{array}{c}\text { exchangeable water-polar organic } \\
\text { solvent system }\end{array}$ & CV-AAS & 0.0005 & $\begin{array}{l}\text { NIST SRMs 1633b (coal fly } \\
\text { ash), } 2711 \text { (Montana soil), }\end{array}$ & 215 \\
\hline
\end{tabular}




\begin{tabular}{|c|c|c|c|c|c|c|c|}
\hline & & & & & & $\begin{array}{c}\text { NRCCRM GBW } 07309 \\
\text { (stream sediment) }\end{array}$ & \\
\hline $\mathrm{Mn}, \mathrm{Sn}, \mathrm{Zn}$ & $\begin{array}{l}\text { Food of plant } \\
\text { origin }\end{array}$ & UA-CPE & $\begin{array}{l}\text { 2-(3,4-dihydroxyphenyl)-3,5,7- } \\
\text { trihydroxy-4H-chromen-4-one, } \\
\text { cetyltrimethylammonium bromide }\end{array}$ & FAAS & $\begin{array}{l}0.34 \text { for } \mathrm{Mn}, \\
0.70 \text { for } \mathrm{Sn}, \\
0.15 \text { for } \mathrm{Zn}\end{array}$ & $\begin{array}{l}\text { NIST SRMs 1548a (typical } \\
\text { diet), } 2385 \text { (slurried spinach) }\end{array}$ & 216 \\
\hline Mo & $\begin{array}{l}\text { Various } \\
\text { foodstuffs }\end{array}$ & $\begin{array}{l}\text { VA- } \\
\text { SFODME }\end{array}$ & $\begin{array}{l}\text { 4-amino-3-hydroxy-1- } \\
\text { naphthalenesulfonic acid, 1- } \\
\text { undecanol }\end{array}$ & ETAAS & 0.010 & $\begin{array}{c}\text { NIST SRM 1568a (rice flour), } \\
\text { 577b (bovine liver), NRCCRM } \\
\text { GBW } 07605 \text { (tea) }\end{array}$ & 217 \\
\hline $\mathrm{Ni}$ & $\begin{array}{c}\text { Alloy, } \\
\text { effluent, soil }\end{array}$ & $\mathrm{CPE}$ & $\begin{array}{c}\text { N,N'-bis(salicylaldehyde) } \\
\text { ethylenediamine }\end{array}$ & FAAS & 0.15 & Spike recovery & 218 \\
\hline $\mathrm{Pb}$ & $\begin{array}{l}\text { Food, } \\
\text { sediment, } \\
\text { soil, water }\end{array}$ & $\begin{array}{c}\text { VA- } \\
\text { DLLME }\end{array}$ & $\begin{array}{l}\text { 2-hydroxypyridine-3-carboxylic } \\
\text { acid, carbon tetrachloride }\end{array}$ & FAAS & 8.3 & $\begin{array}{c}\text { NWRI TMDA } 64.2 \text { (water), } \\
\text { TMDA 53.3 (water), SPS- } \\
\text { WW2 (wastewater), NRCCRM } \\
\text { GBW 07425 (soil), IRMM } \\
\text { BCR146R (sewage sludge), } \\
\text { HR-1 (harbour sediment) and } \\
\text { NCS DC } 73349 \text { (bush branches } \\
\text { and leaves }\end{array}$ & 219 \\
\hline $\mathrm{Pd}$ & $\begin{array}{l}\text { Food, soil, } \\
\text { water }\end{array}$ & DLLME & $\begin{array}{l}\text { 2-mercaptobenzimidazole, } \\
\text { chloroform }\end{array}$ & FAAS & 8.0 & GEOSTATS GPP-10 (ore) & 220 \\
\hline REEs & $\begin{array}{l}\text { Moss, plant, } \\
\text { water }\end{array}$ & LLE & $\begin{array}{l}\text { 3-ethylaminobut-2-enoic acid } \\
\text { phenylamide }\end{array}$ & ICP-MS & $\begin{array}{l}0.0002- \\
0.0037\end{array}$ & $\begin{array}{l}\text { NCS DC } 73348 \text { (bush branches } \\
\text { and leaves) }\end{array}$ & 221 \\
\hline
\end{tabular}


Table 6. Preconcentration methods involving solid phase extraction used in the analysis of soils, plants and related materials

\begin{tabular}{|c|c|c|c|c|c|c|c|}
\hline Analyte(s) & Matrix & Substrate & $\begin{array}{l}\text { Substrate coating/ modifying } \\
\text { agent or analyte complexing } \\
\text { agent }\end{array}$ & Detector & LOD $\left(\mu \mathrm{g} \mathrm{L}^{-1}\right)$ & $\begin{array}{l}\text { CRMs or other } \\
\text { validation }\end{array}$ & Reference \\
\hline As species & $\begin{array}{c}\text { Tea leaves } \\
\text { and infusions }\end{array}$ & $\mathrm{TiO}_{2}$ nanotubes & SFODME + SPE & $\begin{array}{l}\text { ETV-ICP- } \\
\text { MS }\end{array}$ & $\begin{array}{c}0.000046 \text { for } \\
\mathrm{As}^{\mathrm{IIII}}, 0.000072 \\
\text { for } \mathrm{As}^{\mathrm{v}}\end{array}$ & $\begin{array}{l}\text { NRCCRM GBW } \\
07605 \text { (tea leaves) }\end{array}$ & 222 \\
\hline $\begin{array}{c}\text { As, } \mathrm{Cd}, \mathrm{Cr}, \\
\mathrm{Pb}\end{array}$ & Rice & $\begin{array}{l}\text { Dispersion of } \\
\text { MWCNTs }\end{array}$ & & ICP-MS & $\begin{array}{c}5.0 \text { for } \mathrm{As}, 0.6 \\
\text { for } \mathrm{Cd}, 10 \text { for } \\
\mathrm{Cr}, \\
2.1 \text { for } \mathrm{Pb}\end{array}$ & $\begin{array}{l}\text { NRCCRM rice } \\
\text { CRMs GBW10010, } \\
\text { GBW10043, } \\
\text { GBW10044, } \\
\text { GBW10045 }\end{array}$ & 223 \\
\hline $\mathrm{Au}, \mathrm{Pd}$ & $\begin{array}{c}\text { Anodic } \\
\text { slime, } \\
\text { electronic } \\
\text { waste, gold } \\
\text { ore, soil, } \\
\text { water }\end{array}$ & $\begin{array}{c}\text { Amberlite XAD- } \\
1180\end{array}$ & $\begin{array}{l}\text { N-(4-methylphenyl)-2- } \\
\{224 \text { acetyl }\} \text { hydrazine }\end{array}$ & FAAS & $\begin{array}{l}0.29 \text { for } \mathrm{Au} \\
0.19 \text { for } \mathrm{Pd}\end{array}$ & $\begin{array}{l}\text { RTC CRM SA-C } \\
\text { (sandy soil C) }\end{array}$ & 224 \\
\hline $\mathrm{Au}, \mathrm{Pd}, \mathrm{Pt}$ & $\begin{array}{c}\text { Road } \\
\text { sediment }\end{array}$ & Activated carbon & 3,4-dihydroxycinnamic acid & ICP-AES & $\begin{array}{l}0.12 \text { for } \mathrm{Au} \\
0.18 \text { for } \mathrm{Pd} \\
0.32 \text { for } \mathrm{Pt}\end{array}$ & $\begin{array}{l}\text { NRCCRM GBW } \\
07291 \text { (PGE for } \\
\text { geochemical } \\
\text { analysis) }\end{array}$ & 225 \\
\hline $\mathrm{Cd}$ & $\begin{array}{l}\text { Chocolate, } \\
\text { cigarettes, } \\
\text { herb, water }\end{array}$ & MWCNTs & polyvinylpyridine & $\begin{array}{l}\text { TS-FF- } \\
\text { AAS }\end{array}$ & 0.036 & $\begin{array}{l}\text { NRCC DORM-3 } \\
\text { (fish protein) }\end{array}$ & 226 \\
\hline $\mathrm{Cd}$ & $\begin{array}{l}\text { Cigarettes, } \\
\text { coriander, } \\
\text { lettuce, } \\
\text { sediment }\end{array}$ & Amberlite XAD-2 & 3,4-dihydroxybenzoic acid & FAAS & 0.49 & $\begin{array}{c}\text { NIST SRM 1646- } \\
\text { 1(estuarine sediment) }\end{array}$ & 227 \\
\hline $\mathrm{Cd}, \mathrm{Pb}$ & Water & $\begin{array}{l}\text { Amberlite XAD- } \\
1180\end{array}$ & 2-mercaptobenzothiazole & FAAS & $\begin{array}{l}0.35 \text { for } \mathrm{Cd} \\
5.0 \text { for } \mathrm{Pb}\end{array}$ & $\begin{array}{l}\text { NIST RM } 8704 \\
\text { (Buffalo River } \\
\text { sediment) }\end{array}$ & 228 \\
\hline
\end{tabular}




\begin{tabular}{|c|c|c|c|c|c|c|c|}
\hline $\mathrm{Cd}, \mathrm{Pb}, \mathrm{Zn}$ & $\begin{array}{c}\text { Various } \\
\text { foodstuffs, } \\
\text { water }\end{array}$ & $\begin{array}{c}\text { Polyhydroxybutyrate } \\
\text { diethanol amine } \\
\text { polymer }\end{array}$ & DDC & FAAS & $\begin{array}{l}3.47 \text { for } \mathrm{Pb} \\
1.39 \text { for } \mathrm{Cd} \\
0.43 \text { for } \mathrm{Zn}\end{array}$ & $\begin{array}{c}\text { NIST SRM 1515 } \\
\text { (apple leaves), IAEA } \\
336 \text { (lichen), } \\
\text { NRCCRM GBW } \\
07605 \text { (tea) }\end{array}$ & 229 \\
\hline $\mathrm{Cd}, \mathrm{Pb}, \mathrm{Zn}$ & $\begin{array}{l}\text { Vegetables, } \\
\text { water }\end{array}$ & $\begin{array}{l}\text { Amino- } \\
\text { functionalised } \\
\text { hollow core } \\
\text { mesoporous shell } \\
\text { silica spheres }\end{array}$ & & ICP-MS & $\begin{array}{l}0.004 \text { for } \mathrm{Cd}, \\
0.021 \text { for } \mathrm{Pb}, \\
0.007 \text { for } \mathrm{Zn}\end{array}$ & $\begin{array}{c}\text { NIST RM } 8433 \text { (corn } \\
\text { bran) }\end{array}$ & 230 \\
\hline $\mathrm{Cd}, \mathrm{Zn}$ & $\begin{array}{l}\text { Fertiliser, } \\
\text { water }\end{array}$ & Amberlite XAD-2 & $\begin{array}{c}\text { 2-(5-bromo-2-pyridylazo)-5- } \\
\text { diethylaminophenol }\end{array}$ & FAAS & $\begin{array}{l}0.63 \text { for } \mathrm{Cd} \\
0.38 \text { for } \mathrm{Zn}\end{array}$ & $\begin{array}{l}\text { NIST SRM 1573a } \\
\text { (tomato leaves) }\end{array}$ & 231 \\
\hline $\mathrm{Cu}$ & $\begin{array}{l}\text { Fish, tomato } \\
\text { leaves, water }\end{array}$ & Amberlite XAD-4 & $\begin{array}{l}\mathrm{N}-p \text {-anisidine-3,5-di-tert- } \\
\text { butylsalicylaldimine }\end{array}$ & $\begin{array}{l}\text { HR-CS- } \\
\text { FAAS }\end{array}$ & 0.56 & $\begin{array}{l}\text { NIST SRM 1573a } \\
\text { (tomato leaves), } \\
\text { IAEA } 407 \text { (fish } \\
\text { tissue) }\end{array}$ & 232 \\
\hline $\mathrm{Cu}$ & $\begin{array}{l}\text { Walnuts, } \\
\text { water }\end{array}$ & Amberlite CG-120 & & $\begin{array}{l}\text { SQT- } \\
\text { FAAS }\end{array}$ & 0.23 & $\begin{array}{l}\text { NIST SRM 1570a } \\
\text { (spinach leaves) }\end{array}$ & 233 \\
\hline $\mathrm{Cu}$ & Plants, water & $\begin{array}{l}\text { Ion-imprinted } \\
\text { polymer }\end{array}$ & 1-(2-pyridylazo)-2-naphthol & ICP-AES & 0.29 & Spike recovery & 234 \\
\hline $\mathrm{Cu}, \mathrm{Fe}, \mathrm{Mn}$ & $\begin{array}{l}\text { Blood, hair, } \\
\text { honey, } \\
\text { spinach, } \\
\text { water }\end{array}$ & Graphene oxide & $\begin{array}{l}\text { 1-phenyl-3-(2- } \\
\text { thienylmethyl)thiourea }\end{array}$ & FAAS & $\begin{array}{l}0.06 \text { for } \mathrm{Cu}, \\
0.37 \text { for } \mathrm{Fe} \\
0.49 \text { for } \mathrm{Mn}\end{array}$ & $\begin{array}{l}\text { NWRI TMRAIN-95 } \\
\text { (spiked rainwater), } \\
\text { NRCC SLRS-4 (river } \\
\text { water), NIST SRM } \\
\text { 1640a (spring water) }\end{array}$ & 235 \\
\hline $\mathrm{Cu}, \mathrm{Ni}, \mathrm{Zn}$ & Water & $\begin{array}{l}\text { Ion-imprinted } \\
\text { polymer gel }\end{array}$ & & ICP-AES & $\begin{array}{l}0.54 \text { for } \mathrm{Cu}, \\
0.62 \text { for } \mathrm{Ni}, \\
0.58 \text { for } \mathrm{Zn}\end{array}$ & $\begin{array}{l}\text { NRCCRM GBW } \\
08301 \text { (river } \\
\text { sediment) }\end{array}$ & 236 \\
\hline $\mathrm{Cu}, \mathrm{Pb}$ & $\begin{array}{l}\text { Spice, street } \\
\text { dust, water }\end{array}$ & Carbon nanospheres & ionic liquid & FAAS & $\begin{array}{l}0.30 \text { for } \mathrm{Cu} \\
1.8 \text { for } \mathrm{Pb}\end{array}$ & $\begin{array}{l}\text { LGC } 6016 \text { (estuarine } \\
\text { water), NIST RM } \\
8704 \text { (Buffalo River } \\
\text { sediment) and IRMM } \\
\text { BCR } 482 \text { (lichen) }\end{array}$ & 237 \\
\hline
\end{tabular}




\begin{tabular}{|c|c|c|c|c|c|c|c|}
\hline $\mathrm{Ga}, \mathrm{In}, \mathrm{Tl}$ & $\begin{array}{c}\text { Liquid } \\
\text { crystal } \\
\text { displays, } \\
\text { sediment, } \\
\text { water } \\
\end{array}$ & Amino silica gel & $\begin{array}{c}\text { 2-hydroxy-5-(2- } \\
\text { hydroxybenzylideneamino) } \\
\text { benzoic acid }\end{array}$ & FAAS & $\begin{array}{l}4.1 \text { for } \mathrm{Ga}, 1.5 \\
\text { for } \mathrm{In}, 1.2 \text { for } \\
\mathrm{Tl}\end{array}$ & Spike recovery & 238 \\
\hline $\mathrm{Hg}$ & water & $\begin{array}{c}\text { Dispersion of } \mathrm{TiO}_{2} \\
\text { NP }\end{array}$ & & CV-AAS & 0.004 & $\begin{array}{c}\text { NRCC DOLT-2 } \\
\text { (dogfish liver), IAEA } \\
085 \text { (human hair), } \\
\text { NIST SRM 2709 } \\
\text { (San Joaquin soil), } \\
\text { SRM } 2711 \text { (Montana } \\
\text { soil) and SRM } 2704 \\
\text { (Buffalo River } \\
\text { sediment) }\end{array}$ & 239 \\
\hline $\mathrm{Mn}$ & Walnut & Amberlite CG-120 & & $\begin{array}{l}\text { SQT- } \\
\text { FAAS }\end{array}$ & 0.22 & $\begin{array}{c}\text { NIST SRM 1570a } \\
\text { (spinach leaves) }\end{array}$ & 240 \\
\hline $\mathrm{Pb}$ & $\begin{array}{l}\text { Apple, lentil, } \\
\text { street dust, } \\
\text { vegetables, } \\
\text { water }\end{array}$ & $\begin{array}{c}\mathrm{NiCo}_{2} \mathrm{O}_{4} \\
\text { microspheres }\end{array}$ & & FAAS & 5.9 & $\begin{array}{c}\text { IRMM BCR } 482 \\
\text { (lichen), NWRI } \\
\text { TMDA } 70 \text { (lake } \\
\text { water), NIST RM } \\
8704 \text { (Buffalo River } \\
\text { sediment) }\end{array}$ & 241 \\
\hline REEs & Water & Carbon nanofibres & $\begin{array}{l}\text { 1-phenyl-3-methyl-4-benzoyl-5- } \\
\text { pyrazone }\end{array}$ & ICP-MS & $\begin{array}{c}1.5 \text { for } \mathrm{Ce}, \\
0.9 \text { for } \mathrm{Eu}, 0.5 \\
\text { for } \mathrm{Gd}, 0.3 \text { for } \\
\mathrm{Yb}\end{array}$ & $\begin{array}{l}\text { NCS GBW } 07602 \\
\text { (bush branch and } \\
\text { leaves) }\end{array}$ & 242 \\
\hline REEs & Blood, water & $\begin{array}{l}\text { Gold NPs on } \\
\text { poly(glycidyl } \\
\text { methacrylate- } \\
\text { ethylene } \\
\text { dimethacrylate) }\end{array}$ & mercaptosuccinic acid & ICP-MS & $\begin{array}{l}0.00016 \text { for } \\
\mathrm{Tb}, 0.00085 \\
\quad \text { for } \mathrm{Gd}\end{array}$ & $\begin{array}{l}\text { NRCCRM GBW } \\
07301 \text { (stream } \\
\text { sediment) }\end{array}$ & 243 \\
\hline
\end{tabular}




\subsection{Instrumental analysis}

\subsubsection{Atomic absorption spectrometry}

A plethora of articles describing HR-CS-ETAAS methods included a review ${ }^{244}$ (74 references) of 20 years research on the determination of $S$. In the analysis of liquid samples, a method ${ }^{245}$ for the determination of $\mathrm{Er}$ in sediment digests used $\mathrm{La}$ as a chemical modifier, whilst a procedure $^{246}$ for measuring $\mathrm{Cd}$ and $\mathrm{Pb}$ in pharmaceuticals was also applied successfully to NIST SRMs 1515 (apple leaves) and 1547 (peach leaves), giving average recoveries of 98\% for $\mathrm{Cd}$ and $92 \%$ for $\mathrm{Pb}$. Methods proposed for the direct analysis of solid samples included measurement of: $\mathrm{Co}, \mathrm{Mo}, \mathrm{Ni}$ and $\mathrm{V}$ in soils ${ }^{247}$; $\mathrm{Cd}$ and $\mathrm{Cr}$ in yerba mate ${ }^{248}$; and $\mathrm{Cd}, \mathrm{Cr}$ and $\mathrm{Cu}$ in vegetables including eggplant, peppers, potato and tomato ${ }^{249}$.

An interesting trend is the increasing use of molecular species as the basis for elemental analysis by HR-CS-ETMAS, either alone or together with HR-CS-ETAAS. In a method ${ }^{250}$ for direct analysis, soils (up to $0.25 \mathrm{mg}$ ) were pyrolysed at $800^{\circ} \mathrm{C}$, and then $\mathrm{Cd}$ determined at an atomisation temperature of $1700{ }^{\circ} \mathrm{C}$, and $\mathrm{Cr}$ and $\mathrm{Fe}$ (as atomic species) and $\mathrm{Al}$ (as $\mathrm{AlH}$ ) at 2600 ${ }^{\circ} \mathrm{C}$. Results were in agreement with certified values for NIST SRM 2710a (Montana I Soil) according to a t-test at $95 \% \mathrm{CI}$. Two SS-HR-CS-ETMAS methods for determination of F, one for analysis of solid samples of baby food ${ }^{251}$ and the other for $1 \%(w / v)$ slurries of flour ${ }^{252}$, gave recoveries within the uncertainty of the certified value for the NCS CRM DC73349 (bush branches and leaves). In both methods $\mathrm{F}$ was determined at $606.440 \mathrm{~nm}$ as the CaF molecular species, formed following addition of $10 \mu \mathrm{L}$ of a $4 \mathrm{mg} \mathrm{mL}^{-1}$ Ca solution to the sample in the furnace. Even isotopic information has been obtained with this approach. A study ${ }^{253}$ successfully distinguished $\mathrm{Ca}^{79} \mathrm{Br}$ and $\mathrm{Ca}^{81} \mathrm{Br}$ on the basis of their electronic transitions and then used solid sampling, platform vaporisation and Pd-NP matrix modifier to determine $\mathrm{Br}$ concentration in NIST SRM 1573a (tomato leaves). The poor recoveries ( $<8 \%$ of the certified value) obtained with conventional calibration were attributed to $\mathrm{Cl}$ interference. However, when ID was used for calibration the result $\left(1390 \pm 70 \mu \mathrm{g} \mathrm{g}^{-1}, \mathrm{n}=5\right)$ was close to the certified value of $1300 \mu \mathrm{g} \mathrm{g}^{-1}$.

\subsubsection{Atomic emission spectrometry}

Giersz et al. ${ }^{136}$ coupled PVG with conventional pneumatic nebulisation and a programmable temperature spray chamber to achieve simultaneous determination of Hg (as the cold vapour) and non-vapour forming elements (Cu, Fe and $\mathrm{Mn}$ ) in waters and sediments. The Hg LOD of 
$0.090 \mu \mathrm{g} \mathrm{L}^{-1}$ was two orders of magnitude better than that obtained using conventional ICPAES $\left(23 \mu \mathrm{g} \mathrm{L}^{-1}\right)$. Performance for the other analytes was unaffected.

Turner et al. ${ }^{254}$ studied interference from $\mathrm{Fe}$ in the determination of $B$ in highly weathered tropical forest soils by ICP-AES. They recommended use of the less sensitive $208.957 \mathrm{~nm}$ line when measuring B in Mehlich-III extracts and soil digests.

Interest has continued in alternative optical emission sources for atomic spectrometry. A novel flowing liquid anode APGD gave ${ }^{255}$ superior performance - an average 20-fold improvement in LODs - than the more frequently studied flowing liquid cathode APGD for determination of $\mathrm{Ag}, \mathrm{Cd}, \mathrm{Hg}, \mathrm{Pb}, \mathrm{Tl}$ and $\mathrm{Zn}$. Spike recoveries from tea leaves ranged from $98.9 \%$ for $\mathrm{Hg}$ to $102 \%$ for $\mathrm{Ag}$. In a prototype microanalytical system ${ }^{256}, 10 \mu \mathrm{L}$ of soil digest was vaporised on a Rh coil and the vapour introduced into a CCP for measurement of Ag, As, $\mathrm{Cd}, \mathrm{Cu}, \mathrm{Hg}, \mathrm{Pb}, \mathrm{Sb}, \mathrm{Sn}$ and $\mathrm{Zn}$ using a low-resolution microspectrometer. Results and LODs were similar to those obtained with ICP-AES but the new system had the advantages of markedly lower capital and running costs.

\subsubsection{Atomic fluorescence spectrometry}

A new strategy for the generation of volatile species based on solution anode $G D$ was used as an alternative to chemical reducing agents or electrochemical $\mathrm{HG}$ in the determination of $\mathrm{Cd}$ and $\mathrm{Zn}$ by $\mathrm{AFS}^{257}$. A microplasma was used as the cathode and a conventional Pt foil as the anode to generate $\mathrm{CdH}_{2}$ and $\mathrm{ZnH}_{2}$ at the plasma-liquid interface. Under optimised conditions (supporting electrolyte $\mathrm{HCl}$ at $\mathrm{pH} 3.2$, discharge current $10 \mathrm{~mA}$, Ar flow rate $300 \mathrm{~mL} \mathrm{~min}^{-1}$ and sample flow rate $2.5 \mathrm{~mL} \mathrm{~min}^{-1}$ ) the LODs were $0.003 \mu \mathrm{g} \mathrm{L}^{-1}$ for $\mathrm{Cd}$ and $0.3 \mu \mathrm{g} \mathrm{L}^{-1}$ for $\mathrm{Zn}$. Results almost identical to certified values were obtained for analysis of NRCCRM GBW 07311 (sediment), GBW 07401 (soil) and GBW 10045 (rice).

The first room temperature chelate vapour generation method for determination of $\mathrm{Zn}$ involved $^{258}$ continuous on-line mixing of sample (acidified to $0.05 \mathrm{M} \mathrm{HNO}_{3}$ ) and $0.4 \%(\mathrm{~m} / \mathrm{v}$ ) Na-DDC solutions followed by immediate sparging of the volatile zinc chelate from solution, using a stream of Ar gas, for determination by AFS.

Two on-line automated FI-HG-AFS methods were optimised by a research group in Brazil. The first ${ }^{259}$ was used for the sequential determination of $\mathrm{As}, \mathrm{Sb}$ and $\mathrm{Se}$ in peanuts and the second ${ }^{260}$ for the determination and speciation of $\mathrm{Sb}$ in soils.

\subsubsection{Inductively coupled plasma mass spectrometry}


A review article ${ }^{261}$ (209 references) on MS imaging techniques applicable to plants focussed primarily on molecular analysis but LA-ICP-MS was also considered. Another article ${ }^{262}$ (306 references) provided a comprehensive overview of the capability of ICP-MS to support nuclear decommissioning activities, covering environmental applications as well as industrial samples. Applications of LA-ICP-MS in forensic science were also reviewed ${ }^{263}$ (30 references).

Three types of pellet were compared ${ }^{264}$ for determination of 30 elements in soil and sediment by LA-ICP-MS: original sample; sample mixed with boric acid; and sample mixed with hexane, dried at $50{ }^{\circ} \mathrm{C}$, then mixed with DCM and dried again. Treatment with organic solvents was recommended as results for IAES CRM Soil-5 were within 10\% of target values.

Several studies focused on trace element mapping in plants by LA-ICP-MS. Imaging of $\mathrm{As}, \mathrm{Cd}, \mathrm{Cr}, \mathrm{Cu}, \mathrm{H}, \mathrm{Mn}, \mathrm{Ni}, \mathrm{Pb}$ and $\mathrm{Zn}$ in individual grains of rye and wheat ${ }^{265}$ was facilitated by use of a novel though time-consuming serial polishing strategy to expose layers of the sample for analysis. The new open source software package LA-iMageS ${ }^{266}$ was used for rapid processing and visualisation of LA-ICP-MS data as part of a method ${ }^{267}$ for imaging $\mathrm{Cd}, \mathrm{Cu}, \mathrm{Fe}$ and $\mathrm{Mn}$ in sunflower seeds that had been cultivated in soil spiked with different concentrations of Cd. A combination ${ }^{268}$ of LA-ICP-MS and TOF-SIMS imaging revealed that Gd and Y were primarily located at the epidermis in roots of Zea Mays. It was suggested that formation of precipitates under physiological conditions limited uptake and transport of the REEs.

In an interesting article ${ }^{58}$, an atmospheric pressure pulsed $r f$ discharge was proposed as a means to ablate soils and other non-conducting solid for analysis by ICP-MS. Linear calibration graphs were based on analysis of a series of NRCCRM soil CRMs. Although quantitative analysis of unknowns was not demonstrated, the approach shows promise as an inexpensive alternative to LA-ICP-MS.

Methods for the measurement of isotope ratios by MC-ICP-MS included a procedure ${ }^{28}$ for $\mathrm{Cr}$ that used a single AG1-X8 column to remove matrix elements and achieved an analyte recovery of $>93 \%$ from CRM digests. The method was suitable for ${ }^{53} \mathrm{Cr} /{ }^{54} \mathrm{Cr}$ determination in lichens and mosses and has potential for studying environmental contamination arising from stainless steel manufacture. A single column of Bio-Rad AG-MP-1M was used ${ }^{269}$ to isolate $\mathrm{Cd}$ (recovery $>95 \%$ ) for measurement of ${ }^{114} \mathrm{Cd} /{ }^{110} \mathrm{Cd}$ ratio in plants.

Interference reduction in ICP-MS/MS has received attention. Machado et al. ${ }^{270}$ successfully determined $\mathrm{Pt}$ and $\mathrm{Rh}$ in sediments as ${ }^{195} \mathrm{Pt}^{16} \mathrm{O}^{+}$and ${ }^{103} \mathrm{Rh}^{16} \mathrm{O}^{+}$by introducing 0.3 $\mathrm{mL} \mathrm{min}^{-1} \mathrm{O}_{2}$ into the reaction cell. At the same time, ${ }^{112} \mathrm{Cd}^{+},{ }^{106} \mathrm{Pd}^{+}$and ${ }^{120} \mathrm{Sn}^{+}$were determined as their atomic ions. Virgilio et al. ${ }^{271}$ used $0.5 \mathrm{~mL} \mathrm{~min}{ }^{-1} \mathrm{O}_{2}$ to measure ${ }^{75} \mathrm{As}^{16} \mathrm{O}^{+}$and ${ }^{51} \mathrm{~V}^{16} \mathrm{O}^{+}$, along with ${ }^{52} \mathrm{Cr}^{+},{ }^{60} \mathrm{Ni}^{+},{ }^{112} \mathrm{Cd}^{+}$and ${ }^{208} \mathrm{~Pb}^{+}$, in NIST SRM 1573a (tomato leaves). Recoveries 
were $85-113 \%$. Researchers in $\mathrm{China}^{272}$ recommended use of $\mathrm{O}_{2}$ reaction gas for determination of As and Se in plant CRMs because results obtained were more consistent with certified values than when $\mathrm{H}_{2}$ or He were used in collision mode. Beryllium was preferred to Li and $\mathrm{Rh}$ as IS for the determination of $\mathrm{B}$ in plants using ICP-MS/MS with $\mathrm{O}_{2}$ reaction gas ${ }^{273}$. Recoveries from NIST SRMs 1515 (apple leaves) and 1573a (tomato leaves) were 90-108\%.

Analytical methods featuring chromatographic separation coupled with ICP-MS included a HPLC-ICP-MS method ${ }^{274}$ for Sb speciation in plants, which was applied to ryegrass grown hydroponically under controlled conditions. Uptake of trimethylantimony by roots and subsequent translocation to shoots was demonstrated conclusively for the first time. A powerful combination of elemental and molecular MS techniques ${ }^{275}$ including HILIC-ICP-MS and SECICP-MS was used to identify more than 50 metal complexes in xylem and embryo sac liquid of pea plants. Also reported were HPLC-ICP-MS methods for the speciation of mercury ${ }^{276}$ and $\operatorname{tin}^{277}$ in sediments and for the determination of $\mathrm{As}^{\mathrm{III}}$ and $\mathrm{As}^{\mathrm{V}}$ in iron-rich precipitates originating from acid mine drainage ${ }^{278}$. A modified CE-ICP-MS interface ${ }^{279}$ improved sensitivity 2-5 fold for As speciation analysis in Solanum lyratum extracts. An interesting study ${ }^{142}$ demonstrated the feasibility of determining $\mathrm{C}$ along with other analytes ( $\mathrm{Al}, \mathrm{Fe}, \mathrm{Mn}$, $\mathrm{P}$ and $\mathrm{Si}$ ) in both synthetic and natural fine particulate organic matter in water and soil extracts by asymmetric flow FFF-ICP-MS.

The novel coupling of an ETV unit and tungsten coil trap with ICP-MS was used to determine $\mathrm{Cd}$ and $\mathrm{Zn}$ in wheat ${ }^{280}$. Up to $20 \mathrm{mg}$ of solid sample was ashed in a sampling boat and then heated in a porous carbon vapouriser to release the analytes for capture on the coil. Results for corn, rice and wheat CRMs were close to certified values. LODs were $0.01 \mu \mathrm{g} \mathrm{kg}^{-}$ ${ }^{1}$ for $\mathrm{Cd}$ and $0.1 \mu \mathrm{g} \mathrm{kg}^{-1}$ for $\mathrm{Zn}$.

The combination of multi-element analysis by sp-ICP-TOF-MS with advanced chemometrics represented $^{281}$ a potentially significant advance for discriminating between engineered NPs and naturally occurring nanoscale particulates in soil.

\subsubsection{Laser induced breakdown spectroscopy}


An overview ${ }^{282}$ (147 references) of recent development and applications of LIBS in agriculture included the analysis of soils and plants. A critical historical summary ${ }^{283}$ (57 references) of the use of LIBS to measure soil C content placed particular emphasis on soil organic carbon.

Interest continued in the development of LIBS methods for soil analysis. Two research groups used soil as a test substrate to demonstrate new approaches for analysis of particulate matter. The first ${ }^{284}$ employed double-sided foam tape to trap particles from a stream of argon gas, while the second ${ }^{285}$ mixed $2 \mathrm{mg}$ of sample with $2 \mathrm{mg}$ of Si grease and presented it to a TEA $\mathrm{CO}_{2}$ laser as a thin layer smeared on a $\mathrm{Ni}$ subtarget. Labutin et al. ${ }^{286}$ showed that generation of synthetic spectra by thermodynamic modelling could aid determination of REEs in rocks and soils by highlighting potential spectral overlaps in advance. A research team in China $^{287}$ optimised a LIBS-LIF method to eliminate spectral interferences in the determination of $\mathrm{Pb}$ in soil altogether. Pressed pellets of soil CRMs were irradiated with a $\mathrm{Nd}$ :YAG laser in the normal way then, after an optimal delay time of $14 \mu \mathrm{s}$, a second laser at $283.31 \mathrm{~nm}$ (resonant with the $\mathrm{E}_{0} \rightarrow \mathrm{E}_{2}$ transition of the $\mathrm{Pb}$ atom) was fired through the sample plasma. This enhanced the $\mathrm{Pb}$ signal markedly, increased sensitivity and improved the LOD from 24 to $0.6 \mu \mathrm{g} \mathrm{g}^{-1}$. Another interesting article ${ }^{288}$ showed that the ${ }^{235} \mathrm{U}$ isotopic abundance could be estimated through application of appropriate decomposition algorithms to LIBS spectra of mixtures containing NIST SRM 2710a (Montana I soil) and up to $8.6 \%(w / w){ }^{235} \mathrm{U}$-enriched $\mathrm{U}_{3} \mathrm{O}_{8}$. Applications in nuclear forensics were envisaged.

The application of LIBS to the analysis of plants included the successful determination ${ }^{289}$ of $\mathrm{Pb}$ in soft biological materials with high water content, specifically carrots and mango leaf, for which use of a ps rather than a ns laser was necessary to increase the power density delivered to the sample. A method ${ }^{290}$ for the determination of $\mathrm{Ba}, \mathrm{Fe}, \mathrm{Mg}, \mathrm{Mn}$ and $\mathrm{Sr}$ in powdered samples of blue-green algae could be performed in air at atmospheric pressure using a TEA $\mathrm{CO}_{2}$ laser and non-gated detection. Workers in Beijing showed that LIBS could be used to profile the Ca content in endosperm, embryo and epidermis of a single grain of corn under laboratory conditions ${ }^{291}$ and that elemental maps could be obtained from living plants in the field using their portable LipsImag system ${ }^{292}$. Both 2D and 3D maps of chlorpyrifos on leaves of sprayed maize plants were generated by a multi-variable regression model based on the emission lines of $\mathrm{Cl}$ and $\mathrm{P}$.

The combination of multivariate chemometric methods and LIBS has been used to classify soils. One procedure ${ }^{293}$ was based on LS-SVM and the emission lines of Al, Ca, Fe, 
$\mathrm{K}, \mathrm{Mg}, \mathrm{Na}$ and Si. Another ${ }^{294}$ (in Chinese with English abstract) used PCA and Al, Ca, Fe, Mg, $\mathrm{Si}$ and Ti. Tobacco mosaic virus was detected ${ }^{295}$ in a procedure involving PLS-DA.

Remote detection ${ }^{296}$ of $\mathrm{Cd}, \mathrm{Cr}$, Ni and $\mathrm{Pb}$ in NIST SRMs 2710a (Montana I soil) and 2586 (trace elements in soil - containing $\mathrm{Pb}$ from paint) at a distance of up to $6 \mathrm{~m}$ was achieved by stand-off LIBS following careful optimisation of measurement parameters including gate width, gate delay and laser pulse energy. Other workers ${ }^{297}$ demonstrated remote LIBS detection of $\mathrm{Al}, \mathrm{Ca}$ and $\mathrm{Mg}$ in soil from a distance of $15 \mathrm{~m}$ during commissioning of a truck-based mobile laser spectroscopy laboratory. Approaches demonstrated under laboratory conditions, but with clear potential for eventual deployment in stand-off mode, included a procedure ${ }^{298}$ to discriminate between weeds and crops based on the use of plasma temperature and a method ${ }^{299}$ to detect drought stress in plants based on relative concentrations of $\mathrm{Ca}, \mathrm{Fe}, \mathrm{K}$ and $\mathrm{Na}$.

\subsubsection{X-ray spectrometry}

An overview $^{300}$ (102 references) of the use of synchrotron-based XRF mapping and XAS to study interactions between engineered NPs and plants considered primarily the methodological aspects.

Improvements in pXRFS were achieved by using either soil $\mathrm{CRMs}^{301}$ or solid mixtures $^{302}$ of organic (plant) and inorganic (soil and sediment) CRMs as calibrants. Use of pXRFS analysis of till for geochemical exploration was investigated by Sarala ${ }^{303}$ who compared three instruments - two handheld and one truck-mounted system - for analysis of samples from Finland, and Hall et al. ${ }^{304}$ who used a single handheld instrument for analysis of archived samples from sites close to mineral deposits in Canada. Although the concentrations of some pathfinder elements were below the LODs, both groups concluded that pXRFS was fit-for-purpose. A useful method ${ }^{305}$ for measuring P, an indicator of human activities, in archaeological soils was also reported. Dao ${ }^{306}$ showed that normalising the intensity of the P$\mathrm{K}_{\alpha}$ line to that of the $\mathrm{Ag}-\mathrm{K}_{\alpha}$ line was an effective way to compensate for variations in plant moisture content in the determination of $\mathrm{P}$ in maize leaves. This meant that results could be expressed on a dry weight basis.

Proximal sensing using $p X R F S$ continued to be of interest. A method ${ }^{307}$ for in situ estimation of $\mathrm{pH}$ in frozen and permafrost-affected soils proved successful in field trials at five sites in northern Alaska. Models ${ }^{308}$ based on pXRFS and VisNIR DRS data could be used to predict total $\mathrm{C}$ and $\mathrm{N}$ contents in organic-rich soils containing up to $c a$. $50 \% \mathrm{C}$. Combining information from MIR, $\mathrm{pXRF}$ and VisNIR spectroscopies through the use of a model 
averaging technique was recommended ${ }^{309}$ for best prediction of soil geochemical properties based on a study of 322 samples from the Irish National Soil Database Archive.

The preparation of thin specimens in a TXRFS method ${ }^{310}$ for the determination of $\mathrm{Br}$ in soil involved suspension of $20 \mathrm{mg}$ soil in $1 \%$ Triton $\mathrm{X}-110$, addition of $\mathrm{Rh}$ as IS and homogenisation. Finally, a $10 \mu \mathrm{L}$ aliquot was dried onto a quartz sample holder. The LOD was $3.7 \mathrm{mg} \mathrm{kg}^{-1}$ and the recoveries for analysis of 12 soil and sediment CRMs were $89-133 \%$.

A TXRFS method for the analysis of plants ${ }^{311}$ was developed by the determination of $\mathrm{Ca}, \mathrm{K}, \mathrm{Mn}$, and $\mathrm{S}$ in leaves of Arabidopsis thaliana following digestion of $0.3 \mathrm{mg}$ samples in $150 \mu \mathrm{L} \mathrm{HNO}_{3}$. More recently, it was demonstrated ${ }^{312}$ that sample digestion was unnecessary prior to analysis of vegetal foodstuffs by TXRFS. In a procedure similar to that already cited in this Update for determination of $\mathrm{Br}$ in soil, the sample (20 mg) was suspended in deionised water and Ga added as IS before drying onto a quartz holder. Methods for trace element mapping in wheat grains ${ }^{313}$ and carrots ${ }^{314}$ by $\mu$ XRFS were described. Although the resolution of benchtop instruments is poorer than that achievable with synchrotron-based methods, the advantages in terms of cost and accessibility are clear.

\section{$4 \quad$ Analysis of geological materials}

\subsection{Reference materials and data quality}

Precise and accurate geochemical analyses require well-characterised $R M s$ for use as calibrants and QC materials. This section describes new RMs that have recently become available, as well as research to provide additional elemental or isotopic information for existing RMs. Some RMs developed specifically for isotope analysis by SIMS are discussed in section 4.3.5.

There are few certified values available for Au and PGEs in ferromanganese nodule $R M s$, despite the fact that $\mathrm{Mn}$ - and Fe-rich materials are of great economic interest. In a study $^{315}$ on the ferromanganese nodule RM USGS NOD-A-1, Au, Ir, Pd, Pt and Ru were preconcentrated using anion-exchange following acid digestion and their concentrations determined by ICP-MS. The suitability of the Fe- and Mn-rich natural nodule RMs GSJ JMn1, USGS NOD-P-1 and NOD-A-1, and BGR FeMn-1 for trace element determinations in microanalytical research was assessed by analysing pressed powder pellets by LA-ICP-MS using fs and ns LA systems ${ }^{316}$. The pellets exhibited heterogeneities on the $\mu \mathrm{m}$-scale for several elements at spot sizes of $<40 \mu \mathrm{m}$. In contrast, the synthetic USGS RM FeMnOx-1, was shown to be homogeneous for spot sizes $8-10 \mu \mathrm{m}$ and so gave low RSD values of $<10 \%$ for all elements measured, confirming its suitability as a future calibration material. 
Mass fractions of $\mathrm{Br}, \mathrm{Cl}, \mathrm{F}$ and I in USGS geological glass RMs BHVO-2G, BIR-1G, BRC-2G, GSD-1G and GSE-1G, and NIST SRMs 610 and 612 (trace elements in glass) were determined by a variety of techniques ${ }^{317}$. The relatively high halogen contents of glasses GSD$1 \mathrm{G}$ and GSE-1G made them well suited for the calibration of $\mathrm{Br}, \mathrm{Cl}$ and $\mathrm{I}$ in microanalytical studies of silicate glasses, and melt and fluid inclusions by EPMA and LA-ICP-MS.

Molybdenum is an element of increasing interest in magmatic and hydrothermal geology, in planetary sciences and for tracking environmental pollution. The Mo mass fractions and isotopic composition of 24 international geological RMs encompassing a wide range of compositions (i.e. coral, igneous and sedimentary rocks, manganese nodules, ferromanganese crusts and molybdenite) were determined by ID MC-ICP-MS using a ${ }^{97} \mathrm{Mo}-{ }^{100}$ Mo doublespike $^{318}$. The Mo isotopic composition of USGS RMs BCR-2 (basalt), SCo-1 (shale) and SGR$1 \mathrm{~b}$ (shale) were reported for the first time in a study which used MC-ICP-MS analysis after purification of Mo by ion-exchange chromatography ${ }^{319}$.

Zinc isotopes are important tracers of hydrothermal systems relevant in ore genesis studies, identification of sources of contamination in soils and aerosols, monitoring palaeo-pH and studies of the origin and evolution of the solar system. Chen et al. ${ }^{320}$ reported highprecision $\mathrm{Zn}$ isotope data (better than $\pm 0.06 \%$ o $\delta^{66} \mathrm{Zn}, 2 \mathrm{SD}$ ) for 17 rock RMs with a range of compositions, including the first published $\mathrm{Zn}$ isotope data for USGS RMs GSP-1 (grandodiorite), GSP-2 (grandodiorite) and RGM-1 (rhyolite). Determination of $\delta^{66} \mathrm{Zn}$ values $(\mathrm{n}=98)$ in NIST SRM 683 (metal nuggets) by MC-ICP-MS proved the homogeneity of this RM and so demonstrated its suitability as an isotopic CRM for Zn. Araujo et al. ${ }^{163}$ presented the first $\mathrm{Zn}$ isotope ratio measurements for environmental NIST SRMs 2709 (soil) and 1646a (estuarine sediment) as well as $\delta^{66} \mathrm{Zn}$ data for USGS rock RMs AGV-2 (andesite), BCR-2 (basalt) and BHVO-2 (basalt).

There is a trend to publish isotope ratio data for some of the more popular USGS RMS originally characterised for their trace element compositions. Thus, the determination of the $\mathrm{Ca}$ isotope compositions of 16 USGS RMs extended ${ }^{321}$ the range of geological materials analysed and provided the first $\mathrm{Ca}$ isotope data for three sedimentary RMs and one carbonatite RM. Kimura et al. ${ }^{322}$ observed heterogeneities in $\mathrm{B}$ and Li isotope ratios for USGS GSD-1G (synthetic basalt glass) when ablating spot sizes of $<100 \mu \mathrm{m}$ by LA-ICP-MS. The first ${ }^{230} \mathrm{Th} /{ }^{232} \mathrm{Th}$ values for CRPG RM BE-N (nephelinite) and USGS RM BIR-1 (Icelandic basalt) were published in a study ${ }^{323}$ of Th isotopic compositions in silicate RMs using a two-step isolation protocol and MC-ICP-MS measurements. The authors also reported ${ }^{230} \mathrm{Th} /{ }^{232} \mathrm{Th}$ values for USGS RMs BHVO-2 (basalt) and AGV-2 (andesite). 
Well-characterised reference solutions are a cornerstone of reliable and traceable measurements. The isotopic composition of two new $\mathrm{Cu}$ isotope standard solutions developed by Feng et al. ${ }^{324}$ was determined in three different laboratories using MC-ICP-MS. The National Institute of Metrology, China ${ }^{325}$ prepared and certified one natural and 10 synthetic Se solutions with a wide range of Se isotope ratios, for calibration and quality control of chemical and MS procedures. A new standard solution ${ }^{326}$ for the $\mathrm{Zn}$ isotope community, intended as a replacement for the current reference standard solution JMC-Lyon Zn, was calibrated against existing $\mathrm{Zn}$ reference solutions.

New microanalytical RMs included MUL-ZnS-1, a sulfide $\mathrm{RM}^{327}$ prepared by sintering a powdered $(\mathrm{Zn}, \mathrm{Fe}) \mathrm{S}$ matrix doped with several elements (Ag, As, Cd, Co, Cr, Cu, Ga, Ge, In, $\mathrm{Mn}, \mathrm{Mo}, \mathrm{Ni}, \mathrm{Pb}, \mathrm{Sb}$, Se, Sn and Tl). This RM was intended primarily for the matrix-matched calibration of LA-ICP-MS measurements of sphalerites but could also be applied to other sulfides. Chew et al. ${ }^{328}$ proposed a protocol for developing natural apatite mineral RMs. Gem quality crystals of Durango apatite were analysed by LA-ICP-MS and solution ICP-MS and potential interferences examined in detail. The authors claimed that this protocol could easily be modified to characterise other natural minerals as potential microanalytical RMs. CruzUribe et al. ${ }^{329}$ showed that the $c a .100 \mu \mathrm{m}$ wide rims of quartz grains from the Bishop Tuff quartz (California, USA) had homogeneous Ti mass fractions of $c a .41 \mu \mathrm{g} \mathrm{g}^{-1}$ and that they could be used to calibrate Ti-in-quartz thermometry measurements by LA-ICP-MS. Not only did this provide a matrix-matched RM, but it was possible to use ${ }^{48} \mathrm{Ti}$, the most abundant $\mathrm{Ti}$ isotope, because there was no interference of ${ }^{48} \mathrm{Ca}$ on ${ }^{48} \mathrm{Ti}$ due to the absence of $\mathrm{Ca}$ in quartz. For the quantification of $\mathrm{Br}$ abundances in natural materials, a set of $21 \mathrm{Br}$-doped glasses ${ }^{330}$ were prepared from natural volcanic rocks and characterised by INAA. These were used to compare the figures of merit of three micro-analytical techniques (LA-ICP-MS, SIMS and SRXRFS): SRXRF gave the best accuracy and precision ( $10 \%$ for $\mathrm{Br}$ contents $\geq 10 \mu \mathrm{g} \mathrm{g}^{-1} \mathrm{Br}$ ) with an LOD of $<1 \mu \mathrm{g} \mathrm{g}^{-1} \mathrm{Br}$, with SIMS not far behind. In contrast, the precision and accuracy

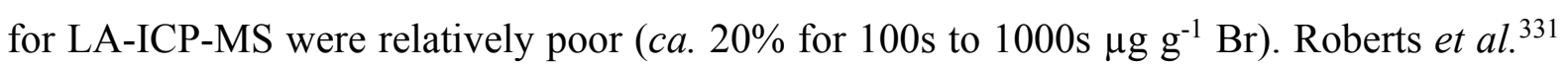
characterised a calcite RM (WC-1, $254.4 \pm 6.4$ Ma, marine calcite cement, Guadalupe Mountains, Texas) for the LA-ICP-MS U-Pb dating of carbonates and advocated its use as the principal RM for U-Pb normalisation. This RM could be used reliably despite its variable common $\mathrm{Pb}$ content, because its isotopic composition fell on a mixing line between initial and radiogenic $\mathrm{Pb}$.

Most available zircon $R M S$ are younger than 1000 Ma so a careful evaluation of a potential zircon $R M$ for $\mathrm{U}-\mathrm{Pb}$ geochronology of the Archean is of particular note ${ }^{332}$. Uranium- 
$\mathrm{Pb}$ data obtained on the Stillwater AN2 zircon (Montana, USA) by ID-TIMS, CA-TIMS and LA-ICP-MS yielded indistinguishable concordia and a weighted mean ${ }^{207} \mathrm{~Pb} /{ }^{206} \mathrm{~Pb}$ age of 2710 Ma. The LA-ICP-MS results demonstrated homogeneity within grain and across multiple grains of Stillwater AN2 zircon on the scale of tens to hundreds of $\mu \mathrm{m}$. This new RM plugs an important gap in U-Pb geochronology. Nasdala et al. ${ }^{333}$ advocated zircon M127-A as a new zircon RM for SIMS U-Pb geochronology as well as isotopic analysis of $\mathrm{Hf}, \mathrm{O}$ and, potentially, Li. A mean concordia age of 524.37 Ma was determined from TIMS analyses made in several laboratories. Zircon M127-A was homogeneous in terms of its chemical and isotopic composition $\left(\delta^{18} \mathrm{O} \quad 8.26 \pm 0.06 \%(2 \mathrm{~s}),{ }^{176} \mathrm{Hf} /{ }^{177} \mathrm{Hf} 0.282396 \pm 0.000004(2 \mathrm{~s})\right.$, and $\delta^{7} \mathrm{Li}-$ $0.6 \pm 0.9 \%$ ( $2 \mathrm{~s})$ ) and had a remarkably concordant $\mathrm{U}-\mathrm{Pb}$ isotopic system. This made it particularly suitable for studies that aim to use the same sample mounts for the determination of O (SIMS), Li (SIMS) or Hf isotopes (LA-ICP-MS). A gem-quality zircon megacryst ${ }^{334}$ from Sri Lanka, named LGC-1, analysed extensively by a variety of techniques, was homogeneous with respect to its $\mathrm{He}$, Th and $\mathrm{U}$ distributions and so was considered as a suitable grain for in situ (U-Th)/He dating. However, the authors emphasised the need for developing more such RMs because of the limited material available. This would also be true for most natural mineral RMs.

Increasing interest in in situ measurement of sulfur isotope ratios in a variety of minerals prompted the development of a suite of S isotope RMs (pyrite, chalcopyrite, pyrrhotite and pentlandite) relevant to magmatic, magmatic-hydrothermal and hydrothermal ore systems $^{335}$. The new sulfide RMs were characterised for their chemical (EPMA) and isotopic (SIMS) compositions and provided appropriate matrix-matched RMs for the samples under investigation. The first scapolite RM (CB1) for in situ $\mathrm{S}$ isotope analysis using SIMS was characterised using LA-ICP-MS, EPMA, SIMS and bulk fluorination gas source IRMS ${ }^{336}$. Results of four SIMS analytical sessions demonstrated that the megacryst was isotopically homogeneous (reproducibility of $\delta^{34} \mathrm{~S}$ values was $0.40 \%$ (2SD), $\mathrm{n}=244$ ) and that the crystallographic orientation did not affect the analysis. The $\delta^{34} \mathrm{~S}$ values in a chalcopyrite glass RM, YN411-m, intended for in situ $\mathrm{S}$ isotope ratio measurements, were determined by GS-MS and solution MC-ICP-MS ${ }^{337}$. The homogeneity was evaluated by replicate analyses by fs LAMC-ICP-MS, which gave an external precision of $0.28 \%$. It was concluded that, for the analysis of a natural chalcopyrite prepared as a pressed powder pellet, YN411-m was better suited as a bracketing RM than a non-matrix-matched pressed pellet made from RM IAEA-S1 (silver sulfide). 
In an excellent publication ${ }^{338}$, new protocols for the determination of $U$-(Th-)Pb ages, as defined by the LA-ICP-MS geochronology international community, included a workflow defining the appropriate propagation of uncertainties. This is not only important for reporting $\mathrm{U}-\mathrm{Pb}$ data but other analytical data as well. New radiogenic ratios presented for commonlyused zircon RMs, based on ID-TIMS measurements, were considered more suitable for LAICP-MS calibrations than an age-equivalent ratio calculated from a published age, which can introduce inaccuracies if only one age $\left({ }^{207} \mathrm{~Pb} /{ }^{206} \mathrm{~Pb},{ }^{206} \mathrm{~Pb} /{ }^{238} \mathrm{U},{ }^{207} \mathrm{~Pb} /{ }^{235} \mathrm{U}\right.$ or ${ }^{208} \mathrm{~Pb} /{ }^{232} \mathrm{Th}$ date, or the concordia age) was assumed to be the correct age of the reference zircon. Recommendations on how to present data and new data reporting standards were provided with the aim of improving the peer-review process when such data are submitted for publication.

Accurate information on isotope abundances and atomic weights, which can vary in natural materials because of physical and chemical processes, is of great importance for mass spectrometric analysis. Therefore, an IUPAC Technical Report ${ }^{339}$ providing isotopic abundances, delta values and atomic weights with the upper and lower boundaries for 12 elements (B, Br, C, Cl, H, Li, Mg, N, O, S, Si, and Tl) is welcome.

\subsection{Sample preparation, dissolution, separation and preconcentration}

A new digestion method ${ }^{340}$ for REE ores using short-wavelength IR radiation to accelerate acid digestion was able to dissolve iron oxide and silicate matrices within 8 minutes using only phosphoric acid. No additional treatment with $\mathrm{HClO}_{4}$ and $\mathrm{HF}$ was necessary. Digests of three ore CRMs containing large amounts of REEs with different mineralogies were successfully analysed by MIP-AES and DRC-ICP-MS with high and reproducible recovery rates of $c a .100 \%$ for REEs, Th and $\mathrm{U}$. A sequential four-step $(\mathrm{HCl}, \mathrm{NaOH}$, aqua regia and $\mathrm{HF}$ ) digestion procedure ${ }^{341}$, designed for the analysis of carbon-rich rocks, was tested on six shale RMs. It provided better recoveries of moderately volatile elements associated with humic substances during the first two extraction steps compared to traditional protocols using aqua regia and HF. The supernatant of each digestion step was analysed by ICP-MS to obtain information on the partitioning of elements between mineral phases. To achieve the rapid and total dissolution of carbonate-rich sediments, Durand et al. ${ }^{181}$ treated samples with concentrated $\mathrm{HCl}$ prior to microwave digestion with $\mathrm{HCl}-\mathrm{HNO}_{3}-\mathrm{HF}$. As a consequence, only $2 \mathrm{~mL}$ HF was required to digest $200 \mathrm{mg}$ of sediment, up to three times less than in previous studies; the formation of an insoluble Ca-F precipitate was negligible. A novel technique to digest silicates by alkali fusion using $\mathrm{NaOH}$ flakes as flux was developed by Sikdar and Rai ${ }^{342}$ 
in order to avoid the use of HF. The entire digestion procedure was carried out in a single Teflon vial to minimise contamination and loss of $\mathrm{Si}$. Recoveries were $99.5 \pm 2.4 \%$ (1SD). Subsequently, purified Si and Mg were extracted from a single aliquot of natural sample using two-step cation-exchange chromatography. The robustness of the protocol was assessed by determining $\delta^{26} \mathrm{Mg}$ and $\delta^{30} \mathrm{Si}$ in seven USGS rock powder RMs by MC-ICP-MS.

Preconcentration and separation protocols can be required in the determination of trace elements by ICP-MS when the sample matrix might otherwise contaminate or physically damage the instrument. Strnad et al. ${ }^{343}$ reported two relatively simple methods for the extraction of $\mathrm{Au}$ from complex matrices using a mixture of $\mathrm{HBr}, \mathrm{HClO}_{4}, \mathrm{HI}$ and aqua regia. These extracts could be analysed by ICP-MS without any further preconcentration or separation. Although the procedures were developed primarily for the determination of Au in electronic waste, they were also applicable to the analysis of geological materials. The accuracy achieved for nine geological RMs was better than $\pm 10 \%$ in most cases, with a precision of $<5 \%$ RSD ( $n=5)$. Possible pitfalls such as nugget effects, spectral interferences and memory effects were evaluated. No significant interferences were observed on ${ }^{197} \mathrm{Au}$. Dubenskiy et al. ${ }^{344}$ tested the efficiencies of six new hypercrosslinked polystyrene sorbents for the simultaneous quantitative extraction of $\mathrm{Au}, \mathrm{Pd}, \mathrm{Pt}$ and $\mathrm{Ru}$ as their chlorocomplexes from rock digests following NiS fire assay pretreatment. The sorbant Stirosorb-514 in TBA, with $1 \mathrm{M} \mathrm{HCl}$ in ethanol as the eluent, was the most effective reversible sorption system for the preconcentration of PGEs prior to ICP-MS measurement.

Several recent studies discussed new or improved chromatographic separation schemes for isotope ratio measurements. Li et al. ${ }^{345}$ based a rapid tandem-column separation procedure for the separation of $\mathrm{Hf}, \mathrm{Nd}, \mathrm{Pb}$ and $\mathrm{Sr}$ from silicate matrices on the enhanced elemental selectivity permitted by the Sr Spec and TODGA Spec resins. The procedure offered a significant improvement in separation efficiency and a reduction in cross-contamination compared to conventional four column protocols. It took $c a .8 \mathrm{~h}$ to process a batch of 25 samples, including column setup, cleaning and preconditioning. The robustness of the method was verified by determining the isotopic compositions of $\mathrm{Nd}, \mathrm{Pb}$ and $\mathrm{Sr}$ (by TIMS) and of $\mathrm{Hf}$ (by MC-ICP-MS) in eight silicate rock RMs with a wide range of matrices. A SPE procedure ${ }^{346}$ was developed for the preconcentration of 28 elements (Ba, C, Co, Cr, Cu, Li, Ni, Rb, REEs, $\mathrm{Sr}$ and $\mathrm{Zn}$ ) present at very low concentrations in magnetite and pyrite prior to their determination by HR-ICP-MS. Following sample decomposition in a mixture of $6 \mathrm{M} \mathrm{HCl}$ and $8 \mathrm{M} \mathrm{HNO}_{3}$, two groups of elements were separated from the iron matrix using anion-exchange resin AG1-X8 and TRUspec ion-exchange resin. Recoveries were $100 \pm 5 \%$ and the procedural 
blanks low. The CCRMP RM FER-2 (iron formation) was used for validation. A three-step ion-exchange method ${ }^{347}$ for the separation and purification of B from clay sediments was published in Chinese. In the first step, cation-exchange resin AG 50W-X8 was used to remove $\mathrm{Al}, \mathrm{Fe}$ and the REEs, to prevent the formation of insoluble hydroxides that can absorb $\mathrm{B}$ in highly alkaline solutions. In subsequent steps, B was separated on Amberlite IRA 743 and purified on a mixed anion- and cation-exchange column. Recoveries were $>90 \%$ with no obvious fractionation of $\mathrm{B}$ isotopes. To perform very precise determinations of $\mathrm{Nd}$ isotope ratios in geological samples, Kagami and Yokoyama ${ }^{348}$ developed a three-step column chemistry procedure involving cation-exchange chromatography for separating major elements from REEs, oxidative extraction chromatography to remove Ce and final purification of $\mathrm{Nd}$ using Eichrom Ln Spec resin . High recoveries (>91\%) and effective separation of $\mathrm{Nd}$ from $\mathrm{Ce}$ and $\mathrm{Sm}\left(\mathrm{Cd} / \mathrm{Nd}<1.2 \times 10^{-5}\right.$ and $\left.\mathrm{Sm} / \mathrm{Nd}<5.2 \times 10^{-6}\right)$ were achieved. Small extraction chromatographic columns (alone or in tandem) were used ${ }^{349}$ to separate 11 elements involved in six radiogenic isotope systems from a rock digest prior to isotope ratio measurements by MC-ICP-MS or TIMS. Commercially available extraction resins, together with a resin prepared in-house for the separation of $\mathrm{Rb}$, provided typical recoveries of $85-95 \%$ with procedural blanks of 10-100 pg. A simplified scheme for the separation of $\mathrm{Hf}, \mathrm{Nd}, \mathrm{Pb}$ and $\mathrm{Sr}$ only was also proposed.

Alkali fusion used for the dissolution of single zircon grains for (U-Th-Sm)/He thermochronometry had ${ }^{350}$ several advantages over previously used methods. Not only was it twice as fast but it avoided the use of HF, thereby making it unnecessary to remove the grains from the metal microvials, as usually required to avoid contamination by co-dissolution of the vial material. A mixture of $\mathrm{B}(\mathrm{OH})_{3}$ and $\mathrm{LiBO}_{2}$ was added to the sample in a Pt crucible and fused at $990{ }^{\circ} \mathrm{C}$ for $2 \mathrm{~h}$. After dissolution in $\mathrm{HNO}_{3}, \mathrm{Sm}$, Th and $\mathrm{U}$ were measured by ICP-MS. The (U-Th-Sm)/He ages of two reference zircons were in good agreement with reported ages and the precision was comparable to that of traditional dissolution procedures.

Chemical abrasion of zircons is a procedure which involves sequential annealing and leaching, and is commonly used to remove parts of the zircon grain that have experienced loss of $\mathrm{Pb}$, thereby improving the precision and accuracy of $\mathrm{U}-\mathrm{Pb}$ dating. Following a detailed evaluation $^{351}$, optimal conditions for CA were annealing at $900{ }^{\circ} \mathrm{C}$ for $48 \mathrm{~h}$ and leaching in a Parr digestion vessel at $190{ }^{\circ} \mathrm{C}$ in conc. HF for $15 \mathrm{~h}$. The application of CA to U-Pb dating of zircons by SIMS rather than by LA-ICP-MS is relatively uncommon. In a recent SIMS study ${ }^{352}$ of the application of CA to zircons of late Eocene age, CA-treated grains yielded older ${ }^{206} \mathrm{~Pb} /{ }^{238} \mathrm{U}$ ages than untreated grains. These differences in measured ages did not correlate 
however with trace element concentrations. Chemical abrasion appeared to improve the accuracy of the age determinations while the precision remained the same. Although the treatment could potentially have affected the secondary ion sputtering rates and so result in biased ages, as observed for LA-ICP-MS analysis, ion microprobe pit depths were in fact identical for both CA and non-CA reference zircons so no loss had occurred.

Fusion techniques are often used to produce homogeneous glass beads for bulk rock analysis by LA-ICP-MS. Zhang et al. ${ }^{353}$ advocated a novel flux-free fusion technique in which a high-energy IR laser was used to prepare glasses from pressed powder pellets. Although this method apparently worked well for felsic and zircon-bearing rock powders rocks, unfortunately the authors compared their LA-ICP-MS data for glasses with results from XRFS analysis of the original pressed powder pellets but not with glasses prepared by other fusion techniques such as Ir-strip fusion ${ }^{354,355}$. The reported precision and accuracy of LA-ICP-MS measurements on the glass beads were better than those obtained from pressed powder pellets but were not as good as the figures of merit achievable by other flux-free methods. In addition, there remained issues of a longer analysis time due to the need to prepare pressed pellets, loss of volatile elements and a much larger sample mass requirement. However, if no Ir-strip heating device is available, this technique would provide suitable material for whole rock analysis by LA-ICPMS, thus avoiding the need for time-consuming sample dissolution. The technique of Bao et $a l .{ }^{356}$ involving a flux-free fusion in boron nitride vessels followed by rapid acid digestion was especially applicable to high- $\mathrm{SiO}_{2}$ rocks containing refractory minerals such as zircon and rutile. The optimum conditions were heating for 1 minute only at 1400 or $1600{ }^{\circ} \mathrm{C}$ for extrusive and intrusive rocks, respectively. Fusion was followed by a rapid $\mathrm{HF}-\mathrm{HNO}_{3}$ digestion of the glasses in capped Savilex screwtop beakers on a hotplate. This procedure was eight times faster than methods using high-pressure PTFE digestion bombs. Element concentrations determined by ICP-MS for ten RMs with $\mathrm{SiO}_{2}$ contents between 44.6 and $73 \mathrm{wt} \%$ were in good agreement $(< \pm 10 \%)$ with reference values for most elements, including volatile elements such as Cs and $\mathrm{Pb}$. Another fusion method ${ }^{357}$ (paper in Chinese), specifically for the preparation of sulfide materials prior to the determination of major and trace elements by LA-ICP-MS and XRFS, employed $\mathrm{HNO}_{3}$ to pre-oxidise the samples to avoid damaging the Pt crucibles. The addition of $\mathrm{GeO}_{2}$ prevented breakage of the glass beads, which were homogeneous ( $<5.6 \%$ ( $\left.1 \mathrm{RSD}\right)$ by XRFS and $<3 \%$ (1 RSD) by LA-ICP-MS) in their major element composition.

An alternative approach to the preparation of samples for bulk rock analysis by LAICP-MS is the preparation of nanoparticulate pressed powder pellets. To evaluate this methodology, six rock RM powders were further pulverised by wet milling and pressed into 
pellets using microcrystalline cellulose as a binder ${ }^{358}$. Analysis of the pellets by LA-ICP-MS using a $193 \mathrm{~nm}$ excimer laser gave a measurement repeatability as low as $0.5-2 \%(1 \mathrm{~s}, \mathrm{n}=6)$ using a spot size of $120 \mu \mathrm{m}$, demonstrating the pellets were homogeneous at this scale. Blank contributions were negligible for most elements and polyatomic interferences caused by the organic binder were insignificant. One advantage of this method was the ability to measure elements such as As, B, Bi, Li, Sb and Tl, which are not always accessible with other methods of sample preparation.

\subsection{Instrumental analysis}

\subsubsection{Review papers}

A series of review papers on the analysis of non-traditional stable isotopes was published in a volume of Reviews in Mineralogy and Geochemistry. The first paper ${ }^{359}$ (157 references) provided an overview on the $\delta$ notation and guidelines for the selection of RMs, as well as an introduction to the relevant isotope systems. The volume included reviews of: the isotope geochemistry of chlorine ${ }^{360}$ (186 references), cobalt and zinc ${ }^{361}$ (267 references), chromium ${ }^{362}$ (193 references), germanium ${ }^{363}$ (233 references), lithium ${ }^{364}$ (306 references), magnesium ${ }^{365}$ (234 references), molybdenum ${ }^{366}$ (249 references), nickel ${ }^{367}$ (134 references) and silicon ${ }^{368}$ (206 references). In addition, isotope systematics of iron $^{369}$ (489 references); recent developments in $\mathrm{Hg}$ stable isotope analysis ${ }^{370}$ (87 references); in situ analysis of non-traditional stable isotopes by SIMS and LA-ICP-MS, using Mg isotopes in olivines and silicate glasses as examples $^{371}$ (142 references); Se isotopes as biogeochemical proxies ${ }^{372}$ (158 references); the isotopic fractionation of thalium ${ }^{373}$ (157 references) and uranium ${ }^{374}$ (223 references) were covered.

An excellent review ${ }^{375}$ (44 references) of the determination of Th by mass spectrometric techniques detailed the advantages and pitfalls associated with the measurement of Th isotope ratios by a range of techniques, including TIMS, ICP-MS and SIMS. Problems of contributions to the blank and the poor ionisation efficiency of Th were discussed and the need for CRMs with certified ${ }^{230} \mathrm{Th} /{ }^{232} \mathrm{Th}$ isotope ratios was highlighted.

A brief history ${ }^{376}$ of the development of laser ablation ICP-MS was presented in an issue of Elements (vol 12, number 5, 2016) dedicated to a wide range of applications of this technique to the Earth sciences. Other reviews of interest in this issue included articles on elemental analysis of igneous systems ${ }^{377}$ (30 references), advances in isotope ratio determinations $^{378}$ (29 references) and the role of ICP-MS in palaeoclimate research ${ }^{379}$ (31 references). An overview (150 references) of the principles of LA-ICP-MS analysis of solid 
inorganic materials by Shazzo and Karpov ${ }^{380}$ emphasised the problems arising from elemental fractionation. A paper ${ }^{381}$ in Czech (104 references) focused on the principles of LA-ICP-MS instrumentation and its application to geochemistry, parameters influencing the ablation process, quantification strategies, limitations of the technique and the use of RMs. Bruand et $a l .{ }^{382}$ (53 references) highlighted how the trace element and isotopic composition of apatite can provide important insights into the petrogenesis and provenance of igneous rocks. Recent advances $^{383}$ (169 references) in the application of LA-ICP-MS to magmatic-hydrothermal ores to determine the trace element composition of minerals included appropriate methodology, RMs, new mineral matrices, analytical uncertainties and future applications.

The application of LA-ICP-MS to the analysis of fluid inclusions to derive information on fluid-rock interactions and ore deposit formation, as well as tracking evolution of fluids along fluid pathways, was summarised by Wagner et al. ${ }^{384}$ (30 references). To obtain absolute elemental concentrations in fluid inclusions, microanalytical measurements (by LA-ICP-MS) are usually interpreted in relation to microthermometric observations. Steele-MacInnis et al. ${ }^{385}$ (83 references) assessed the use of such data to obtain robust results for the composition of low- to intermediate-salinity chlorine-dominated inclusions.

\subsubsection{Atomic absorption and atomic emission spectrometry}

Volzhenin et al. ${ }^{386}$ evaluated two-stage probe atomisation for the determination of $\mathrm{Au}$ and $\mathrm{Pd}$ in geological samples by electrothermal $A A S$. Digestion of ores in $\mathrm{HNO}_{3}-\mathrm{HCl}(1+3)$ using an autoclave microwave system yielded a suitable suspension for analysis. Optimisation of the atomisation programme, the position of the probe and the argon flow rate resulted in LODs of 0.01 and $0.04 \mu \mathrm{g} / \mathrm{g}\left(10^{-6} \mathrm{wt} \%\right)$ for $\mathrm{Au}$ and $\mathrm{Pd}$, respectively. The sensitivity and precision of the determination $^{245}$ of Er in sediments and rocks by high-resolution continuum source ETAAS were improved by addition of lanthanum as a chemical modifier. The characteristic mass, LOD and LOQ of $29 \mathrm{pg}, 0.71 \mu \mathrm{g} \mathrm{L} \mathrm{L}^{-1}$ and $2.4 \mu \mathrm{g} \mathrm{L} \mathrm{L}^{-1}$, respectively, compared favourably with those obtained using other ETAAS methods.

The use of decrepitation to release the contents of fluid inclusions for analysis was first developed more than three decades ago and before the advent of LA-ICP-MS. In a reappraisal of the technique, Piperov et al. ${ }^{387}$ devised a system in which a simple 'decrepitator' was inserted between the nebuliser and the plasma torch of an ICP-AES instrument. The performance of this system was compared with conventional crush-leach or decrepitation leach methods of preparation, as well as analysis by LA-ICP-MS. The decrepitation ICP-AES 
technique was able to provide relatively rapid preliminary information at low cost and was particularly useful for sample materials that were not amenable to analysis by LA-ICP-MS.

Bachari et $a l .{ }^{388}$ examined the effects of spectral interferences on the ICP-AES determination of $U$ concentrations in phosphate ore. Results from three different acid digestion procedures confirmed that the acid used was one of the most important influences on the choice of emission line for measurement. Spectral interferences affecting the accurate determination ${ }^{389}$ of Rh in molybdenum and copper concentrates by ICP-AES were investigated using two different ICP-AES systems. Quantitative databases for the type and magnitude of spectral interferences in the presence of $\mathrm{Al}, \mathrm{Ca}, \mathrm{Cu}, \mathrm{Fe}, \mathrm{Mg}$, Mo and Ti were obtained for both a radial viewing $40.68 \mathrm{MHz}$ ICP with a high resolution spectrometer and an axial viewing 27.12 $\mathrm{MHz}$ ICP with a medium resolution spectrometer.

\subsubsection{Laser-induced breakdown spectroscopy and related techniques}

The potential of LIBS for the determination of La and Y in soils and rocks was evaluated ${ }^{286}$ using thermodynamic modelling of the LIBS spectra to estimate the technique's sensitivity. The experimental LODs for La and Y were $6 \mu \mathrm{g} \mathrm{g}^{-1}$, sufficiently lower than their abundances in the Earth's crust to be of value. The LOD was close to that predicted by theory for La but an order of magnitude higher than the theoretical LOD of $0.4 \mu \mathrm{g} \mathrm{g}^{-1}$ for Y. This discrepancy appeared to be a consequence of theoretical extrapolation to low concentrations without considering all the possible spectral interferences. A detailed assessment ${ }^{390}$ of the most suitable experimental conditions for the routine analysis of shale samples by LIBS was made using a $\mathrm{Nd}$ :YAG laser operating at $1064 \mathrm{~nm}$ in air. The LODs of 27.4, 28.5, 5.6 and $6.5 \mu \mathrm{g} \mathrm{g}^{-1}$ for $\mathrm{Cr}$, $\mathrm{Ni}$, Sr and V, respectively, illustrated the potential of LIBS in shale gas exploration and production, although a matrix effect was still observed due to the complex composition of these materials. An interesting approach ${ }^{391}$, with the aim of obtaining radiometric age data from future one-way space missions, involved the development of an isochron-based in situ K-Ar dating method based on a combination of LIBS and quadrupole MS analyses of rocks after sampling by LA. Potassium abundances were determined by LIBS, while those of the different Ar isotopes were measured by quadrupole MS. Spot-by-spot measurements allowed the construction of an isochron from a single rock sample. The LIBS-MS method was validated by analysing mineral and rock samples with known ages and $\mathrm{K}$ content. The results indicated that absolute ages for rocks with $\mathrm{K}$ concentrations of $c a .1 \mathrm{wt} \%$ could be determined with an uncertainty of $10-20 \%$. 
A very large suite of LIBS spectra of rock samples ${ }^{392}$ - 1356 spectra from 452 geological samples - was used to compare the accuracy of different models for prediction of elemental compositions. In general, the accuracy of the predicted values for $\mathrm{Al}, \mathrm{Ca}, \mathrm{Co}, \mathrm{Cr}, \mathrm{Fe}$, $\mathrm{K}, \mathrm{Mg}, \mathrm{Mn}, \mathrm{Na}, \mathrm{Ni}, \mathrm{Si}$, Ti and $\mathrm{Zn}$ was much better for multivariate analysis using PLS than for univariate analysis, especially when based on single emission lines. This conclusion was not surprising given the wide range of geological matrices involved. The ChemCam team ${ }^{393}$ used a 'sub-model' method with PLSR to improve the accuracy of quantitative LIBS analysis of geological materials on the Mars Science Laboratory rover. The method was conceptually simple but did require a substantial number of RMs to provide the training set of data. Dyar et $a l .{ }^{394}$ presented an excellent compilation of methods for baseline removal from LIBS spectra. Results from different approaches demonstrated the complexity of this issue and indicated that sophisticated types of multivariate analysis, with optimisation of adjustable parameters, were always necessary to improve prediction accuracy. Aguilera and Aragón ${ }^{395}$ proposed a new approach to quantitative analysis by LIBS, designated as CSigma-LIBS, where conventional calibration for each element using a range of RMs was replaced with a procedure based on CSigma graphs. These graphs were constructed to include reference lines of an emitting species with well-known transition probabilities, together with lines for the elements of interest, both in the same ionisation state. Two glasses of known composition, prepared from mixtures of pure compounds, were used for calibration. This technique was applied to the determination of mass fractions of $\mathrm{Al}, \mathrm{Ca}, \mathrm{Fe}, \mathrm{Mg}, \mathrm{Mn}, \mathrm{Si}$, Ti and $\mathrm{V}$ of geological RMs prepared as fused glass beads. The average precision was $3.4 \%$ for concentrations $>0.1 \mathrm{wt} \%$, with good agreement with the certified values for the four rock RMs analysed. The main drawbacks were the need to prepare fused glass beads, which removed the versatility and speed of the LIBS technique, and the dilution involved, thereby preventing the determination of trace elements.

There is increasing interest in high resolution geochemical characterisation of materials by LIBS. Lefebvre et al. ${ }^{396}$ demonstrated that LIBS was capable of providing semiquantitative geochemical signatures of multi-layered, sub-mm thick coatings on a rock surface. The test sample was a basaltic rock with sub-mm Ca-Mg-Fe-Si rich mineral coatings. The authors considered the method suitable for fine-scale 3D LIBS analysis of coatings on Martian rocks.

An innovative approach ${ }^{397}$ of double-pulse LIBS coupled with a petrographic, optical microscope was used to analyse thin sections of iron meteorite samples directly in air rather than in a controlled atmosphere. Qualitative and quantitative analysis by calibration-free LIBS and one-point calibration LIBS methods, respectively, provided results in good agreement with 
data from ICP-MS and SEM analyses. Double-pulse LIBS $^{398}$, combined with multivariate statistics, was also used to generate a map of the spatial distribution of $U$ in sandstone-hosted U ores. The lateral resolution was limited to $100 \mu \mathrm{m}$. Unfortunately, there was no comparison of the LIBS results with other in situ techniques such as EPMA or LA-ICP-MS.

A well-documented study ${ }^{399}$ on the application of handheld LIBS instrumentation to geological materials included an excellent review of the operational principles of LIBS and portable instrumentation in general, and its possible application to geochemical fingerprinting and provenance determination. Samples including carbonates, silicates, oxide minerals and native gold were analysed using a commercially available, handheld LIBS instrument under simulated field conditions. Connors et al. ${ }^{400}$ evaluated the performance of one specific commercially-available handheld LIBS instrument for the analysis of geological materials. All the samples were tested after pressing into thin cakes with a 6-ton press and data reported using traditional peak ratio calibrations. This research indicated a significant potential for qualitative analysis and elemental mapping. Because of its high sensitivity, LIBS has the capability to measure elements such as $\mathrm{Ba}, \mathrm{Be}$ and $\mathrm{Li}$ which cannot be measured by $\mathrm{pXRFS}$. However, more work was necessary to implement PCA and PLS model generation software for fully quantitative analysis.

\subsubsection{Inductively coupled plasma mass spectrometry}

4.3.4.1 Instrumentation Maoyong et $a .^{401}$ demonstrated how the sensitivity of a multicollector ICP-MS instrument could be improved by using different combinations of sample and skimmer cones with different orifice diameters and geometries. Tests conducted while measuring B isotope ratios in a reference solution suggested that sensitivity could be enhanced by using sample cones with larger orifices and skimmer cones with trumpet-shaped entrances and exits. Richter et al. ${ }^{402}$ highlighted the importance of testing the linearity of the ion counting system in MC-ICP-MS. Another consideration was the accurate determination of the dead time of the system. For both operations, the authors provided a detailed static measurement procedure based on CRMs from the IRMM-072 series of $U$ isotope reference solutions.

4.3.4.2 Trace element determinations by solution-based ICP-MS Incomplete sample digestion, isobaric interference and instrumental drift can be problems for the unwary in the determination of trace element abundances in geological samples by ICP-MS. Chen et al. ${ }^{403}$ developed some cost-effective practical procedures to address these issues. For example, they 
demonstrated that the fluoride complexes formed during high-pressure digestion could be readily redissolved if the digestion were carried out at $190{ }^{\circ} \mathrm{C}$ for $2 \mathrm{~h}$ using $50 \mathrm{mg}$ of sample. The measurement protocol involved an off-line procedure for making isobaric interference corrections and drift corrections based on repeated measurements of a QC solution, and was validated by the analysis of five USGS rock RMs. Although the authors claimed that their methodology saved over $60 \%$ of the time normally taken for analysis, such procedures have been in use in many laboratories since the early days of ICP-MS. A reference method ${ }^{165}$ to determine $\mathrm{Cd}, \mathrm{Cu}, \mathrm{Hg}, \mathrm{Pb}$ and $\mathrm{Zn}$ mass fractions in marine sediments based on ID-ICP-MS used a multiple spiking approach to reduce the number of analytical steps. Isotope ratio data were acquired by quadrupole ICP-MS and SF-ICP-MS instruments, both run in two different measurement modes. The consistency of the results obtained confirmed that quadrupole ICPMS can be the method of choice if the mass fractions of the elements of interest are sufficiently high to obtain good counting statistics. The procedure was successfully applied to the characterisation of IAEA-458 (marine sediment) candidate RM, achieving an uncertainty target of $1.5-3.0 \%(\mathrm{k}=2)$ and SI traceable values. The ability of ICP-MS/MS instrumentation to minimise polyatomic interferences for accurate and precise REE determinations in geological matrices was demonstrated ${ }^{404}$ by analysing samples following three different digestion methods: open vessel acid digestion, microwave digestion and alkaline fusion. An assessment of the analytical performance of the ICP-MS/MS system against MIP-AES, ICP-AES and quadrupole ICP-MS concluded that ICP-MS/MS yielded the best figures of merit.

Spectral interferences have an impact on the accuracy and precision of trace element and isotope ratio measurements by ICP-MS. A detailed study ${ }^{405}$ investigated the formation of doubly charged alkaline earth-argon ions $\left(\mathrm{MAr}^{2+}\right.$, e.g. $\left.{ }^{86} \mathrm{Sr}^{40} \mathrm{Ar}^{2+}\right)$ in the ICP, which can potentially interfere with isotopes of analyte elements, e.g. ${ }^{63} \mathrm{Cu}^{+}$. The relative abundances of the various $\mathrm{MAr}^{2+}, \mathrm{M}^{2+}$ and $\mathrm{MAr}^{+}$ions agreed with assumed properties of the ICP and the ion extraction process in ICP-MS. An exception was the relatively low abundance of $\mathrm{MgAr}^{2+}$, which was assumed to result from collision-induced dissociation during the ion extraction process. The same authors ${ }^{406}$ looked at the abundance of doubly charged polyatomic Ar interferences in ICP-MS spectra and how they affect ultratrace analyses and isotope ratio measurements. Changing ICP parameters, such as raising carrier gas flow or lowering gas temperatures, increased the abundance of the doubly charged molecular ions significantly.

4.3.4.3 Trace element determinations by laser ablation ICP-MS An interesting contribution ${ }^{407}$ highlighted the complexity of oxide production in LA-ICP-MS compared to that in solution 
ICP-MS. Although the total amount of oxygen in the ICP was significantly lower in LA-ICPMS, the contribution of oxygen from the ablated material influenced the oxide production rate (OPR) for some elements. For example, the OPR was four times higher for Al, Si and W when a silicate was ablated compared to a metal because of the much higher oxygen content of silicates. In particular, the OPRs for Hf and Th were highly dependent on the minerals analysed. Thus, Th OPRs varied between 0.09 and $0.2 \%$ depending on the mineral ablated, whereas those for $U$ were much more consistent (0.058-0.063\%), with the exception of uraninite.

The high spatial resolution of LA-ICP-MS analysis, one of the major advantages of this technique since it permits elemental and isotopic mapping and depth profiling, was exploited ${ }^{408}$ to resolve chemical variations in daily growth bands of Miocene and modern giant clams. A rotating rectangular aperture was used to maximise the spatial resolution of line scans across the sample surface. Data were acquired using laser spots of $4 \times 50 \mu \mathrm{m}$ at a scan speed of 1.5 $\mu \mathrm{m} \mathrm{s}^{-1}$ and a $15 \mathrm{~Hz}$ repetition rate. No signal smoothing device was used. Six masses were monitored. Results obtained by LA-ICP-MS at a spatial resolution of $4 \mu \mathrm{m}$ in this study were comparable to data obtained in other laboratories by nanoSIMS at a resolution of $2 \mu \mathrm{m}$. In another application of in situ multi-element 2D imaging by LA-ICP-MS, single pyrite grains ${ }^{409}$ were mapped for nine elements to obtain information on the redox conditions existing during pyrite formation. Raimondo et al. ${ }^{410}$ presented a technique for the routine acquisition of $2 \mathrm{D}$ trace element maps of garnet minerals at high spatial resolution. They also developed an extension to the XMapTools software package for rapid processing of the LA-ICP-MS data in order to visualise and interpret compositional zoning patterns. The elemental maps obtained were used to identify the mechanisms controlling geochemical mobility in garnet. The distributions of $\mathrm{Au}, \mathrm{Hg}$, Se and $\mathrm{Te}$ in reduction spheroids (cm-scale pale spheroids in an otherwise red rock) from continental red bed successions, measured by LA-ICP-MS, revealed $^{411}$ increased concentrations of Te towards the core. This showed that Te is mobile and can be concentrated in such low temperature sedimentary environments, probably controlled by a process such as microbiological activity. Petrelli et al. ${ }^{412}$ examined the potential of a LAQ-ICP-MS system for high resolution trace element analysis of volcanic glasses from ash particles using laser beam sizes of 5 to $15 \mu \mathrm{m}$. They concluded that, for most geological applications, a measurement precision of $15 \%$ for concentrations $>1.7 \mu \mathrm{g} \mathrm{g}^{-1}$ and an accuracy of $<15 \%$, obtained using ${ }^{42} \mathrm{Ca}$ as the IS and with an $8 \mu \mathrm{m}$ spot size, was acceptable.

Warburton et al. ${ }^{413}$ tested the reliability of depth profiling to obtain high resolution trace element data for otolith microchemistry. The technique could yield accurate data if important factors such as tailing effects, elemental fractionation and spot size were considered carefully. 
A combination of SIMS U-Pb and elemental LA-ICP-MS depth profiling techniques for acquiring maps of unpolished zircon grains provided ${ }^{414}$ information on zircon recrystallisation, rim development and mineral-fluid interactions.

4.3.4.4 Isotope ratio determinations Recent advances in the measurement of isotope ratios have mainly involved the use of MC-ICP-MS, although quadrupole ICP-MS or SF-ICP-MS featured in some applications. Table 7 provides a summary of some of the more significant developments in the determination of the isotopic signatures of different isotope systems in geological and environmental materials over the current review period.

Essential reading for anyone new to geological applications of LA-ICP-MS is an issue of Elements (volume 12, number 5, 2016, see also section 4.3.1) which consists of a series of review articles, including one ${ }^{378}$ (29 references) on the state-of-the-art in isotope ratio determinations by LA-MC-ICP-MS, written by some of the leading practitioners in the field. They highlighted developments in instrumentation and methodology that provided rapid and cost-effective isotopic analysis with considerable flexibility compared to other microanalytical techniques. The ability to acquire isotope maps and depth profiles was seen to be a particular advantage in geoscientific research such as the elucidation of zonation patterns. Continuing challenges such as matrix effects, uncertainty assessment, suitability of RMs and interferences were considered, as well as new hardware advances, such as ICP instruments coupled to TOF analysers.

The application of ICP-MS/MS to the LA analysis of geological materials is particularly advantageous for in situ $\mathrm{Rb}-\mathrm{Sr}$ and K-Ca dating. Holgmalm et al. ${ }^{415}$ evaluated $\mathrm{N}_{2} \mathrm{O}$ and $\mathrm{SF}_{6}$ as reaction gases in preference to $\mathrm{O}_{2}$ for separating ${ }^{87} \mathrm{Sr}$ from ${ }^{87} \mathrm{Rb}$ in the reaction cell. The main reaction products were $\mathrm{SrO}^{+}$with $\mathrm{N}_{2} \mathrm{O}$ and $\mathrm{SrF}^{+}$with $\mathrm{SF}_{6}$; $\mathrm{Rb}$ does not react with either gas. Sensitivity was improved by a factor of $c a$. 10 with $\mathrm{N}_{2} \mathrm{O}$ and $c a$. 8 for $\mathrm{SF}_{6}$ compared to when $\mathrm{O}_{2}$ was used. The same precisions for isotopic ratios and $\mathrm{Rb}-\mathrm{Sr}$ ages could be obtained with spot sizes of 50 and $80 \mu \mathrm{m}$. Furthermore, when $\mathrm{SF}_{6}$ was mixed with $\mathrm{H}_{2}$, it was possible to measure ${ }^{40} \mathrm{Ca}^{+}$free from ${ }^{40} \mathrm{~K}^{+}$and ${ }^{40} \mathrm{Ar}^{+}$interferences, thereby enabling simultaneous $\mathrm{K}-\mathrm{Ca}$ and $\mathrm{Rb}$-Sr dating of high-K and low-Ca minerals, such as micas. Ohata et al. ${ }^{416}$ investigated the potential of ICP-MS/MS for reducing or eliminating polyatomic ${ }^{16} \mathrm{O}^{18} \mathrm{O}^{1} \mathrm{H}$ and ${ }^{36} \mathrm{Ar}^{1} \mathrm{H}$ interferences on ${ }^{35} \mathrm{Cl}$ and ${ }^{37} \mathrm{Cl}$, respectively, during $\mathrm{Cl}$ isotope ratio measurements. The $\mathrm{Cl}$ isotope ratios were an order of magnitude more precise when measured using a mixture of $\mathrm{H}_{2}$ and $\mathrm{O}_{2}$ as reaction gas than when no reaction gas was used. In the concentration range $1-10 \mathrm{mg}$ 
$\mathrm{kg}^{-1}$, the sensitivity and precision (0.2-0.5\% RSD) obtained using $\mathrm{H}_{2}$ as reaction gas were similar to those obtained using SF-ICP-MS.

Double-spike methods, commonly utilised for the measurement of radiogenic isotope systems by TIMS for many years, are now being more widely adopted by the MC-ICP-MS community. The double-spike technique normally requires the measurement of four isotopes of the element of interest, but Coath et al. ${ }^{417}$ demonstrated that it was possible to apply doublespiking to elements with three isotopes, e.g. $\mathrm{K}, \mathrm{Mg}$ and Si. Precisions and accuracies of around $0.01 \%$ were obtained for $\mathrm{Mg}$ and $\mathrm{Si}$ isotopic abundances measured by MC-ICP-MS but, in contrast, the low abundance of ${ }^{40} \mathrm{~K}$ and the presence of the ${ }^{40} \mathrm{Ar}$ isobar made $\mathrm{K}$ ill-suited to this technique. A new protocol ${ }^{418}$ used a ${ }^{180} \mathrm{~W}-{ }^{183} \mathrm{~W}$ double spike for the MC-ICP-MS determination of the stable $\mathrm{W}$ isotope composition of geological RM, steel, iron meteorite and chondrite samples. An important aspect of this procedure was the efficient chemical separation of $\mathrm{Hf}$ from $\mathrm{W}$ involving a three-stage anion exchange chromatography prior to measurement to avoid isobaric interferences from highly abundant ${ }^{180} \mathrm{Hf}$ ( $\left.c a .35 \%\right)$ on the low abundance ${ }^{180} \mathrm{~W}$ ( $c a$. $0.12 \%$ ). Isobaric dilution analysis (IBDA) was proposed as a novel calibration tool for longlived radionuclides ${ }^{419}$. In contrast to IDA, the spike is not an isotope of the target element but of another element that shares an isobaric isotope and has similar chemical properties, thus potentially providing a cheaper alternative to conventional IDA. The principle was demonstrated by analysis of a mixture of Dy and Gd standard solutions by single collector SFICP-MS. These elements have isobaric isotopes at $\mathrm{m} / \mathrm{z} 160$. The resulting ratio of $\mathrm{m} / \mathrm{z} 157$ to $\mathrm{m} / \mathrm{z} 160$ differed by only $0.01 \%$ from the same ratio determined by IDA. The concept was subsequently applied to the determination of ${ }^{99} \mathrm{Tc}$ in a contrast agent.

The importance of accurate correction of mass-dependent fractionation during $\mathrm{Pb}$ isotope measurements was highlighted ${ }^{420}$ in a MC-ICP-MS study of lavas, from islands in French Polynesia, previously characterised by TIMS for their $\mathrm{Hf}-\mathrm{Nd}-\mathrm{Pb}-\mathrm{Sr}$ signatures. $\mathrm{The} \mathrm{Pb}$ isotope ratios obtained by MC-ICP-MS were significantly different from TIMS literature data and had a much smaller spread. This discrepancy resulted from an improved mass fractionation correction procedure applied in MC-ICP-MS analysis, in which a Tl-doped solution was added to all the sample solutions in a SSB approach. Regional variations in the Pb isotope data seen in previous TIMS studies disappeared when the new MC-ICP-MS data were plotted, thus necessitating a revised geological interpretation of the origin of the lavas. Using silicate glasses as samples, Dai et al. ${ }^{421}$ employed the LA split-stream (LASS) technique with MC-ICP-MS and quadrupole ICP-MS analyses to obtain in situ major and trace element concentration data and $\mathrm{Pb}$ isotope ratio data simultaneously from a single laser spot. Operation of an excimer $\mathrm{ArF}$ 
LA system at a repetition rate of $15-20 \mathrm{~Hz}$ and a spot size of $160 \mu \mathrm{m}$ gave precisions of $0.17 \%$, $0.074 \%, 6.7 \%, 3.0 \%$ and $4.3 \%$ for ${ }^{208} \mathrm{~Pb} /{ }^{206} \mathrm{~Pb},{ }^{207} \mathrm{~Pb} /{ }^{206} \mathrm{~Pb},{ }^{208} \mathrm{~Pb} /{ }^{204} \mathrm{~Pb},{ }^{207} \mathrm{~Pb} /{ }^{204} \mathrm{~Pb}$ and ${ }^{206} \mathrm{~Pb} /{ }^{204} \mathrm{~Pb}$, respectively, for samples with $\mathrm{Pb}$ contents $>20 \mu \mathrm{g} \mathrm{g}{ }^{-1}$. A gas-exchange device used $^{422}$ in the measurement of $\mathrm{Pb}$ isotopes in ore samples by MC-ICP-MS removed $\mathrm{Hg}$ vapour from sample aerosol particles produced by LA of mercury-rich sulfides. The device reduced the interference of ${ }^{204} \mathrm{Hg}$ on ${ }^{204} \mathrm{~Pb}$ without affecting the $\mathrm{Pb}$ signal intensity, thereby improving the within-run precision, external reproducibility and accuracy of the measurements. As noted by other researchers, matrix effects occurred when silicate RMs were used for external standardisation in the analysis of sulfide samples so matrix-matched calibration was necessary. The USGS RM MASS-1 (synthetic polymetal sulfide) and a natural sphalerite Sph-HYLM were demonstrated to be suitable for this purpose.

In the field of $L A-I C P-M S U-P b$ zircon geochronology, an interesting contribution ${ }^{423}$ demonstrated the capabilities of a detector system equipped with 16 FCs, 4 EMs and two Daly detectors for the simultaneous detection of ${ }^{206} \mathrm{~Pb}$ and ${ }^{207} \mathrm{~Pb}$. The Daly detectors featured better long-term gain stability compared to a conventional EM during $10 \mathrm{~h}$ runs monitoring ${ }^{135} \mathrm{Ba} /{ }^{138} \mathrm{Ba}$ and ${ }^{136} \mathrm{Ba} /{ }^{138} \mathrm{Ba}$. The wide dynamic range of the Daly detectors $\left(10^{0}\right.$ to $\left.10^{7} \mathrm{cps}\right)$ overlapped by several orders of magnitude that of a FC $\left(10^{4}\right.$ to $\left.10^{10} \mathrm{cps}\right)$, making crosscalibration between the detectors possible. The ${ }^{207} \mathrm{~Pb} /{ }^{206} \mathrm{~Pb}$ ratio for the zircon $91500 \mathrm{RM}$ was measured on the Daly detectors with an analytical precision of $c a .5 \%(n=15)$ and a relative deviation from the literature value of $-0.04 \%$. This instrument configuration was particularly advantageous for the analysis of young zircons and small sample masses. In another LA-MCICP-MS zircon study ${ }^{424}$, a multiple ion counting system equipped with six full-size EMs was used to detect simultaneously the ion signals from ${ }^{202} \mathrm{Hg},{ }^{204}(\mathrm{Hg}+\mathrm{Pb}),{ }^{206} \mathrm{~Pb},{ }^{207} \mathrm{~Pb},{ }^{208} \mathrm{~Pb}$ and ${ }^{238} \mathrm{U}$ and so achieve high-precision $\mathrm{U}-\mathrm{Pb}$ isotope ratio measurements at improved spatial resolution. The U-Pb age of 336.3 \pm 1.9 Ma obtained for the Plešovice zircon (Czech Republic) using a LA spot size of $25 \mu \mathrm{m}$ and ablation duration of $2.5 \mathrm{~s}$ was more precise than that of 340.3 \pm 3.5 Ma achieved by single collector SF-ICP-MS under the same ablation conditions. To take full advantage of the instrumental setup, $1 \mathrm{~s}$ ablations were adopted. These produced craters with depths of $<1 \mu \mathrm{m}$ and diameters of $25 \mu \mathrm{m}$ so, unsurprisingly, the resultant $\mathrm{U}-\mathrm{Pb}$ age of 339.5 $\pm 6.7 \mathrm{Ma}$ for Plešovice was significantly less precise but still comparable to the age obtained using conventional ablation with single collector ICP-MS. Marillo-Sialer et al. ${ }^{425}$ considered radiation-induced structural defects, trace element composition, colour and crystallographic orientation as possible causes of variation in ablation behaviour between 
different zircon matrices that might bias U-Pb ages as determined by LA-MC-ICP-MS. Crystallographic orientation and colour had a negligible effect compared to the combined influences of radiation damage and cation substitution in some zircon samples. Thermal annealing at temperatures $>1000{ }^{\circ} \mathrm{C}$ resulted in much more uniform ablation behaviour between different zircon matrices, thereby improving accuracy of $\mathrm{U}-\mathrm{Pb}$ age determinations significantly.

Guillong et al. ${ }^{426}$ applied a new ${ }^{230} \mathrm{Th} /{ }^{238} \mathrm{U}$ disequilibrium method to obtain age determinations of young zircons (10-300 ka) using single collector LA-SF-ICP-MS. Special attention was paid to the correction of polyatomic oxide interferences on $\mathrm{m} / \mathrm{z} 228$ and 230, to abundance sensitivity correction for the tail of the intense ${ }^{232} \mathrm{Th}$ signal on ${ }^{230} \mathrm{Th}$ and to corrections for mass bias and the relative sensitivity of Th and U. A robust procedure for the determination of the LODs, especially that for ${ }^{230} \mathrm{Th}$, was applied. The method was validated by analysing well-characterised zircons RMs (91500, AusZ-7, Temora2, GJ-1, OD-3, FCT and Plešovice) and samples previously analysed by SIMS. The Th-U ages derived by LA-SF-ICPMS and their precision ( $c a .1 \%$ ) were comparable with SIMS data for these zircons.

The application of uranium-Pb geochronology to other accessory minerals, such as apatite, is also possible. When Thompson et al. ${ }^{427}$ used LA with quadrupole ICP-MS to determine the $\mathrm{U}-\mathrm{Pb}$ ages of several apatite $\mathrm{RMs}$, there was a systematic bias of up to $3 \%$ compared to data obtained by IDMS. This bias was attributed to elemental fractionation at the ablation site. Because accurate U-Pb age determinations in apatite are compromised by variable amounts of common $\mathrm{Pb}$ incorporated into the crystal during growth, Wohlgemuth-Ueberasser et al $^{428}$ used LA-ICP-MS to determine the $\mathrm{Pb}$ isotopic composition in a coexisting mineral in order to estimate the initial $\mathrm{Pb}$ isotopic composition of apatite. The resulting age information was deemed to be accurate and precise using plagioclase for the common $\mathrm{Pb}$ corrections, rather than K-feldspar which is normally used for this purpose. The U-Pb dating of hematite $\left(\alpha-\mathrm{Fe}_{2} \mathrm{O}_{3}\right)$ can provide valuable information on the formation of ore deposits, but relies on the availability of matrix-matched calibration materials for LA-ICP-MS analysis. To address this problem ${ }^{429}$, a $\mathrm{U}-\mathrm{Pb}$ solution in $2 \% \mathrm{HNO}_{3}$ with known isotopic ratios was aspirated and mixed in the nebuliser with the aerosol produced by ablating a pure synthetic hematite sample. Apart from dispensing with the need for a isotopically homogeneous natural hematite RM, this approach meant that the concentration and isotope ratios of the solution could be adjusted to match those of the unknown samples, making the method efficient for dating hematite samples containing low $\left(c a .10 \mu \mathrm{g} \mathrm{g}^{-1}\right)$ to high $(>1 \mathrm{wt} \%) \mathrm{U}$ concentrations. An empirical study ${ }^{430}$ of allanite U-Pb geochronology using $193 \mathrm{~nm}$ LA-ICP-MS examined the use of NIST SRM 610 (trace elements 
in glass) for calibration purposes to overcome the lack of homogeneous matrix-matched materials. Although such an approach has been attempted before with mixed results, optimised laser operating conditions of $25 \mathrm{~s}$ ablations at $1 \mathrm{~J} \mathrm{~cm}^{-2}, 3 \mathrm{~Hz}$ and a $45 \mu \mathrm{m}$ crater produced negligible time-dependent $\mathrm{Pb} / \mathrm{U}$ and $\mathrm{Pb} / \mathrm{Th}$ fractionation. The results of this study were promoted as a guide for the LA-ICP-MS community towards matrix-independent U-Th-Pb geochronology for a wide variety of major and accessory minerals.

Molybdenum isotope variations in magmatic rocks were the focus of a detailed review $^{431}$ (229 references), which included an overview of separation techniques using anionicexchange resins and analytical methods mainly involving MC-ICP-MS combined with doublespike methods. Willbold et al. ${ }^{432}$ developed a new low-volume, single-pass chromatographic technique for the separation of Mo from silicate and Fe-rich metal matrices prior to MC-ICPMS analysis. The procedure, which used a combination of a strong anionic-exchange resin with a loading solution of a mixture of $\mathrm{HCl}$ and ascorbic acid, was said to be ideal for treating silicate samples with low Mo contents, such as basalts and andesites. An improved methodology ${ }^{433}$ for the calibration of Mo isotope ratio measurements by MC-ICP-MS employed NIST SRM 987 (Sr isotope standard) to correct for instrumental mass discrimination using a regression model. The novelty of the method was the use of controlled changes in the magnitude of instrumental mass discrimination, achieved by small incremental changes in plasma rf power, to define the relationship between isotope ratios of the analyte (Mo) and the IS ( $\mathrm{Sr}$ ).

The influence of LA parameters on the isotope fractionation of $B$ and $L i$ was explored ${ }^{322}$ using $193 \mathrm{~nm}$ ns and $266 \mathrm{~nm}$ fs laser systems coupled to a MC-ICP-MS instrument and crater diameters of 30-200 $\mu \mathrm{m}$. Higher repetition rates and larger spot sizes increased the fractionation of lighter isotopes by up to $8 \%$ for $\delta^{11} \mathrm{~B}$ and $\delta^{7} \mathrm{Li}$. This was primarily caused by mass loading effects in the ICP, although thermal fractionation at the LA site was also a contributory factor. Thermal effects are usually smaller with fs laser system but, in this study, the shape of the fs laser craters was not very reproducible, resulting in a larger bias compared to the ns LA results. Reproducible ablation of basalts and reference glasses could be achieved by maintaining a constant spot size, a repetition rate of $5 \mathrm{~Hz}$ and an energy density of $20 \mathrm{~J} \mathrm{~cm}^{-2}$. A novel correction for ablation volume resulted in repeatability and laboratory bias better than $1 \%$ for both $\delta^{11} \mathrm{~B}$ and $\delta^{7} \mathrm{Li}$.

The influence of different inorganic acids on $B$ isotope measurements by MC-ICP-MS was studied ${ }^{434}$ using $\mathrm{B}$ solutions containing $\mathrm{HCl}, \mathrm{HNO}_{3}$ and $\mathrm{HF}$ at concentrations up to $0.2 \mathrm{M}$. In general, the acids enhanced the B signal intensities and reduced the isotopic mass bias compared to the same $\mathrm{B}$ concentration in water. The use of $\mathrm{HNO}_{3}$ was recommended since it 
yielded similar signal intensities as $\mathrm{HCl}$ but did not require rigorous acidity matching to avoid mass bias and was less hazardous than HF, which gave the highest signal intensities. Previous studies have observed differences in MC-ICP-MS and NTIMS measurements of $\delta^{11} \mathrm{~B}$ in marine carbonates. This was investigated ${ }^{435}$ using a suite of 18 samples, comprising inorganic calcite grown under controlled $\mathrm{pH}$ conditions and planktonic foraminifera of Quaternary age. The NTIMS results were $0.5-2.5 \%$ higher than those from MC-ICP-MS but the cause for this offset remained unclear and could not be attributed to varying $\mathrm{B} / \mathrm{Ca}$ ratio in NTIMS or the increased sample processing necessary for MC-ICP-MS. However, measurements of inorganic calcites precipitated from parent solutions of varying $\mathrm{pH}$ confirmed that both techniques showed the same relationship of $\mathrm{pH}$ to calcite $\delta^{11} \mathrm{~B}$ within uncertainty, indicating that relative $\delta^{11} \mathrm{~B}$ changes generated from NTIMS and MC-ICP-MS measurements were comparable.

An innovative analytical method ${ }^{144}$ involving on-line separation of $\mathrm{Sr}$ from the sample matrix by IC prior to MC-ICP-MS analysis provided high throughput, robust and sensitive online measurements of ${ }^{87} \mathrm{Sr} /{ }^{86} \mathrm{Sr}$ ratios with minimum contamination in complex natural samples including carbonate and silicate rocks. The precision of $0.003 \%(2 \sigma)$ was only 2-3 times worse than could be obtained by labour- and time-intensive off-line TIMS or MC-ICP-MS techniques. A thorough investigation ${ }^{436}$ of potential $\mathrm{Ca}$ - and P-based interferences, which could have a significant influence on $\mathrm{Sr}$ isotope ratio measurements in bioapatite and calcium carbonate matrices by LA-ICP-MS, underlined the complex nature of such analysis. Correction of instrumental isotopic fractionation was identified as the biggest challenge. Accurate Sr isotope ratios could be obtained provided adequate corrections for interferences and instrumental isotopic fractionation were incorporated into the analytical protocol and consideration was given to the resulting expanded uncertainties, which might limit the use of LA-MC-ICP-MS depending on the particular application. Another contribution ${ }^{437}$ on ${ }^{87} \mathrm{Sr} /{ }^{86} \mathrm{Sr}$ ratios measurements by LA-MC-ICP-MS focused on the analysis of fossil teeth. The major polyatomic interference at mass 87 was ${ }^{40} \mathrm{Ar}^{31} \mathrm{P}^{16} \mathrm{O}$ rather than ${ }^{40} \mathrm{Ca}^{31} \mathrm{P}^{16} \mathrm{O}$ and could significantly bias results towards higher values compared to TIMS analyses, especially for samples with low Sr mass fractions. Tuning the instrument to low oxide production rates reduced the offset between TIMS and LA-MC-ICP-MS ${ }^{87} \mathrm{Sr} /{ }^{86} \mathrm{Sr}$ ratios from 0.00266 obtained without special tuning to an absolute mean difference of $0.00003(\mathrm{n}=21)$.

A method ${ }^{438}$ for high precision measurements of Os isotopes by MC-ICP-MS and NTIMS, incorporating a ${ }^{188} \mathrm{Os}^{1}{ }^{190}$ Os double spike, permitted simultaneous measurement of ${ }^{187} \mathrm{Os} /{ }^{188} \mathrm{Os}$ and ${ }^{186} \mathrm{Os} /{ }^{188} \mathrm{Os}$ ratios as well as the stable Os isotope composition expressed as $\delta^{190}$ Os. Relative to the IAG DROsS Os isotope RM, the internal precision was $0.01-0.02 \%$ for 
$\delta^{190} \mathrm{Os}$ and $<40 \mathrm{ppm}$ for ${ }^{187} \mathrm{Os} /{ }^{188} \mathrm{Os}$ and ${ }^{186} \mathrm{Os} /{ }^{188} \mathrm{Os}$ for both techniques. This study reported the first stable Os isotope compositions for four geological RMs: Durham University in-house RM GP-13 (Iherzolite) and CRPG RMs UB-N (serpentinite), CHR-Bkg (chromitite) and CHR$\mathrm{Pt}+$ (chromitite). The Os ratios were the same within the analytical uncertainty and so provided a preliminary $\delta^{190}$ Os value of $+0.130 \pm 0.032 \%$ ( $\left.2 S D ; n=4\right)$ for the Earth's upper mantle. Ultrafine sulfide powder pellets and fused beads, used as calibrants for in situ measurements of Os isotope ratios in sulfides by LA-MC-ICP-MS, were prepared ${ }^{439}$ from CNRCG RMs GBW07268 (chalcopyrite) and GBW07267 (pyrite) doped with standard solutions of Ir, Os, and $\mathrm{Rh}$. The homogeneity of the powder pellets for ${ }^{187} \mathrm{Os} /{ }^{188} \mathrm{Os}$ and ${ }^{187} \mathrm{Re} /{ }^{185} \mathrm{Re}$ was assessed by line scans and spot analyses. Greater phase separation was detected in the chalcopyrite fused beads than in the pyrite ones. Using the pressed pellets as matrix-matched RMs and applying a modified method to calculate mass fractionation coefficients, data for ${ }^{187} \mathrm{Os} /{ }^{188} \mathrm{Os}$ in sulfides were within $0.5 \%$ of the reference values for samples with ${ }^{187} \mathrm{Re} /{ }^{188} \mathrm{Os}<0.6$.

To date, very few measurements have been made of the isotopic composition of Ga in geological samples. Zhang et al. ${ }^{164}$ developed a three-column ion-exchange chromatography method for the determination of Ga isotopes by MC-ICP-MS in a range of geological materials. One anion-exchange AG MP-1M column and two cation-exchange AG 50W-X8 columns were employed in the purification scheme. The SSB technique corrected for instrument mass bias using $\mathrm{Cu}$ as the IS. The bracketing standard was a $200 \mathrm{ng} \mathrm{g}^{-1}$ solution of NIST SRM 994 (Ga metal) and the IS was prepared from NIST SRM 3114 (copper solution). The long-term reproducibility for $\delta^{71} \mathrm{Ga}$ was $0.04 \%$ (2SD). Interestingly, Kato et al. ${ }^{440}$ described a similar three-step ion-exchange chromatography protocol to separate Ga from rock samples prior to the determination of their Ga isotopic composition by MC-ICP-MS. Initially, matrix elements were removed on anion-exchange resin AG MP1, then Fe was separated from Ga on AG 50WX12 and finally $\mathrm{Ba}$ was separated using a similar elution protocol to step 1 but with much smaller volumes. Analysis of a range of mafic rocks from geological settings yielded almost identical $\delta^{71} \mathrm{Ga}$ values of $0.00 \pm 0.06$ (2SD) relative to a commercial ICP Ga standard solution. This was interpreted as the best estimate for the Ga isotopic composition of the bulk silicate Earth. External reproducibility was $0.05 \%$ based on replicate measurements of basalts USGS BHVO-2 and BCR-2. However, in this study, all the $\delta^{71}$ Ga data were calculated relative to a commercial ICP Ga standard solution and not NIST SRM 994. Consequently, the $\delta^{71}$ Ga values for USGS RMs BCR-2 and BHVO-2 (basalts) differed greatly from those reported by Zhang et al. ${ }^{164}$. A two-stage purification method for the determination of $\mathrm{Ga}$ isotope ratios by $\mathrm{MC}$ ICP-MS was based ${ }^{441}$ on columns containing AG 1-X4 and Ln-Spec resins. The reproducibility 
of the MC-ICP-MS analyses was better than 0.05\% (2SD). Some of the measurements were performed in the IPGP laboratories in Paris where the protocol of Kato et al. ${ }^{440}$ was developed, so similarities in some of the methodology is not surprising. Although it is likely that the large spread of $-0.05 \%$ to $+0.74 \%$ in $\delta^{71} \mathrm{Ga}$ values for BHVO-2 reported from these three studies can be explained by differences in correction strategies and the RMs employed, there is insufficient information to be certain. Unfortunately, none of the publications offered information on how well the ${ }^{71} \mathrm{Ga} /{ }^{69} \mathrm{Ga}$ ratios measured for the bracketing RMs agreed with certified or published data. What is clear is the Ga isotope community needs to address the issue of an internationally recognised delta zero for this system with some urgency!

Particle size distributions in aerosols produced during fs and ns LA were found to have a significant influence on the accuracy of stable Fe isotope ratio measurements by LA-MCICP-MS ${ }^{442}$. The ablation characteristics of the ns laser $(193 \mathrm{~nm})$ varied according to the substrate and laser fluence and resulted in variable particle morphology, particle size distributions and $\mathrm{Fe}$ isotope fractionations, with possible non-stoichiometric sampling of different natural $\mathrm{Fe}$ minerals, including magnetite $\left(\mathrm{Fe}_{3} \mathrm{O}_{4}\right)$, siderite $\left(\mathrm{FeCO}_{3}\right)$, pyrrhotite $\left(\mathrm{Fe}_{4} \mathrm{~S}_{5}\right)$, and pyrite $\left(\mathrm{FeS}_{2}\right)$. In contrast, fs LA $(266 \mathrm{~nm})$ produced more consistent ablation as these dependencies were minimised. It was concluded that fs LA was superior to ns LA because of the more uniform particle size distributions and stoichiometric sampling. The advantages and disadvantages of cold plasma conditions ${ }^{443}$ for Fe isotopic analysis by MC-ICP-MS were evaluated under wet and dry aerosol conditions and different instrument cone configurations. When standard interface cones were in place, changing from a hot to a cold plasma reduced $\mathrm{Fe}$ instrumental mass discrimination but with a high-efficiency jet interface mass discrimination was about the same under both plasma conditions. A cold plasma combined with pneumatic nebulisation (wet plasma) suppressed the spectral interferences ${ }^{40} \mathrm{Ar}^{16} \mathrm{O}^{+}$and ${ }^{40} \mathrm{Ar}^{14} \mathrm{~N}^{+}$but not ${ }^{40} \mathrm{Ar}^{16} \mathrm{O}^{1} \mathrm{H}^{+}$. Analysis of several geological RMs, including USGS PCC-1 (peridotite) and BHVO-2G (basalt) and CRPG IF-G (iron formation), demonstrated that accurate ${ }^{56} \mathrm{Fe} /{ }^{54} \mathrm{Fe}$ measurements could be achieved in low resolution mode using a cold plasma and standard interface.

In an investigation of factors affecting instrumental mass bias when measuring Si stable isotopes by MC-ICP-MS under dry plasma conditions, Oelze et al. ${ }^{444}$ discovered that the addition of $\mathrm{Mg}$ was very beneficial. Not only did the addition of $\mathrm{Mg}$ reduce variations in mass bias but it also increased Si ion intensities. In addition, variations in $\mathrm{Mg}$ and $\mathrm{Si}$ concentrations and $\mathrm{HCl}$ molarity between samples and the bracketing standards were tolerated to a much greater degree without affecting the instrumental mass bias. Two approaches for the 
simultaneous in situ determination of the elemental composition and stable Si isotope ratios of geological samples were evaluated ${ }^{445}$. The first used LASS with MC-ICP-MS and quadrupole ICP-MS detection and the second one employed direct observation of the emission profile of an MC-ICP-MS plasma. A fs LA system provided the sample aerosol to both setups. International geological RMs were used to evaluate both methods, which provided accurate $\delta^{30} \mathrm{Si}$ data with an uncertainty of better than $0.23 \%$ (2SD). The LASS method was considered to be superior for the measurement of element concentrations down to the $\mu \mathrm{g} \mathrm{g}^{-1}$ level because of its higher sensitivity and the ability to determine trace as well as major element concentrations.

Discrepancies in $\delta^{26} \mathrm{Mg}$ data obtained by different laboratories for the San Carlos Olivine prompted a thorough investigation of the homogeneity of this material ${ }^{446}$. Analytical artefacts (e.g. levels of matrix removal, low $\mathrm{Mg}$ yields of column chemistry, mismatch of $\mathrm{Mg}$ concentrations and acid molarity) and changes in $\delta^{26} \mathrm{Mg}$ values of standard solutions during long-term storage were responsible for the differences rather than any heterogeneity in the $\mathrm{Mg}$ isotopic composition of the olivine. The new $\delta^{26} \mathrm{Mg}$ data were homogeneous to within $0.03 \%$ and therefore consistent with the narrow range of $\delta^{26} \mathrm{Mg}$ values of mantle olivine worldwide. Thus it was confirmed that San Carlos Olivine is a suitable RM for Mg isotope analysis.

\subsubsection{Thermal ionisation mass spectrometry}

It is now widely accepted that the accuracy of TIMS measurements can be improved by modifications in the configuration of the detection system. Quemet et al. ${ }^{447}$ demonstrated that the increased sensitivity achieved by using either Faraday cups (FCs) coupled to a $10^{12} \Omega$ resistors, rather than the commonly used $10^{11} \Omega$ resistors, or EMs for ${ }^{235} \mathrm{U}$ and ${ }^{234} \mathrm{U}$ measurements reduced the $\mathrm{U}$ quantity required from $250 \mathrm{ng}$ to $100 \mathrm{ng}$ for ${ }^{235} \mathrm{U} /{ }^{238} \mathrm{U}$ and from $50 \mathrm{ng}$ to $3 \mathrm{ng}$ for ${ }^{234} \mathrm{U} /{ }^{238} \mathrm{U}$. A useful synthesis of the findings from this study provided the range of sample masses for which a target accuracy could be achieved with different detector configurations. Wotzlaw et al. ${ }^{448}$ used $10^{13} \Omega$ resistors to obtain precise and accurate measurement of $U$ abundances in zircons by ID using the $\mathrm{UO}_{2}$ isotopologues at masses 265 , 267, 270 and 272 and with an improved correction for isobaric interferences from minor $\mathrm{UO}_{2}$ isotopologues. The different data collection routines compared included dynamic peak hopping on a secondary EM and static multicollection. Single U-Pb dates were determined with uncertainties of $<0.2 \%$ and the corresponding weighted mean dates with uncertainties of $<0.1 \%$. 
The deterioration of $\mathrm{FCs}^{449}$ caused by strong ion beams is an issue when making highprecision isotope ratio measurements by TIMS. A comparison of the long-term fluctuations and reproducibility of $\mathrm{Nd}$ isotope ratios measurements acquired over 8 months in three different modes (static, dynamic and multistatic) revealed that static methods yielded high-precision data only when all the FCs were relatively new. Data from the multistatic method were more sensitive to deterioration of the FCs than those from the dynamic method, which therefore was most effective in minimising FC degradation. Li et al. ${ }^{450}$ developed a method for Cr isotope ratio measurements based on an improved two-column chemical separation procedure and addition of a highly sensitive $\mathrm{Nb}_{2} \mathrm{O}_{5}$ emitter to enhance the $\mathrm{Cr}$ ionisation efficiency. The 10fold increase in sensitivity provided by the $\mathrm{Nb}_{2} \mathrm{O}_{5}$ emitter allowed the amount of sample on the filament to be reduced from $200 \mathrm{ng}$ to $5 \mathrm{ng}$. In addition, the use of $\mathrm{W}$ filaments instead of the more commonly used Re filaments reduced costs significantly. The isotopic fractionation of Ca during column chemistry followed an exponential law ${ }^{451}$. The more $\mathrm{Ca}$ that was eluted, the lower the $\delta^{44} \mathrm{Ca}^{140} \mathrm{Ca}$ value of the eluate became. Instrumental fractionation deviated from an exponential law when mixing of sample reservoirs on the filaments occurred. A model for checking the behaviour and degree of instrumental fractionation was proposed as a quick check on the TIMS data quality. Fukami et al. ${ }^{452}$ reported an optimised analytical protocol for precise isotope ratio measurements of sub-ng amounts of $\mathrm{Pb}$ by total evaporation TIMS. Parameters examined included different ionisation activators, quantity of activator, width of the sample on the filament, various filament heating regimes and data reduction strategies. The method was suitable for use with a ${ }^{204} \mathrm{~Pb}_{-}{ }^{207} \mathrm{~Pb}$ double spike, which is an advantage for laboratories that have difficulty in sourcing ${ }^{202} \mathrm{~Pb}-{ }^{205} \mathrm{~Pb}$ spike solutions.

Vollstaedt et al. ${ }^{453}$ investigated the potential and limitations of Se isotope ratio measurement with state-of-the-art TIMS instrumentation in static mode. The NTIMS analysis provided better precision than HG-ICP-MS with fewer isobaric interferences, which can be a big drawback in the measurement of Se by ICP-MS, but Se memory effects accumulated during analysis and could not be removed sufficiently by cleaning techniques. This led to the degradation of precision for $\delta^{80} \mathrm{Se} /{ }^{78} \mathrm{Se}$ over time. The authors concluded that if these memory problems could be solved, the accuracy and precision of NTIMS analysis of Se isotope ratios would be superior to those by HG-ICP-MS.

Additional contributions to high-precision isotope ratio determinations by TIMS are included in Table 7. 


\begin{tabular}{|c|c|c|c|c|}
\hline Chromites & $\begin{array}{l}\text { High pressure/temperature acid digestion using an } \\
\text { UltraCLAVE system and a one pass, single column } \\
\text { matrix separation on AG 1-X8 anion-exchange resin. }\end{array}$ & $\begin{array}{l}\text { MC-ICP- } \\
\text { MS }\end{array}$ & $\begin{array}{c}\text { Measurements using } 9 \text { FCs in dynamic mode. } \\
\text { Reproducibility over several months was } 0.11 \% \text { o } \\
\text { (2SD). NIST SRM } 979 \text { (Cr solution) used as } \delta \text { - } \\
\text { zero standard. }\end{array}$ & 28 \\
\hline $\begin{array}{c}\text { Silicate rock } \\
\text { RMs }\end{array}$ & $\begin{array}{l}\text { Li-free glass, prepared from } \mathrm{SiO}_{2}, \mathrm{MgO}, \mathrm{Al}_{2} \mathrm{O}_{3}, \mathrm{CaO} \\
\mathrm{FeO}, \mathrm{TiO}_{2} \text { and } \mathrm{Na}_{2} \mathrm{O} \text { powders, used as a wash } \\
\text { sample. Eight } \mathrm{RMs} \text { and wash sample mounted in } \\
\text { epoxy resin for ablation with } 193 \mathrm{~nm} \text { excimer laser. }\end{array}$ & $\begin{array}{l}\text { LA-ICP- } \\
\text { MS }\end{array}$ & $\begin{array}{l}\text { In situ measurements optimised for signal } \\
\text { intensity and isotope ratio stability. SSB approach } \\
\text { using USGS glass RM BCR-2G (basalt). Li-free } \\
\text { glass ablated as a wash sample to reduce Li } \\
\text { memory effect between each sample. }\end{array}$ & 455 \\
\hline $\begin{array}{l}\text { Iron meteorites } \\
\text { and chondrites }\end{array}$ & 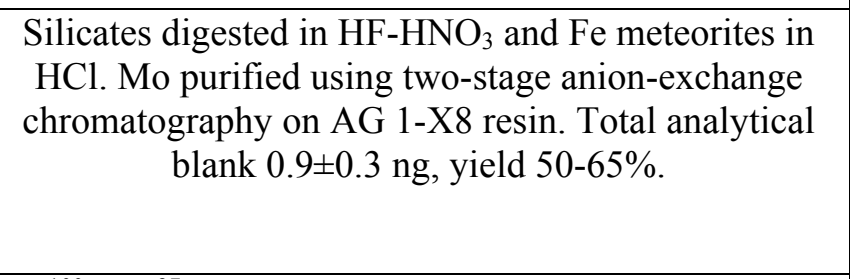 & NTIMS & $\begin{array}{l}\text { Re double filaments with } \mathrm{La}\left(\mathrm{NO}_{3}\right)_{2} \text { added as an } \\
\text { electron emitter. Mo isotopes measured as } \mathrm{MoO}_{3}{ }^{-} \\
\text {on } 9 \mathrm{FCs} \text { in a single line static method. In situ } \\
\text { oxide correction made using }{ }^{100} \mathrm{Mo}^{18} \mathrm{O}^{16} \mathrm{O}_{2}^{-} \text {and } \\
{ }^{92} \mathrm{Mo}^{17} \mathrm{O}^{16} \mathrm{O}_{2}^{-} \text {measured on FCs equipped with } \\
10^{12} \Omega \text { resistors. }\end{array}$ & 456 \\
\hline $\begin{array}{l}\text { Rock RMs and } \\
\text { standard } \\
\text { solutions }\end{array}$ & $\begin{array}{l}{ }^{100} \mathrm{Mo}-{ }^{97} \mathrm{Mo} \text { double-spike added before stepwise } \\
\text { digestion methods according to lithology. } \\
\text { Purification by anion/cation-exchange resin double- } \\
\text { column procedure using AG 1-X8 (100-200 mesh) } \\
\text { and AG 50W-X8 (200-400 mesh). }\end{array}$ & $\begin{array}{c}\text { MC-ICP- } \\
\text { MS }\end{array}$ & $\begin{array}{l}\text { SSB and }{ }^{100} \mathrm{Mo}^{-97}{ }^{97} \text { Mo double-spike methods of } \\
\text { correcting for mass fractionation compared. } \\
\text { Results consistent, within error, but double spike } \\
\text { method preferred for samples with }<0.5 \mu \mathrm{g} \mathrm{g}^{-1} \\
\text { Mo. Analytical precision better than } \pm 0.04 \% \text { o } \\
\mathrm{amu}^{-1} \text { for } 10^{1} \text { to } 10^{3} \mathrm{ng} \mathrm{g}^{-1} \mathrm{Mo} \text {. }\end{array}$ & 457 \\
\hline $\begin{array}{l}\text { Rock RMs and } \\
\text { synthetic Nd } \\
\text { RMs }\end{array}$ & $\begin{array}{c}\text { Rock powders digested with HF-HNO }{ }_{3} \text {; final } \\
\text { solution in HCl. } 4 \text { column separation of Nd using: (a) } \\
\text { AG 50W-X8 200-400 mesh resin (b) Ln-spec 50- } \\
100 \mathrm{~mm} \text { resin, (c) Ln-spec } 25-50 \mathrm{~mm} \text { resin, (d) AG } \\
50 \mathrm{~W}-\mathrm{X} 8 \text { 200-400 mesh resin. Nd recovery was } \\
>99 \% .\end{array}$ & $\begin{array}{c}\text { MC-ICP- } \\
\text { MS }\end{array}$ & $\begin{array}{l}\text { Nd isotopes measured in static low-resolution } \\
\text { mode with FCs with } 10^{11} \Omega \text { resistors; }{ }^{140} \mathrm{Ce} \text { and } \\
{ }^{147} \mathrm{Sm} \text { monitored using FCs with } 10^{12} \Omega \text { resistors } \\
\text { to correct for isobaric interferences. SBB } \\
\text { approach using GSJ RM JNdi-1 (Nd oxide). }\end{array}$ & 458 \\
\hline
\end{tabular}




\begin{tabular}{|c|c|c|c|c|}
\hline Iron meteorites & $\begin{array}{l}\text { After leaching in } \mathrm{HCl} \text {, samples dissolved in } \mathrm{HNO}_{3^{-}} \\
\mathrm{HCl} \text {. Pd purified in a two column anion-exchange } \\
\text { procedure using AG 1-X8 resin, with an intermediate } \\
\text { evaporation step, to remove } \mathrm{Ru} \text {, before loading onto } \\
\text { the second anion-exchange column. Total yield from } \\
\text { both columns was generally }>50 \% \text {. Procedural blanks } \\
\text { were }<1.2 \mathrm{ng} \mathrm{g}^{-1} \mathrm{Pd} \text {. }\end{array}$ & $\begin{array}{c}\text { MC-ICP- } \\
\text { MS }\end{array}$ & $\begin{array}{c}\text { All Pd isotopes measured simultaneously on FCs } \\
\text { fitted with } 10^{11} \Omega \text { resistors, while also monitoring } \\
{ }^{101} \mathrm{Ru} \text { and }{ }^{111} \mathrm{Cd} \text { on FCs with } 10^{12} \Omega \text { resistors. } \\
\text { Instrumental mass fractionation correction via } \\
\mathrm{SSB} \text {. External reproducibility (2SD) was } 1.29 \text { for } \\
\varepsilon^{102} \mathrm{Pd}, 0.22 \text { for } \varepsilon^{104} \mathrm{Pd}, 0.11 \text { for } \varepsilon^{106} \mathrm{Pd} \text { and } 0.27 \\
\text { for } \varepsilon^{110} \mathrm{Pd} \text {. }\end{array}$ & 459 \\
\hline $\begin{array}{l}\text { Iron meteorites } \\
\text { and chondritic } \\
\text { metal }\end{array}$ & $\begin{array}{l}\text { Dissolution in reverse aqua regia }\left(3+1 \mathrm{HNO}_{3} \text { and }\right. \\
\mathrm{HCl}) \text {. After Os extraction using solvent extraction } \\
\text { with } \mathrm{CCl}_{4} \text {, Re purified in } 2 \text { column procedure using } \\
\text { cation-exchange resin AG } 50 \mathrm{~W}-\mathrm{X} 8 \text { followed by } \\
\text { anion-exchange on AG 1-X8 resin. Final solutions } \\
\text { spiked with NIST SRM } 3163 \text { (W standard). }\end{array}$ & $\begin{array}{l}\text { MC-ICP- } \\
\text { MS }\end{array}$ & $\begin{array}{l}\text { All Re isotopic ratios measured on an instrument } \\
\text { equipped with } 9 \text { FCs and } 10^{11} \Omega \text { resistors. Mass } \\
\text { fractionation corrected by normalising to } \\
{ }^{186} \mathrm{~W} /{ }^{184} \mathrm{~W}=0.927672 \text { using the exponential law. } \\
\text { Precision of } \delta^{187} \mathrm{Re} \text { values was } \pm 0.02 \% \text { ( } 2 \mathrm{SE} \text { ). }\end{array}$ & 460 \\
\hline $\begin{array}{l}\text { Chromitites, Os- } \\
\text { Ir-Ru alloy } \\
\text { grains and } \\
\text { meteorites }\end{array}$ & $\begin{array}{l}\text { Chromitites and Os-Ir-Ru alloys digested by the } \\
\text { Carius tube technique, meteorite digested with } \mathrm{HCl} \text {. } \\
\text { Purification using a two-step column chemistry with } \\
\text { AG 50W-X8 cation-exchange resin and AG 1-X8 } \\
\text { anion-exchange resin. Ru further purified by } \\
\text { microdistillation. }\end{array}$ & NTIMS & $\begin{array}{l}\text { Samples loaded onto single Pt filaments and } \\
\text { coated with activator solution of } \mathrm{NaOH}-\mathrm{Ba}(\mathrm{OH})_{2} \text {. } \\
\mathrm{Ru} \text { isotopes measured as trioxides }\left(\mathrm{RuO}^{3-}\right) \text { in a } \\
\text { static method on } 7 \mathrm{FCs} \text {. Corrections for possible } \\
\text { interferences from } \mathrm{Ba} \text {, Mo, } \mathrm{Pd} \text { and } \mathrm{Zr} \text { were not } \\
\text { necessary. External reproducibility for } \\
{ }^{100} \mathrm{Ru} /{ }^{101} \mathrm{Ru} \pm 6.4 \text { ppm }(2 \mathrm{SD})\end{array}$ & 461 \\
\hline $\begin{array}{l}\text { Geological RMs, } \\
\text { chromitites }\end{array}$ & $\begin{array}{l}{ }^{98} \mathrm{Ru}-{ }^{101} \mathrm{Ru} \text { double spike added prior to sample } \\
\text { digestion in Carius tubes. Purification of Ru by } \\
\text { cation-chromatography on AG } 50 \mathrm{~W}-\mathrm{X} 8 \text { resin } \\
\text { followed by distillation of } \mathrm{Ru} \text { as volatile oxides. } \\
\text { Total recovery of } \mathrm{Ru} \text { from column chemistry was } \\
>95 \% \text {.Total procedural blank was } 41 \pm 17 \mathrm{pg} \mathrm{Ru} \\
\text { (1SD). }\end{array}$ & $\begin{array}{l}\text { MC-ICP- } \\
\text { MS }\end{array}$ & $\begin{array}{l}\text { Addition of } \mathrm{N}_{2} \text { to the sample gases minimised } \\
\text { oxide formation. Simultaneous collection in a } \\
\text { single cycle using FCs connected to amplifers } \\
\text { with } 10^{11} \Omega \text { resistors for } \mathrm{Ru} \text { isotopes and } 10^{12} \Omega \\
\text { resistors for Mo and Pd isotopes. External } \\
\text { reproducibility of } 0.05 \% \text { for } \delta^{102} \mathrm{Ru} /{ }^{99} \mathrm{Ru}(2 \mathrm{SD}) \text {. }\end{array}$ & 462 \\
\hline Solid RMs & $\begin{array}{l}\text { Isotopic RMs IAEA-S-1 (solid } \mathrm{Ag}_{2} \mathrm{~S} \text { ), IAEA-S-2 } \\
\text { (solid } \mathrm{Ag}_{2} \mathrm{~S} \text { ) and IAEA-S-4 (pure } \mathrm{S} \text { ) dissolved by } \\
\text { microwave-assisted digestion in } \mathrm{HNO}_{3} \text { and } \mathrm{H}_{2} \mathrm{O}_{2} \text {. }\end{array}$ & $\begin{array}{l}\text { SF-ICP- } \\
\text { MS, Q-ICP- } \\
\text { MS, ICP- } \\
\text { MS/MS, } \\
\text { MC-ICP- } \\
\text { MS }\end{array}$ & $\begin{array}{l}\text { Evaluation of }{ }^{34} \mathrm{~S} /{ }^{32} \mathrm{~S} \text { measurements on different } \\
\text { single collector ICP-MS instruments and by MC- } \\
\text { ICP-MS using different instrumental isotopic } \\
\text { fractionation corrections. Combined uncertainties } \\
0.3-0.5 \% \text { for Q-ICP-MS, } 0.08 \% \text { for SF-ICP-MS, } \\
0.26 \% \text { for ICP-MS/MS and } 0.02 \% \text { for MC-ICP- } \\
\text { MS in edge mass resolution mode. }\end{array}$ & 463 \\
\hline
\end{tabular}




\begin{tabular}{|c|c|c|c|c|}
\hline Pyrite & $\begin{array}{c}\text { Pyrite and silver sulfide RMs were embedded } \\
\text { separately in epoxy resin on glass slides and polished } \\
\text { to obtain flat surfaces. }\end{array}$ & $\begin{array}{l}\text { LA-MC- } \\
\text { ICP-MS }\end{array}$ & $\begin{array}{l}\text { Study of S isotope fractionation behaviour in } \\
\text { pyrite during LA with } 193 \mathrm{~nm} \text { ArF excimer } \\
\text { system. SEM and TEM used to characterise } \\
\text { debris formed during LA. SSB approach with } \\
\text { matrix-matched pyrite RM recommended with } \\
\text { high raster velocity to reduce fractionation. }\end{array}$ & 464 \\
\hline $\begin{array}{l}\text { Igneous and } \\
\text { sedimentary } \\
\text { rocks }\end{array}$ & $\begin{array}{c}\text { Silicate rocks decomposed with } \mathrm{HF}-\mathrm{HClO}_{4}-\mathrm{HNO}_{3} \text {, } \\
\text { dolomitic sample leached with } 6 \mathrm{M} \mathrm{HCl} \text {. Separation } \\
\text { of Sm from other REEs achieved by four-step cation- } \\
\text { exchange column chromatography procedure using } \\
\text { AG 50W-X8 resin. Sm yield }>97 \% \text {, total chemical } \\
\text { blank of } \mathrm{Sm}<20 \mathrm{pg} \text {. }\end{array}$ & TIMS & $\begin{array}{l}\text { Comparison of unspiked and samples spiked } \\
\text { with }{ }^{150} \mathrm{Sm}-{ }^{154} \mathrm{Sm} \text {. Samples loaded on Re triple } \\
\text { filaments together with } 0.5 \mu \text { of } 2 \mathrm{M} \mathrm{H}_{3} \mathrm{PO}_{4} \text {. } \\
\text { Isobaric interferences of } \mathrm{Nd}^{+} \text {on }{ }^{144} \mathrm{Sm},{ }^{148} \mathrm{Sm} \text {, and } \\
{ }^{150} \mathrm{Sm} \text { corrected using the Nd natural isotope } \\
\text { ratios. Interference of } \mathrm{Gd}^{+} \text {on }{ }^{152} \mathrm{Sm} \text { and }{ }^{154} \mathrm{Sm} \\
\text { was negligible. }\end{array}$ & 465 \\
\hline Cassiterite & $\begin{array}{l}\text { Cassiterite powders mixed with } \mathrm{KCN} \text { and reduced in } \\
\text { a muffle furnace at } 900{ }^{\circ} \mathrm{C} \text {. One half of the } \mathrm{Sn} \text { beads } \\
\text { produced was dissolved in } \mathrm{HCl} \text {, diluted and spiked } \\
\text { with } \mathrm{Sb} \text {. The other half was embedded in epoxy resin } \\
\text { for LA. }\end{array}$ & $\begin{array}{l}\text { MC-ICP- } \\
\text { MS, fs LA- } \\
\text { MC-ICP- } \\
\quad \text { MS }\end{array}$ & $\begin{array}{l}\text { Comparison of Sn isotope ratios measured by } \\
\text { solution and fs LA MC-ICP-MS. In-house RMs } \\
\text { defined for SSB, with a pure Sn rod used as the } \\
\text { bracketing standard for LA and an Sb solution for } \\
\text { mass bias correction. }\end{array}$ & 466 \\
\hline $\begin{array}{l}\text { Standard } \\
\text { solutions }\end{array}$ & $\begin{array}{l}\text { Ta standard solution prepared from high purity Ta } \\
\text { metal purchased from the Ames laboratory, USA. Ta } \\
\text { metal and commercially-available standard solutions } \\
\text { were used throughout this study. }\end{array}$ & $\begin{array}{c}\text { MC-ICP- } \\
\text { MS }\end{array}$ & $\begin{array}{l}\text { Comparison of data from two different collector } \\
\text { setups ,involving FCs with } 10^{10} \Omega, 10^{11} \Omega, 10^{12} \Omega \text {, } \\
\text { and } 10^{13} \Omega \text { resistors in different combinations. } \\
\text { External mass bias correction using Yb spiked } \\
\text { into Ta solutions. Isobaric interferences } \\
\text { corrections based on }{ }^{180} \mathrm{Hf} /{ }^{178} \mathrm{Hf}=1.2863 \text { and } \\
{ }^{180} \mathrm{~W} /{ }^{183} \mathrm{~W}=0.008304 \text {. External reproducibility } \\
\text { was } \pm 4 \varepsilon \text { for }{ }^{180} \mathrm{Ta} /{ }^{181} \mathrm{Ta} \text { (2SD). }\end{array}$ & 467 \\
\hline $\begin{array}{l}\text { Ca-Al-rich } \\
\text { inclusions in } \\
\text { Allende CV3 } \\
\text { chondrite }\end{array}$ & $\begin{array}{l}\text { Synthetic glass RMs were prepared from } \mathrm{Ca}-\mathrm{Mg}- \\
\text { Al-Si oxides to mimic composition of Ti-Al rich } \\
\text { pyroxene commonly found in Ca-Al-rich inclusions } \\
\text { in chrondites. Glass then powdered and doped with } \\
\text { varying amounts of pure oxide powders of } \mathrm{Ca}, \mathrm{Cr} \text { and } \\
\text { V, before re-melting and quenching to produce } \\
\text { glasses for correction of potential isobaric } \\
\text { interferences and matrix effects. These were mounted } \\
\text { with an undoped glass in epoxy and polished. }\end{array}$ & $\begin{array}{l}\text { LA-MC- } \\
\text { ICP-MS }\end{array}$ & $\begin{array}{l}\text { Measurements by MC-ICP-MS in medium } \\
\text { resolution in multi-dynamic mode on } \mathrm{FCs} \text { in two } \\
\text { peak jumping steps. Correction of instrumental } \\
\text { and natural mass-dependent fractionation using } \\
\mathrm{SSB} \text { and internal normalisation to }{ }^{49} \mathrm{Ti} /{ }^{47} \mathrm{Ti}= \\
0.749766 \text {. Isobaric interferences from } \mathrm{Ca}, \mathrm{Cr} \text { and } \\
\text { V corrected using the synthetic glasses. External } \\
\text { reproducibility (2SD) was } \pm 0.4, \pm 0.5 \text { and } \pm 1.8 \text { for } \\
\varepsilon^{46} \mathrm{Ti}, \varepsilon^{48} \mathrm{Ti} \text { and } \varepsilon^{50} \mathrm{Ti} \text {, respectively. }\end{array}$ & 468 \\
\hline
\end{tabular}




\begin{tabular}{|c|c|c|c|c|}
\hline $\begin{array}{l}\text { V-rich minerals } \\
\text { and basalt RMs }\end{array}$ & $\begin{array}{l}\text { (a) For in situ analyses, samples mounted in epoxy in } \\
\text { separate holding rings. (b) For solution MC-ICP-MS, } \\
\text { various digestion schemes depending on starting } \\
\text { material. After drying, all samples were treated with } \\
\mathrm{HCl} \text {. Three column purification to remove, stepwise, } \\
\text { Fe, Ti+Zr+Hf, and then the remaining matrix } \\
\text { elements. }\end{array}$ & $\begin{array}{c}\text { fs LA-MC- } \\
\text { ICP-MS, } \\
\text { MC-ICP- } \\
\text { MS }\end{array}$ & $\begin{array}{l}\text { In situ analyses of stable V isotopes using a } 194 \\
\mathrm{~nm} \text { fs LA system. Solution of Fe standard IRMM- } \\
014 \text { aspirated into ablation aerosol for } \\
\text { instrumental mass bias monitoring by measuring } \\
{ }^{57} \mathrm{Fe} /{ }^{56} \mathrm{Fe} ; \delta^{51} \mathrm{~V} \text { values determined relative to } \mathrm{V} \\
\text { metal via SSB. LA and solution data agreed well } \\
\text { with each other, typically within } 0.1 \% \text { units. } \\
\text { Average precision of } 0.1 \% \text {. }(2 \mathrm{SD}) \text { for } \delta^{51} \mathrm{~V} \text { for } \\
\text { solution MC-ICP-MS and }<0.33 \% \text { (2SD) by fs } \\
\text { LA-MC-ICP-MS. }\end{array}$ & 469 \\
\hline $\begin{array}{l}\text { W solutions and } \\
\text { iron meteorites }\end{array}$ & $\begin{array}{l}\text { Commercial W standard solutions measured without } \\
\text { any pretreatment. Method said to be applicable to } \\
\text { analysis of iron meteorites but no details given. }\end{array}$ & NTIMS & $\begin{array}{c}\text { Solutions loaded onto single Re filaments with } \\
\text { activator solution containing } 5 \mu \mathrm{g} \text { of La and } \mathrm{Gd} \text { in } \\
5 \% \mathrm{HNO}_{3} \text {. Oxide corrections made using } \\
{ }^{86} \mathrm{~W}^{16} \mathrm{O}_{2}{ }^{18} \mathrm{O}^{-} \text {and }{ }^{187} \mathrm{Re}^{16} \mathrm{O}_{2}{ }^{18} \mathrm{O}^{-} \text {measured on } 2 \\
\mathrm{FCs} \text { equipped with } 10^{12} \Omega \text { resistors. Long-term } \\
\text { reproducibilities (2SD) for }{ }^{182} \mathrm{~W} /{ }^{184} \mathrm{~W} \text { and } \\
{ }^{183} \mathrm{~W} /{ }^{184} \mathrm{~W} \text { better than } 5.7 \text { ppm and } 6.6 \mathrm{ppm} \text {, } \\
\text { respectively. }\end{array}$ & 470 \\
\hline Metal alloys & $\begin{array}{l}\text { NIST SRM 129c (Fe-Ni steel) digested in } \mathrm{HNO}_{3-} \\
\mathrm{HCl} \text {, dried and fluxed in concentrated } \mathrm{HCl} \text {, dried and } \\
\text { redesolved in } \mathrm{HCl}-\mathrm{HF} \text {. Purification of } \mathrm{W} \text { two-column } \\
\text { procedure using AG } 1-\mathrm{X} 8 \text { anion-exchange resin. } \\
\text { Total chemical yields } 60-80 \% \text {, full procedural blank } \\
0.26 \pm 0.15 \mathrm{ng} \text {. }\end{array}$ & $\begin{array}{l}\text { MC-ICP- } \\
\text { MS }\end{array}$ & $\begin{array}{l}{ }^{178} \mathrm{Hf},{ }^{181} \mathrm{Ta} \text { and }{ }^{188} \mathrm{Os} \text { monitored to correct } \\
\text { isobaric interferences on }{ }^{180} \mathrm{~W},{ }^{184} \mathrm{~W} \text { and }{ }^{186} \mathrm{~W} \text {. } \\
\text { Instrumental mass bias corrected via SSB with } \\
\text { NIST SRM } 3163 \text { (W solution). External } \\
\text { reproducibility (2SD) for } \varepsilon^{180} \mathrm{~W} \text { was } \pm 0.49 \text { and } \\
\pm 0.48 \text { using }{ }^{186} \mathrm{~W} /{ }^{184} \mathrm{~W} \text { and }{ }^{186} \mathrm{~W} /{ }^{183} \mathrm{~W} \text {, } \\
\text { respectively, better by a factor of } c a .2 .4 \\
\text { compared to previous studies. External precisions } \\
\text { (2SD) for other W isotope ratios }< \pm 0.08 \text {. }\end{array}$ & 471 \\
\hline
\end{tabular}




\subsubsection{Secondary ion mass spectrometry}

Trace element measurements were performed ${ }^{472}$ across the interface of synthetic zircons and their co-existing silicate melt by nanoSIMS to determine zircon/melt partition coefficients. Because of heterogeneities in zircon's chemical composition at the sub- $\mu \mathrm{m}$ to $\mu \mathrm{m}$ scale, an analytical technique with very high spatial resolution, such as nanoSIMS, was required. Results for $\mathrm{Ce}, \mathrm{Ho}, \mathrm{Lu}, \mathrm{P}, \mathrm{Sm}$, Ti and Y indicated a much smaller variation in zircon/melt partition coefficients than previously published. This was thought to be due to the lower spatial resolution of the analytical techniques used previously, which were unable to resolve zones of variable elemental composition within the zircon grain. The nanoSIMS methodology was also applicable to the determination of elemental distributions in other zoned minerals. Nitrogen was determined in melt inclusions in silicate glasses ${ }^{473}$ by SIMS to obtain information on the release of volatile elements through volcanic eruptions. A novel aspect of this procedure was the use of ion implants of basaltic and rhyolitic glasses for $\mathrm{N}$ calibrations. The water content in the inclusions significantly affected the ion yields of ${ }^{14} \mathrm{~N}^{+}$and ${ }^{14} \mathrm{~N}^{16} \mathrm{O}^{-}$as well as the background intensities of ${ }^{12} \mathrm{C}^{+}$and ${ }^{14} \mathrm{~N}^{+}$. In the application of Ti-in-zircon thermometry to very old zircons $^{474}$, higher Ti values were obtained when using LA-ICP-MS than when using SIMS. Plots of the Ti/Zr intensity ratio against time or depth showed an increase in the ratio with depth for these zircons, suggesting that the elevated $\mathrm{Ti}$ contents were an artefact of downhole fractionation in LA-ICP-MS.

The relative sensitivity factors ( $R S F S$ ) of REEs determined in the nanoSIMS analysis of zircon, apatite and NIST SRM 610 (trace elements in glass) varied ${ }^{475}$ considerably so it was concluded that absolute concentrations of REEs could only be determined using calibrations based on matrix-matched RMs. Steele et al. ${ }^{476}$ highlighted the difficulty in making accurate $\mathrm{Cr} / \mathrm{Mn}$ measurements in carbonate minerals by SIMS because of matrix effects. The $\mathrm{Cr} / \mathrm{Mn}$ RSFs for a range of carbonate phases implanted with $\mathrm{Cr}$ varied systematically with the chemical composition of the different carbonate minerals. An empirical correction scheme was therefore proposed.

The increasing importance of stable isotope analysis by SIMS is reflected in the number of newly-developed isotope RMs for SIMS analysis. Such RMs are vital because matrixmatched calibrations are essential for this technique. In addition to zircon M127- ${ }^{333}$ (see section 4.1), gem-quality apatites were evaluated as potential oxygen RMs ${ }^{477}$. A suite of carbonate RMs was developed for the calibration of oxygen and carbon isotope measurements ${ }^{478,479}$. Two quartz samples, UNIL-Q1 (Torres del Paine Intrusion, Chile) and BGI-Q1 (Shandong province, China), previously characterised as RMs for trace element 
analysis by Audetat et al. ${ }^{480}$, were proposed ${ }^{481}$ as suitable RMs for SIMS analysis. The SIMS measurement precisions were $<0.41 \%$ (2SD) for UNIL-Q1 and $<0.48 \%$ ( $2 \mathrm{SD}$ ) for BGI-Q1. Reference $\delta^{18} \mathrm{O}$ values were determined by $\mathrm{CO}_{2}$ laser fluorination. Monazite RMs are scarce. Three monazites $^{482}$, from Brazil, Madagascar and Namibia, were considered to be potential $\mathrm{RMs}$ for $\mathrm{O}$ isotope analysis because of their homogeneous chemical and oxygen isotope composition. Uncertainties for the SIMS measurements were in the range of 0.3 to $0.4 \%$ (2SD); $\delta^{18} \mathrm{O}$ values by laser fluorination were also available. To widen the applicability of SIMS oxygen isotope analysis to solid solution minerals, the homogeneity of two new pyroxene RMs (augite NRM-AG-1 and enstatite NRM-EN-2) was evaluated ${ }^{483}$. As these materials showed no bias caused by crystallographic orientation and were homogeneous at a scale of $20 \mu \mathrm{m}$, they were considered to be suitable RMs for SIMS $\delta^{18} \mathrm{O}$ analysis.

Instrumental mass fractionation (IMF) during the measurement of stable isotopes by SIMS occurs at several stages of the analysis and is strongly influenced by the major element composition of the target material. To correct for these matrix effects, Fabrega et al. ${ }^{484}$ developed a predictive surface response methodology, based on multivariate statistics, and applied it to the measurement of $\delta^{18} \mathrm{O}$ in plagioclase, K-feldspar and quartz. The great advantage of SIMS for research into carbon sequestration is its ability to analyse very small sample volumes. For example, in situ $\delta^{13} \mathrm{C}$ and $\delta^{18} \mathrm{O}$ measurements could be made ${ }^{485}$ on single carbonate crystallites as small as 3-10 $\mu \mathrm{m}$ in width with sub per-mil (\%o) precision and accuracy. The study focused on characterising the mineralogy and isotopic fingerprinting of underground rock formations prior to $\mathrm{CO}_{2}$-injection and made predictions regarding the $\delta^{13} \mathrm{C}$ values of carbonate mineral cements that may form in response to long-term storage of $\mathrm{CO}_{2}$. The oxygen isotope composition of coal and kerogen samples ${ }^{486}$ was determined by SIMS on organic matter residues isolated from a quartz matrix. The procedure included a method of filtering out $\delta^{18} \mathrm{O}$ data from the oxygen-bearing micro-inclusions of various mineral phases present in the impure OM. In order to constrain the effect of $\delta^{37} \mathrm{Cl}$ values derived from primary magmas, olivine-hosted melt inclusions were targeted for $\mathrm{Cl}$ isotope analyses. Data from different volcanic arc settings were obtained ${ }^{487}$ using an experimental setup designed specifically for the analysis of glasses containing $>900 \mu \mathrm{g} \mathrm{g}^{-1} \mathrm{Cl}$. Two FCs were used instead of an EM to improve the measurement precision; total uncertainties were $0.4 \%$ (2SD). Observed variations in instrumental mass fractionation were mainly caused by the presence of $\mathrm{Al}_{2} \mathrm{O}_{3}, \mathrm{~K}_{2} \mathrm{O}$ and $\mathrm{SiO}_{2}$.

Sharpe and Fayek $^{488}$ demonstrated that the mass bias for $U-P b$ isotope ratio measurements in uraninite increased with increasing $\mathrm{Pb}$ content. A three-point calibration 
curve, based on uraninite $\mathrm{RMs}$ with different $\mathrm{Pb}$ concentrations, facilitated the accurate determination of $\mathrm{U}-\mathrm{Pb}$ ratios. Alternatively, mass bias correction could be achieved by using a uraninite $\mathrm{RM}$ with a $\mathrm{Pb}$ content similar to that of the unknown samples. Bastnaesite is a major economic REE mineral in which the incorporation of Th is favoured relative to that of $U$. A comparison of ages gained by $\mathrm{U}-\mathrm{Pb}$ dating of zircons and $\mathrm{Th}-\mathrm{Pb}$ dating of bastnaesite provided $^{489}$ information on intrusion of the host magma and the mineralisation ages of REE deposits in the Himalayan Mianning-Dechang REE belt. Monazite RW-1 was characterised ${ }^{490}$ as a RM for SIMS U-Pb and Th-Pb isotope analyses.

A novel SIMS scanning ion-imaging technique was developed ${ }^{491}$ to investigate $\mu \mathrm{m}$ scale $\mathrm{U}-\mathrm{Pb}$ systematics in a lunar zircon with a complex internal structure. The spatial resolution was improved by a factor of four compared to traditional SIMS analyses, facilitating the analysis of features of the zircon that could not be accessed by traditional SIMS methodology.

\subsubsection{Other mass spectrometric techniques}

A contribution ${ }^{492}$ on halogen determination by noble gas mass spectrometry of terrestrial and extraterrestrial materials provided detailed information on analytical protocols and data reduction procedures. The use of RMs to determine halogen abundances was preferred to direct calculation based on neutron flux determinations. Recommendations on the most suitable RMs were given.

A novel approach for measuring ${ }^{14} \mathrm{C}$, using a combination of LA sampling with accelerator mass spectrometry (AMS), provided flexible and time-resolved acquisition of ${ }^{14} \mathrm{C}$ profiles in carbonates ${ }^{493}$. The considerable advantages over conventional gas measurements offered by the LA-AMS technique included the speed of analysis (because no time-consuming sample preparation was required), low sample consumption and higher spatial resolution. Depending on the measurement mode, typical precisions of $1-5 \%$ combined with a spatial resolution of $100 \mu \mathrm{m}$ were obtained for speleothems and a variety of terrestrial and marine carbonates.

A new resonance ionisation mass spectrometer ${ }^{494}$, known as the Chicago instrument for laser ionisation (CHILI), was developed specifically to measure isotopic ratios in small samples such as interstellar dust at high spatial resolution and high sensitivity. This RIMS instrument was capable of determining all the stable isotopes of Fe and Ni simultaneously in presolar $\mathrm{SiC}$ grains when a special timing scheme for the ionisation lasers was used to separate 
the Fe and Ni isotopes in the TOF spectrum. The lateral resolution was $0.8 \mu \mathrm{m}$ : the ultimate goal was to achieve $10 \mathrm{~nm}$ resolution with $30-40 \%$ useful yield.

Two studies applied isotope ratio mass spectrometry (IRMS) to the determination of clumped isotopes in carbonates. Schauer et al. ${ }^{495}$ showed that the choice of ${ }^{17} \mathrm{O}$ correction strategy could have a large effect on the accuracy of $\Delta 47$ values. Differences as large as $0.1 \%$ obtained in an inter-laboratory comparison were thought to have their origins in the ${ }^{17} \mathrm{O}$ correction strategies applied. Wang et al. ${ }^{496}$ systematically evaluated the effectiveness of a Porapak ${ }^{\mathrm{TM}} \mathrm{Q}$ absorbent trap (PQT) for purifying $\mathrm{CO}_{2}$. Comparison of the $\Delta_{47}$ values obtained from different experiments showed that a setup with $\mathrm{CO}_{2}$ passing through the PQT driven by liquid $\mathrm{N}_{2}$ and high vacuum pumping gave the most promising results, because it saved time without compromising the extraction efficiency. An elemental analyser (EA) equipped with purge-and-trap technology and interfaced to an IRMS instrument was used to perform highprecision $\mathrm{S}$ isotope measurements in bioapatite ${ }^{497}$. These determinations are normally limited by the low $\mathrm{S}$ content of such samples but results from this study demonstrated the capacity of this analytical methodology to discriminate between marine, freshwater and terrestrial environments based on $\delta^{34} \mathrm{~S}$ values from modern and fossil vertebrate bioapatite containing as little as $0.14-1.19 \mathrm{wt} \% \mathrm{~S}$. This methodology has potential for characterising the living environment of an extinct vertebrate purely from its fossilised bones and teeth. The redox conditions for the extraction of $\mathrm{N}$ from an organic-rich RM prior to measurement by EA IRMS were investigated as these were known to affect the accuracy and precision of $\delta^{15} \mathrm{~N}$ data ${ }^{498}$. Injection of more than $20 \mathrm{~mL} \mathrm{O}_{2}$ into the reaction tube resulted in improved combustion and better $\mathrm{N}$-yields than when $\mathrm{CuO}$ or $\mathrm{V}_{2} \mathrm{O}_{5}$ was added.

The ultimate aim of Hoegg et al. ${ }^{499}$ in combining a liquid sampling-atmospheric pressure glow discharge ( $L S$-APGD) microplasma ion source with an Orbitrap mass analyser was to produce an IRMS instrument capable of being deployed in the field. Their current system had minimal mass bias for ${ }^{235} \mathrm{U} /{ }^{238} \mathrm{U}$, better than that obtained with beam-type mass analysers, and a dynamic range of 4 orders of magnitude. The precision obtained with this system ${ }^{500}$ was $c a .0 .1 \%$ RSD for $\mathrm{U}$ isotope ratio measurements but poorer (1-3\% RSD) for low abundance species.

\subsubsection{X-ray spectrometry}

4.3.8.1 Laboratory-based XRFS An uncommon but elegant method to quantify sulfur species by $W D X R F S$, utilising satellite intensities, has recently experienced a revival for ore deposit research. Following the use of about 100 synthetic samples with different concentration ratios 
of sulfides and sulfates to test two alternative WDXRFS strategies ${ }^{501}$, the peak height approach was recommended to determine sulfate/sulfide ratios quantitatively. Similarly, sulfide ore samples prepared as pressed powder pellets were analysed using the ratios of K-series line intensities for quantification ${ }^{502,503}$.

Younis et al. ${ }^{504}$ used only two RMs to establish WDXRFS calibrations for elements of interest. The dilution factor in a fusion bead technique was varied to generate a wide range of concentrations from each RM. Calibration lines for major elements, including $\mathrm{Al}, \mathrm{Ca}, \mathrm{Fe}, \mathrm{Mg}$, $\mathrm{Mn}, \mathrm{Na}, \mathrm{Si}$ and $\mathrm{Ti}$, were constructed from fused beads which had $\mathrm{Li}_{2} \mathrm{~B}_{4} \mathrm{O}_{7}$ flux : sample ratios of 2 to 54. As a result, RMs with matrices similar to those of the samples to be analysed could be selected. This approach was validated by analysing several USGS geological RMs with different matrices.

Elemental variations in drill cores can be assessed by the fast and nondestructive technique XRFS core-scanning. Six GSJ geological RMs were analysed to determine the influence of exposure times and choice of X-ray tube ${ }^{505}$. Increasing the counting time had only a minor effect on the accuracy of measurements. Thus, caution was required when interpreting data for elements present at low concentrations or low sensitivities, e.g. Al, even when the counting times were long and scanning counts reasonably high. Based on linear regression lines and correlation coefficients of 17 elements with different exposure times and X-ray tubes, the use of a Mo X-ray tube rather than a $\mathrm{Cr}$ one was recommended for all XRFS-scanning experiments. Interstitial water can give rise to serious matrix effects during XRFS corescanning so a new polynomial correction for water content was implemented ${ }^{506}$ for two existing calibration methods. This removed the influence of changes in water content in long sediment sequences.

Combining optical imaging and XRFS analysis had $^{507}$ the aim of determining whether images of rock surfaces could be used to predict the elements present in a sample. The ultimate goal would be the remote characterisation of inaccessible underground mine voids. The machine learning algorithm developed was able to predict the elemental composition with a high degree of accuracy. However, the success of this approach was likely to depend on the suite of minerals present and the ability of expert geologists to identify minerals through visual inspection.

4.3.8.2 Portable XRFS Portable XRFS instruments have revolutionised the lives of exploration geochemists over the last few years. Therefore it is disappointing that a review paper ${ }^{508}$ on handheld XRFS technology (admittedly written by space scientists) referenced none of the 
recent thorough examinations of such instrumentation by practicing geochemists. Fortunately previous ASUs, e.g. the Environmental ${ }^{1}$ and $\mathrm{XRFS}^{5} \mathrm{Updates}$ provide better coverage. Another deficiency of the review was that most of the rocks tested were fine-grained basaltic rocks. Key factors affecting data quality were correctly identified as the calibration protocols employed and the degree of sample preparation. Similar conclusions were made in a study ${ }^{509}$ on the use of pXRFS instruments for mapping lithological units and areas of hydrothermal alteration in New Zealand. Results from pXRFS analyses of untreated geothermal drill cuttings were compared with laboratory XRFS data. Steiner et al. ${ }^{510}$ demonstrated that the current generation of pXRFS instruments can yield accurate data as long as great attention is paid to the method of calibration. They developed material-specific calibrations for the determination of major, minor and trace elements in a range of geological materials using minimal sample preparation. A research group in Canada ${ }^{511}$ compared portable XRFS data with those obtained using INAA, ICP-MS and EPMA to evaluate the overall suitability of pXRFS for provenance studies on obsidian stone tools. Whereas trace element concentrations for $\mathrm{Rb}, \mathrm{Sr}$ and $\mathrm{Zr}$ were in good agreement with INAA and ICP-MS data, there was poorer agreement for Ga, $\mathrm{Mn}$ and $\mathrm{Zn}$ concentrations determined by $\mathrm{pXRFS}$.

Portable XRFS instruments are valuable for informing rapid decision-making. The fast determination of the concentration of $\mathrm{Cu}$ and contaminants in $\mathrm{Cu}$ ore slurry allowed ${ }^{512}$ the slurry composition to be modified, if necessary, before entering a high-capacity smelter, thereby improving the smelting and refining process. Quantitative high-density data for drilled igneous rocks were obtained ${ }^{513}$ on-board a ship during an IODP expedition in order to improve the selection of samples for further analysis and provide key information for drilling operations. A combination of pXRFS and benchtop SEM was used ${ }^{514}$ in the field to characterise the igneous stratigraphy in a drill core and its relationship to $\mathrm{Cu}-\mathrm{Pd}$ mineralisation. The geochemical data were used to inform the sampling strategy and increase the efficiency of mineral exploration. Mineralogical and geochemical characterisation of drill fines from a borehole by a combined pXRFS and portable XRD approach enabled geologists to identify different lithologies during drilling and modify their strategy as necessary ${ }^{515}$. In this context, a comparison ${ }^{516}$ of pXRFS measurements on unprepared cores and their equivalent powders showed that data quality was not compromised if an average of multiple measurements of different points on the intact sample were taken. Between three and seven measurements were recommended for a significant improvement in precision. 


\subsection{Data reduction software}

Together with sample preparation and the actual measurement strategies, data reduction is a very important stage in yielding reliable and accurate data from different analytical techniques. For this purpose, laboratories often apply either commercially-available software or in-house data reduction strategies via spreadsheets.

Various algorithms and software packages for handling isotopic data have been made available to the scientific community, including ET_Redux ${ }^{517}$, a free open-source software for $\mathrm{U}-\mathrm{Pb}$ geochronology using LA-ICP-MS data. An excellent description was provided of the principles of LA-ICP-MS data handling, statistical analysis of the data and uncertainty propagation, as well as the underlying algorithms. The new software was developed as a part of a collaborative effort to aid the compilation, comparison and archiving of data from different laboratories. A novel modelling procedure ${ }^{518}$, coded in $\mathrm{R}$, has been made available for the analysis of U-Pb datasets that contain discordant analyses, often the case when analysing detrital zircons. A new R-based software package ${ }^{519}$, IsotopeHf, was developed for handling data from Lu-Hf ID analyses by MC-ICP-MS.

For elemental analysis, an R script program ${ }^{520}$ called TERMITE provided very fast data reduction of trace element measurements obtained by the LA-ICP-MS of samples such as carbonates with a homogeneous matrix. The underlying calculations were described in detail. A Matlab-based program ${ }^{521}$, AERYN, improved the reliability of element distribution maps acquired by techniques such as EPMA and LA-ICP-MS. A new Matlab algorithm ${ }^{522}$ was developed to quantify $\mathrm{K}$, Th and $\mathrm{U}$ from natural gamma radiation spectra generated on-board ships. The performance of this algorithm was demonstrated by comparing results with those obtained using shore-based ICP-MS, ICP-AES and WDXRFS techniques. 


\section{Glossary of terms}

2D

3D

AAS

AES

AFS

AMS

APDG

AR

ASU

$\mathrm{BCR}$

$\mathrm{C}_{18}$

CA

CCP

CCRMP

CE

CNRCG

CPE

CRDS

CRM

CRPG

CS

CV

DA

DCM

DDC

DGT

DLLME

DMA

DME

DOC

DRC two-dimensional

three-dimensional

atomic absorption spectrometry

atomic emission spectrometry

atomic fluorescence spectrometry

accelerator mass spectrometry

atmospheric pressure glow discharge

Alpha Resources Inc. (USA)

Atomic Spectrometry Update

Community Bureau of Reference (of the European Community) now

IRMM

octadecyl bonded silica

chemical abrasion

capacitively coupled plasma

Canadian Certfied Reference Materials Project

capillary electrophoresis

China National Research Centre for Geoanalysis

cloud point extraction

cavity ring-down spectroscopy

certified reference material

Centre de Recherches Pétrographiques et Géochimiques (France)

continuum source

cold vapour

discriminant analysis

dichlormethane

diethyldithiocarbamate

diffusion gradient in thin films

dispersive liquid liquid microextraction

dimethylarsenic acid

dispersive microextraction

dissolved organic carbon

dynamic reaction cell 


\begin{tabular}{|c|c|}
\hline DRS & diffuse reflectance spectrometry \\
\hline EDS & energy dispersive X-ray spectroscopy \\
\hline EDTA & ethyldiaminetetraacetic acid \\
\hline EDXRFS & energy dispersive X-ray fluorescence spectrometry \\
\hline EM & electron multiplier \\
\hline $\mathrm{EN}$ & European Committee for Standardisation \\
\hline EPA & Environmental Protection Agency (USA) \\
\hline EPMA & electron probe microanalysis \\
\hline ERM & European Reference Material \\
\hline ETAAS & electrothermal atomic absorption spectrometry \\
\hline ETMAS & electrothermal molecular absorption spectrometry \\
\hline ETV & electrothermal vaporisation \\
\hline FAAS & flame atomic absorption spectrometry \\
\hline $\mathrm{FC}$ & faraday cup \\
\hline FFF & field flow fractionation \\
\hline FI & flow injection \\
\hline$f_{S}$ & femtosecond \\
\hline FTIR & Fourier transform infrared \\
\hline \multirow[t]{2}{*}{ GBW } & CRMs of the National Research Centre for Certified Reference \\
\hline & Materials (China) \\
\hline $\mathrm{GC}$ & gas chromatography \\
\hline GD & glow discharge \\
\hline GEOSTATS & Geostats Pty Ltd (Australia) \\
\hline GLS & gas liquid separator \\
\hline \multirow[t]{2}{*}{ GSB } & CRMs of the Institute for Environmental Reference Materials (of \\
\hline & Ministry of Environmental Protection, China) \\
\hline GSJ & Geological Survey of Japan \\
\hline GS-MS & gas source mass spectrometry \\
\hline $\mathrm{HG}$ & hydride generation \\
\hline HILIC & hydrophobic interaction liquid chromatography \\
\hline HPLC & high performance liquid chromatography \\
\hline HPS & High Purity Standards (USA) \\
\hline HR & high resolution \\
\hline IAEA & International Atomic Energy Agency \\
\hline
\end{tabular}


IAG

IC

ICP

ICP-AES

ICP-MS

ICP-MS/MS

id

ID

IDA

IGGE

INAA

INCT

IMS

IODP

IPGP

IRMM

IRMS

IS

IUPAC

LA

LASS

LGC

LIBS

LIF

LLE

LLME

LOD

LOQ

MAE

MC

MIL

MIP

MIR
International Association of Geoanalysts

ion chromatography

inductively coupled plasma

inductively coupled plasma atomic emission spectrometry

inductively coupled plasma mass spectrometry

inductively coupled plasma mass spectrometry with a quadrupole-cell-

quadrupole design

internal diameter

isotope dilution

isotope dilution analysis

Institute of Geochemical and Geochemical Exploration (China)

instrumental neutron activation analysis

Institute of Nuclear Chemistry and Technology (Poland)

Ion mobility spectrometry

International Ocean Discovery Program

Institute de Physigque du Globe de Paris (France)

Institute for Reference Materials and Measurements

isotope ratio mass spectrometry

internal standard

International Union of Pure and Applied Chemistry

laser ablation

laser ablation split stream

Laboratory of the Government Chemist (UK)

laser induced breakdown spectroscopy

laser induced fluorescence

liquid liquid extraction

liquid liquid microextraction

limit of detection

limit of quantification

microwave assisted extraction

multicollector

magnetic ion liquid

microwave induced plasma

mid infra red 
MMA

MP

MRI

MS

MWCNT

$m / z$

NBL

NCS

Nd:YAG

NEXAFS

$\mathrm{NIOSH}$

NIR

NIST

NKK

NMIA

NP

NRCC

NRCCRM

ns

NTIMS

NWRI

PGE

PLS

PLSR

$\mathrm{PM}_{2.5}$

$\mathrm{PM}_{10}$

ppm

PTE

PTFE

PVG

pXRFS

QC

REE

RIMS monomethylarsenic acid

microwave plasma

magnetic resonance imaging

mass spectrometry

multiwalled carbon nanotube

mass to charge ratio

New Brunswick Laboratories (USA)

National Analysis Centre for Iron and Steel (China)

neodymium doped:yttrium aluminum garnet

near edge X-ray absorption fine structure

National Institute of Occupational Safety and Health

near infrared

National Institute of Standards and Technology (USA)

Nippon Keikinzoku Kogyo (Japan)

National Measurement Institute of Australia

nanoparticle

National Research Council (of Canada)

National Research Centre for Certified Reference Materials (China)

nanosecond

negative thermal ionisation mass spectrometry

National Water Research Institute (Canada)

platinum group element

partial least squares

partial least squares regression

particulate matter (with an aerodynamic diameter of up to $2.5 \mu \mathrm{m}$ )

particulate matter (with an aerodynamic diameter of up to $10 \mu \mathrm{m}$ )

parts per million

potentially toxic element

poly(tetrafluoroethylene)

photochemical vapour generation

portable x-ray fluorescence spectrometry

quality control

rare earth element

resonance ionisation mas spectrometry 
$\mathrm{RM}$

rpm

RSD

RTC

SBME

SD

SEC

SEM

SF

SFODME

SI

SIMS

SMPS

$\mathrm{sp}$

SPE

SQT

SPS

SR

SRM

SSB

SVM

SXRFS

TBA

TEA

TEM

TEOM

TIMS

TLC

TOF

TXRFS

UAE

USGS

USN

UV reference material

revolutions per minute

relative standard deviation

RT Corporation (now Sigma-Aldrich RTC) (USA)

stir bar microextraction

standard deviation

size exclusion chromatography

scanning electron microscopy

sector field

solidification of a floating organic droplet microextraction

Système international (d'unités) (International System of Units)

secondary ion mass spectrometry

scanning mobility particle sizer

single particle

solid phase extraction

slotted quartz tube

Spectrapure Standards (Norway)

synchrotron radiation

standard reference material (of NIST)

sample-standard bracketing

support vector machine

synchrotron X-ray fluorescence spectrometry

tributylamine

transverse excited atmospheric

transmission electron microscopy

tapered element oscillating microbalance

thermal ionisation mass spectrometry

thin layer chromatography

time of flight

total reflection X-ray fluorescence spectrometry

ultrasonic extraction

United States Geological Survey

ultrasonic nebulisation

ultra violet 
VALLME

VIS

WDXRFS

XRD

$\mathrm{XRF}$

XRFS vortex assisted liquid liquid microextraction

visible

wavelength dispersive X-ray fluorescence spectrometry

$\mathrm{X}$-ray diffraction

$\mathrm{X}$-ray fluorescence

$\mathrm{X}$-ray fluorescence spectrometry 
1 O. T. Butler, W. R. L. Cairns, J. M. Cookc and C. M. Davidson, J. Anal. At. Spectrom., 2017, 32(1), 11-57.

2 A. Taylor, N. Barlow, M. P. Day, S. Hill, M. Patriarca and M. White, J. Anal. At. Spectrom., 2017, 32(3), 432-476.

3 E. H. Evans, J. Pisonero, C. M. M. Smith and R. N. Taylor, J. Anal. At. Spectrom., 2017, 32(5), 869-889.

4 R. Clough, C. F. Harrington, S. J. Hill, Y. Madrid and J. F. Tyson, J. Anal. At. Spectrom., 2017, 32(7), 1239-1282.

5 M. West, A. T. Ellis, C. Streli, C. Vanhoof and P. Wobrauschek, J. Anal. At. Spectrom., 2017, 32(9), 1629-1649.

6 S. Carter, A. Fisher, B. Gibson, J. Marshall, B. Russell and I. Whiteside, J. Anal. At. Spectrom., 2017, 32(11), 2068-2117.

7 I. De la Calle, M. Menta and F. Seby, Spectrochim. Acta, Part B, 2016, 125, 66-96.

8 C. Contado, Anal. Bioanal. Chem., 2017, 409(10), 2501-2518.

9 J. M. Costa-Fernández, M. Menéndez-Miranda, D. Bouzas-Ramos, J. R. Encinar and A. Sanz-Medel, TrAC, Trends Anal. Chem., 2016, 84(Part A), 139-148.

10 K. M. M. Kabir, S. J. Ippolito, A. E. Kandjani, Y. M. Sabri and S. K. Bhargava, TracTrends Anal. Chem., 2017, 88, 77-99.

11 T. Lee, L. Lee, E. Cauda, J. Hummer and M. Harper, J. Occup. Environ. Hyg., 2017, 14(5), 335-342.

12 C.-H. Chien, A. Theodore, C. Zhou, C.-Y. Wu, Y.-M. Hsu and B. Birky, J. Occup. Environ. Hyg., 2017, 14(7), 562-571.

13 J. Stewart, D. K. Sleeth, R. G. Handy, L. F. Pahler, T. R. Anthony and J. Volckens, J. Occup. Environ. Hyg., 2017, 14(3), 207-213.

14 D. J. H. Vosburgh, J. H. Park, L. W. D. Mines, I. A. Mudunkotuwa, T. R. Anthony and T. M. Peters, J. Occup. Environ. Hyg., 2017, 14(5), 368-376.

15 P. McGarry, S. Clifford, L. D. Knibbs, C. He and L. Morawska, J. Occup. Environ. Hyg., 2016, 13(10), D175-D197.

16 L. Zheng, P. Kulkarni, K. Zavvos, H. Liang, M. E. Birch and D. D. Dionysiou, J. Aerosol Sci, 2017, 104 (Supplement C), 66-78.

17 S. Gschwind, H. Graczyk, D. Gunther and M. Riediker, Environ.-Sci. Nano, 2016, 3(2), 357-364.

18 S. Q. Abad, P. Rodriguez-Gonzalez and J. I. G. Alonso, J. Trace Elem.Med. Bio., 2016, 36, 16-21.

19 S. Raja, S. R. Chandrasekaran, L. Lin, X. Xia, P. K. Hopke and K. T. Valsaraj, Aerosol and Air Quality Research, 2017, 17(1), 14-23.

20 J. Arndt, G. Ilgen and B. Planer-Friedrich, J. Volcanol.Geoth. Res., 2017, 331, 16-25.

21 R. J. C. Brown, E. C. Braysher, E. A. McGhee, S. L. Goddard, H. Ent, K.-H. Kim and J. Nielsen, Anal. Methods, 2017, 9(18), 2654-2659.

22 D. J. Mrozek, C. van der Veen, M. E. G. Hofmann, H. Chen, R. Kivi, P. Heikkinen and T. Röckmann, Atmos. Meas. Tech., 2016, 9(11), 5607-5620.

23 M. M. Schantz, D. Cleveland, N. A. Heckert, J. R. Kucklick, S. D. Leigh, S. E. Long, J. M. Lynch, K. E. Murphy, R. Olfaz, A. L. Pintar, B. J. Porter, S. A. Rabb, S. S. V. Pol, S. A. Wise and R. Zeisler, Anal. Bioanal. Chem., 2016, 408(16), 4257-4266.

24 K. J. Mathew, F. E. Stanley, M. R. Thomas, K. J. Spencer, L. P. Colletti and L. Tandon, Anal. Methods, 2016, 8(40), 7289-7305. 
P. Sperlich, N. A. M. Uitslag, J. M. Richter, M. Rothe, H. Geilmann, C. van der Veen, T. Rockmann, T. Blunier and W. A. Brand, Atmospheric Meas. Tech., 2016, 9(8), 37173737.

26 C. R. Quetel, M. Zampella and R. J. C. Brown, Trac-Trends in Analytical Chemistry, 2016, 85, 81-88.

27 M. V. B. Krishna, G. Venkateswarlu and D. Karunasagar, Anal. Methods, 2017, 9(13), 2031-2040.

28 S. Ponter, N. Pallavicini, E. Engstrom, D. C. Baxter and I. Rodushkin, J. Anal. At. Spectrom., 2016, 31(7), 1464-1471.

29 J. A. H. Alpofead, C. M. Davidson and D. Littlejohn, Anal. Methods, 2016, 8(27), 54665474.

30 M. L. Avramescu, P. E. Rasmussen, M. Chenier and H. D. Gardner, Environ. Sci. Pollut. Res., 2017, 24(2), 1553-1564.

31 L. G. Cao, J. Zheng, H. Tsukada, S. M. Pan, Z. T. Wang, K. Tagami and S. Uchida, Talanta, 2016, 159, 55-63.

32 N. Dzigal, E. Chinea-Cano, S. Walsh and A. Limbeck, Talanta, 2017, 167, 583-592.

33 M. Schindler, W. Kretschmer, A. Scharf and A. Tschekalinskij, Nucl. Instrum. Methods Phys. Res. Sect. B-Beam Interact. Mater. Atoms, 2016, 375, 100-106.

34 E. Grygo-Szymanko, A. Tobiasz and S. Walas, Trac-Trends in Analytical Chemistry, 2015, 80, 112-124.

35 N. Ozbek and A. Baysal, Int. J. Environ. Anal. Chem., 96(6), 505-514.

36 A. Baysal and S. Akman, Anal.Letters, 2016, 49(12), 1896-1902.

37 J. Górecki, A. Łoś, M. Macherzyński, J. Gołaś, P. Burmistrz and K. Borovec, Fuel Process. Technol., 2016, 154(Supplement C), 44-51.

38 N. Reed, J. X. Fang, S. Chavalmane and P. Biswas, Aerosol Sci. Technol., 2017, 51(3), 311-316.

39 V. Mohr, M. Miro and A. Limbeck, Anal. Bioanal. Chem., 2017, 409(10), 2747-2756.

40 A. J. Hynes, S. Everhart, D. Bauer, J. Remeika and C. T. Ernest, Atmos. Chem. Phys., 2017, 17(1), 465-483.

41 L. Zheng, P. Kulkarni, M. E. Birch, G. Deye and D. D. Dionysiou, Aerosol Sci. Technol., 2016, 50(11), 1155-1166.

42 T. Suoranta, S. N. H. Bokhari, T. Meisel, M. Niemela and P. Peramaki, Geostand. Geoanal. Res., 2016, 40(4), 559-569.

43 Z. Guo, D. D. Li, X. K. Luo, Y. H. Li, Q. N. Zhao, M. M. Li, Y. T. Zhao, T. S. Sun and C. Ma, J. Colloid Interface Sci., 2017, 490, 11-22.

44 M. Ohata and K. Nishiguchi, J. Anal. At. Spectrom., 2017, 32(4), 717-722.

45 Q. Huang, J. B. Chen, W. L. Huang, P. Q. Fu, B. Guinot, X. B. Feng, L. H. Shang, Z. H. Wang, Z. W. Wang, S. L. Yuan, H. M. Cai, L. F. Wei and B. Yu, Atmos. Chem. Phys., 2016, 16(18), 11773-11786.

46 S. Y. Huang, D. X. Yuan, H. Y. Lin, L. M. Sun and S. S. Lin, Appl. Geochem., 2017, 76, 159-167.

47 G. Y. Sun, J. Sommar, X. B. Feng, C. J. Lin, M. F. Ge, W. G. Wang, R. S. Yin, X. W. Fu and L. H. Shang, Environ. Sci. Technol., 2016, 50(17), 9232-9241.

48 J. Yin, X. Q. Yu, Y. E. Zhang, D. S. Shen, M. Z. Wang, Y. Y. Long and T. Chen, Bioresource Technol., 2016, 216, 996-1003.

49 F. Esaka, K. Yasuda, D. Suzuki, Y. Miyamoto and M. Magara, Talanta, 2017, 165, 122-127.

50 M. M. Arienzo, J. R. McConnell, N. Chellman, A. S. Criscitiello, M. Curran, D. Fritzsche, S. Kipfstuhl, R. Mulvaney, M. Nolan, T. Opel, M. Sigl and J. P. Steffensen, Environ. Sci. Technol., 2016, 50(13), 7066-7073. 
51 W. Said-Ahmad, K. Wong, M. McNall, L. Shawar, T. Jacksier, C. Turich, A. Stankiewicz and A. Amrani, Anal. Chem., 2017, 89(5), 3199-3207.

52 A. Hess, M. Tarik, D. Foppiano, P. Edinger and C. Ludwig, Energy Fuels, 2016, 30(5), 4072-4084.

53 M. S. Robinson, I. Grgić, V. S. Šelih, M. Šala, M. Bitsui and J. T. van Elteren, Atmospheric. Meas. Tech., 2017, 10(5), 1823-1830.

54 S. J. Walsh, N. Dzigal, E. Chinea-Cano and A. Limbeck, J. Anal. At. Spectrom., 2017, 32(6), 1155-1165.

55 C. Stephan and R. Thomas, Spectroscopy, 2017, 32(3), 12-25.

56 M. D. Montano, J. W. Olesik, A. G. Barber, K. Challis and J. F. Ranville, Anal. Bioanal. Chem., 2016, 408(19), 5053-5074.

57 P. L. Hayes, Analyst, 2017, 142(5), 687-690.

58 W. Xu, P. Croteau, L. Williams, M. Canagaratna, T. Onasch, E. Cross, X. Zhang, W. Robinson, D. Worsnop and J. Jayne, Aerosol Sci. Technol., 2017, 51(1), 69-83.

59 J. Peck, L. A. Gonzalez, L. R. Williams, W. Xu, P. L. Croteau, M. T. Timko, J. T. Jayne, D. R. Worsnop, R. C. Miake-Lye and K. A. Smith, Aerosol Sci.Technol., 2016, 50(8), 781-789.

60 W. Hu, P. Campuzano-Jost, D. A. Day, P. Croteau, M. R. Canagaratna, J. T. Jayne, D. R. Worsnop and J. L. Jimenez, Aerosol Sci. Technol., 2017, 51(6), 735-754.

61 C. M. Kenseth and G. A. Petrucci, Aerosol Sci. Technol., 2016, 50(8), 790-801.

62 P. Reitz, S. R. Zorn, S. H. Trimborn and A. M. Trimborn, J. Aerosol Sci, 2016, 98 (Supplement C), 1-14.

63 J. Park, T. H. Kim, C. G. Lee, J. Lee, S. H. Lim, S. H. Han and K. Song, J. Radioanal. Nucl. Chem., 2017, 311(2), 1535-1544.

64 D. Willingham, B. E. Naes, P. G. Heasler, M. M. Zimmer, C. A. Barrett and R. S. Addleman, J. Vac. Sci. Technol. B, 2016, 34(3), 9.

65 J. G. Tarolli, B. E. Naes, B. J. Garcia, A. E. Fischer and D. Willingham, J. Anal. At. Spectrom., 2016, 31(7), 1472-1479.

66 K. X. Li, B. Sinha and P. Hoppe, J. Vac. Sci. Technol. B, 2016, 34(3), 4.

67 J. H. Park and E. J. Choi, Talanta, 2016, 160, 600-606.

68 F. Esaka, D. Suzuki, T. Yomogida and M. Magara, Anal. Methods, 2016, 8(7), 15431548.

69 W. A. Brand, M. Rothe, P. Sperlich, M. Strube and M. Wendeberg, Rapid Commun. Mass Spectrom., 2016, 30(13), 1523-1539.

70 P. M. Magyar, V. J. Orphan and J. M. Eiler, Rapid Commun. Mass Spectrom., 2016, 30(17), 1923-1940.

71 L. van Roij, A. Sluijs, J. J. Laks and G. J. Reichart, Rapid Commun. Mass Spectrom., 2017, 31(1), 47-58.

72 S. Yatkin and M. Gerboles, Microchem. J., 2017, 133 (Supplement C), 423-430.

73 J. H. Park, I. A. Mudunkotuwa, K. J. Crawford, T. R. Anthony, V. H. Grassian and T. M. Peters, Aerosol Sci. Technol., 2017, 51(1), 108-115.

74 M. Furger, M. C. Minguillón, V. Yadav, J. G. Slowik, C. Hüglin, R. Fröhlich, K. Petterson, U. Baltensperger and A. S. H. Prévôt, Atmospheric. Meas. Tech., 2017, 10(6), 2061-2076.

75 M. Natali, A. Zanella, A. Rankovic, D. Banas, C. Cantaluppi, L. Abbadie and J. C. Lata, Environ. Sci. Pollut. Res., 2016, 23(23), 23496-23510.

76 A. F. Longo, D. J. Vine, L. E. King, M. Oakes, R. J. Weber, L. G. Huey, A. G. Russell and E. D. Ingall, Atmos. Chem. Phys., 2016, 16(21), 13389-13398.

77 E. Hansson, H. B. L. Pettersson, C. Fortin and M. Eriksson, Spectrochim. Acta, Part B, 2017, 131(Supplement C), 130-137. 

2415-2424.

79 L. Adams, A. Agrawal, J. P. Cronin and K. Ashley, Int. J. Environ. Anal. Chem., 2017, 97(3), 264-275.

80 D. B. Wang, M. H. Sowlat, M. M. Shafer, J. J. Schauer and C. Sioutas, Sci. Total Environ., 2016, 565, 123-131.

81 C. Wu, X. H. H. Huang, W. M. Ng, S. M. Griffith and J. Z. Yu, Atmos. Meas. Tech., 2016, 9(9), 4547-4560.

82 P. M. Davy, A. H. Tremper, E. M. G. Nicolosi, P. Quincey and G. W. Fuller, Atmos. Environ., 2017, 152 (Supplement C), 24-33.

83 L. Durdina, P. Lobo, M. B. Trueblood, E. A. Black, S. Achterberg, D. E. Hagen, B. T. Brem and J. Wang, Aerosol Sci. Technol., 2016, 50(9), 906-918. P. Stacey, K. T. Mader and C. Sammon, J. Raman Spectrosc., 2017, 48(5), 720-725.

85 E. I. Braun, A. Huang, C. A. Tusa, M. A. Yukica and P. Pantano, J. Occup. Environ. Hyg., 2016, 13(12), 915-923.

86 J. E. Krechmer, M. Groessl, X. Zhang, H. Junninen, P. Massoli, A. T. Lambe, J. R. Kimmel, M. J. Cubison, S. Graf, Y. H. Lin, S. H. Budisulistiorini, H. F. Zhang, J. D. Surratt, R. Knochenmuss, J. T. Jayne, D. R. Worsnop, J. L. Jimenez and M. R. Canagaratna, Atmospheric. Meas. Tech., 2016, 9(7), 3245-3262.

87 J. Puton and J. Namieśnik, TrAC, Trends Anal. Chem., 2016, 85(Part B), 10-20.

88 A. Karpf, Y. H. Qiao and G. N. Rao, Appl. Opt., 2016, 55(16), 4497-4504.

89 I. Galli, S. Bartalini, R. Ballerini, M. Barucci, P. Cancio, M. De Pas, G. Giusfredi, D. Mazzotti, N. Akikusa and P. De Natale, Optica, 2016, 3(4), 385-388.

90 N. Kallithrakas-Kontos and S. Foteinis, Curr. Anal. Chem., 2016, 12(1), 22-36.

91 B. Gworek, O. Bemowska-Kalabun, M. Kijenska and J. Wrzosek-Jakubowska, Water Air Soil Pollut., 2016, 227(10), 19.

92 A. Fisher and D. Kara, Anal. Chim. Acta, 2016, 935, 1-29.

93 J. P. Merrick, D. L. Saxby, I. White, L. Antin and E. J. Murby, Anal. Bioanal. Chem., 408(16), 4413-4424.

94 K. Kocot, K. Pytlakowska, B. Zawisza and R. Sitko, Trac-Trends in Analytical Chemistry, 2016, 82, 412-424.

95 L. B. Escudero, M. A. Maniero, E. Agostini and P. N. Smichowski, Trac-Trends in Analytical Chemistry, 2016, 80, 531-546.

96 Y. A. Azarova, A. V. Pestov and S. Y. Bratskaya, Cellulose, 2016, 23(4), 2273-2289.

97 J. Huber and K. Leopold, Trac-Trends in Analytical Chemistry, 2015, 80, 280-292.

98 I. de la Calle, F. Pena-Pereira, I. Lavilla and C. Bendicho, Anal. Chim. Acta, 2016, 936, 12-39.

99 L. Shen, J. Fischer, J. Martin, M. E. Hoque, L. Telgmann, H. Hintelmann, C. D. Metcalfe and V. Yargeau, Sci. Total Environ., 2016, 569, 223-233.

100 M. Marcinkowska and D. Baralkiewicz, Talanta, 2016, 161, 177-204.

101 A. K. Das, J. Indian Chem. Soc., 2016, 93(7), 809-814.

102 B. Daus and H. R. Hansen, Environ. Chem., 2016, 13(6), 913-918.

103 L. Trzonkowska, B. Lesniewska and B. Godlewska-Zylkiewicz, Crit. Rev. Anal. Chem., 2015, 46(4), 305-322.

104 I. Karadjova, I. Dakova, T. Yordanova and P. Vasileva, J. Anal. At. Spectrom., 2016, 31(10), 1949-1973.

105 S. L. Didukh, V. N. Losev, A. N. Mukhina and A. K. Trofimchuk, J. Anal. Chem., 2016, 71(11), 1081-1088.

106 H. Ahmad, A. A. Jalil and S. Triwahyono, RSC Adv., 2016, 6(91), 88110-88116.

107 M. Krawczyk-Coda, Spectrochim. Acta, Part B, 2017, 129, 21-27. 
108 G. Alpdogan, Fresenius Environ. Bull., 2016, 25(8), 2900-2908.

109 K. Pytlakowska, V. Kozik, M. Matussek, M. Pilch, B. Hachula and K. Kocot, RSC Adv., 2016, 6(49), 42836-42844.

110 E. Zolfonoun and S. R. Yousefi, J. Braz. Chem. Soc., 2016, 27(12), 2348-2353.

111 N. Zari, J. Hassan, K. Tabar-Heydar and S. H. Ahmadi, J. Braz. Chem. Soc., 2016, 27(10), 1881-1888.

112 I. Lopez-Garcia, S. Rengevicova, M. J. Munoz-Sandoval and M. Hernandez-Cordoba, Talanta, 2017, 162, 309-315.

113 K. Chandrasekaran and D. Karunasagar, J. Anal. At. Spectrom., 2016, 31(5), 1131 1140.

114 N. N. Meeravali, R. Manjusha, K. Madhavi and S. J. Kumar, Desalin. Water Treat., 2016, 57(55), 26880-26885.

115 M. S. Dundar, C. Caner, F. Kaptan and H. Altundag, At. Spectrosc., 2016, 37(5), 178183.

116 M. Ezoddin, K. Abdi and N. Esmaeili, Microchem. J., 2016, 129, 200-204.

117 E. A. Afshar, M. A. Taher, H. Fazelirad and M. Naghizadeh, Anal. Bioanal. Chem., 2017, 409(7), 1837-1843.

118 J. A. Lopez-Lopez, B. Herce-Sesa and C. Moreno, Talanta, 2016, 159, 117-121.

119 J. Ali, M. Tuzen and T. G. Kazi, Water Air Soil Pollut., 2017, 228(1), 13.

120 E. Aliyari, M. Alvand and F. Shemirani, Rsc Advances, 2016, 6(69), 64193-64202.

121 X. Y. Jia, D. R. Gong, J. N. Wang, F. Y. Huang, T. C. Duan and X. Zhang, Talanta, 160, 437-443.

122 Q. X. Zhou, Z. W. Zheng, J. P. Xiao and H. L. Fan, Talanta, 2016, 156, 196-203.

123 N. N. Meeravali, K. Madhavi and S. J. Kumar, J. Anal. At. Spectrom., 2016, 31(8), 1582-1589.

124 W. A. Al Rawahi and N. I. Ward, Talanta, 2017, 165, 391-397.

125 L. M. Furtado, M. Bundschuh and C. D. Metcalfe, Bull. Environ. Contam. Toxicol., 2016, 97(4), 449-455.

126 D. M. Schwertfeger, J. R. Velicogna, A. H. Jesmer, R. P. Scroggins and J. I. Princz, Anal. Chem., 2016, 88(20), 9908-9914.

127 C. Toncelli, K. Mylona, M. Tsapakis and S. A. Pergantis, J. Anal. At. Spectrom., 2016, 31(7), 1430-1439.

128 R. P. Lamsal, G. Jerkiewicz and D. Beauchemin, Anal. Chem., 2016, 88(21), 1055210558.

129 K. A. Huynh, E. Siska, E. Heithmar, S. Tadjiki and S. A. Pergantisi, Anal. Chem., 2016, 88(9), 4909-4916.

130 J. Soto-Alvaredo, F. Dutschke, J. Bettmer, M. Montes-Bayon, D. Profrock and A. Prange, J. Anal. At. Spectrom., 2016, 31(7), 1549-1555.

131 E. Begu, Y. Shlyapnikov, A. Stergarsek, P. Frkal, J. Kotnik and M. Horvat, Int. J. Environ. Anal. Chem., 2016, 96(7), 609-626.

132 H. Cui, W. Guo, L. L. Jin, Q. H. Guo and S. H. Hu, Anal. Methods, 2017, 9(8), $1307-$ 1312.

133 Y. T. Li, W. Guo, A. K. Souders, L. L. Jin, Y. Q. Ke, Q. H. Guo and S. H. Hu, RSC $A d v ., 2016,6(110), 108247-108254$.

134 Y. Gao, S. Z. Li, H. Y. He, T. L. Li, T. Yu, R. Liu, S. J. Ni and Z. M. Shi, Microchem. J., 2017, 130, 281-286.

135 R. X. Zhang, B. A. Shen, C. H. Li, C. B. Zheng and X. D. Hou, Microchem. J., 2016, 129, 98-103.

136 J. Giersz, M. Bartosiak and K. Jankowski, Talanta, 2017, 167, 279-285. 
137 V. K. Karandashev, A. Y. Leikin, V. A. Khvostikov, N. K. Kutseva and S. V. Pirogova, Inorg. Mater., 2016, 52(14), 1391-1404.

138 E. Kmiecik, B. Tomaszewska, K. Wator and M. Bodzek, Environ. Sci. Pollut. Res., 2016, 23(12), 11658-11667.

139 M. K. Behrens, J. Muratli, C. Pradoux, Y. Z. Wu, P. Boning, H. J. Brumsack, S. L. Goldstein, B. Haley, C. Jeandel, R. Paffrath, L. D. Pena, B. Schnetger and K. Pahnke, Mar. Chem., 186, 110-120.

140 F. F. de Campos and J. Enzweiler, Environ. Monit. Assess., 2016, 188(5), 18.

141 V. Hatje, K. W. Bruland and A. R. Flegal, Environ. Sci. Technol., 2016, 50(8), 41594168.

142 V. Nischwitz, N. Gottselig, A. Missong, T. Meyn and E. Klumpp, J. Anal. At. Spectrom., 2016, 31(9), 1858-1868.

143 J. Karasinski, E. Bulska, M. Wojciechowski, L. Halicz and A. A. Krata, Talanta, 2017, 165, 64-68.

144 J. Karasinski, E. Bulska, M. Wojciechowski, A. A. Krata and L. Halicz, J. Anal. At. Spectrom., 2016, 31(7), 1459-1463.

145 A. M. Desaulty, M. Meheut, C. Guerrot, C. Berho and R. Millot, Chem. Geol., 2017, 450, $122-134$.

146 B. M. Goodridge and D. L. Valentine, Anal. Chem., 2016, 88(20), 10126-10133.

147 A. M. Popov, A. N. Drozdova, S. M. Zaytsev, D. I. Biryukova, N. B. Zorov and T. A. Labutin, J. Anal. At. Spectrom., 2016, 31(5), 1123-1130.

148 X. Y. Yang, Z. Q. Hao, C. M. Li, J. M. Li, R. X. Yi, M. Shen, K. H. Li, L. B. Guo, X. Y. Li, Y. F. Lu and X. Y. Zeng, Opt. Express, 2016, 24(12), 13410-13417.

149 Q. Y. Lin, X. D. Han, J. Wang, Z. M. Wei, K. P. Liu and Y. X. Duan, J. Anal. At. Spectrom., 2016, 31(8), 1622-1630.

150 J. Jiao, X. C. Zhan, L. Zhai, X. T. Fan, H. L. Wen, J. H. Yuan, X. Liu and S. Guo, Spectrosc. Spectr. Anal., 2017, 37(1), 267-272.

151 K. Hagiwara, S. Kai, Y. Koike, M. Aizawa and T. Nakamura, Bunseki Kagaku, 2016, 65(9), 489-495.

152 L. L. Wang, H. S. Yu, L. N. Li, X. J. Wei and Y. Y. Huang, Nucl. Instrum. Methods Phys. Res. Sect. B-Beam Interact. Mater. Atoms, 2016, 375, 49-55.

153 B. Karbowska, Environ. Monit. Assess., 2016, 188(11), 19.

154 W. T. Bu, J. Zheng, X. M. Liu, K. M. Long, S. Hu and S. Uchida, Spectrochim. Acta, Part B, 2016, 119, 65-75.

155 X. L. Hou, M. Olsson, L. Togneri, S. Englund, K. Vaaramaa, C. Askeljung, O. Gottfridsson, H. Hirvonen, H. Ohlin, M. Forsstrom, F. Anders, M. Lampen and A. Hatakka, J. Radioanal. Nucl. Chem., 2016, 309(3), 1283-1319.

156 A. Rugova, M. Puschenreiter, G. Koellensperger and S. Hann, Anal. Chim. Acta, 2017, 956, 1-13.

157 E. Malucelli, M. Fratini, A. Notargiacomo, A. Gianoncelli, L. Merolle, A. Sargenti, C. Cappadone, G. Farruggia, S. Lagomarsino and S. Iotti, Analyst, 2016, 141(18), 52215235.

158 M. S. Ermolin and P. S. Fedotov, Rev. Anal. Chem, 2016, 35(4), 185-199.

159 A. Pastor, G. Gallello, M. L. Cervera and M. de la Guardia, Trac-Trends in Analytical Chemistry, 2016, 78, 48-59.

160 H. L. Byers, L. J. McHenry and T. J. Grundl, Geostand. Geoanal. Res., 2016, 40(3), 433-445.

161 Z. Fiket, N. Mikac and G. Kniewald, Geostand. Geoanal. Res., 2017, 41(1), 123-135.

162 H. Sahli, S. Rollin and J. A. C. Alvarado, J. Radioanal. Nucl. Chem., 2017, 311(3), 1633-1642. 
163 D. F. Araujo, G. R. Boaventura, J. Viers, D. S. Mulholland, D. Weiss, D. Araujo, B. Lima, I. Ruiz, W. Machado, M. Babinski and E. Dantas, J. Braz. Chem. Soc., 2017, 28(2), 225-235.

164 S. Liu, H. Z. Cui, Y. L. Li, A. L. Yang, J. F. Zhang, R. Zhong, Q. Zhou, M. Lin and X. F. Hou, Microchem. J., 2017, 131, 130-136.

165 I. Wysocka and E. Vassileva, Microchem. J., 2016, 128, 198-207.

166 E. Bulska, A. Krata, M. Kaabun and M. Wojciechowski, Environ. Sci. Pollut. Res., 2017, 24(9), 7889-7897.

167 D. Schwertfeger, J. Velicogna, A. Jesmer, H. McShane, R. Scroggins and J. Princz, Environ. Chem., 2017, 14(2), 123-133.

168 D. M. Schwertfeger, J. R. Velicogna, A. H. Jesmer, S. Saatcioglu, H. McShane, R. P. Scroggins and J. I. Princz, Anal. Chem., 2017, 89(4), 2505-2513.

169 H. El Hadri and V. A. Hackley, Environ.-Sci. Nano, 2017, 4(1), 105-116.

170 Y. B. Dan, X. M. Ma, W. L. Zhang, K. Liu, C. Stephan and H. L. Shi, Anal. Bioanal. Chem., 2016, 408(19), 5157-5167.

171 J. Jimenez-Lamana, J. Wojcieszek, M. Jakubiak, M. Asztemborska and J. Szpunar, J. Anal. At. Spectrom., 2016, 31(11), 2321-2329.

172 Z. T. Wang, J. Zheng, Y. Y. Ni, W. Men, K. Tagami and S. Uchida, Anal. Chem., 2017, 89(4), 2221-2226.

173 Z. T. Wang, J. Zheng, L. G. Cao, K. Tagami and S. Uchida, Anal. Chem., 2016, 88(14), 7387-7394.

174 Z. T. Wang, J. Zheng, K. Tagami and S. Uchida, J. Radioanal. Nucl. Chem., 2017, 312(1), 151-160.

175 Y. Miyamoto, K. Yasuda and M. Magara, J. Radioanal. Nucl. Chem., 2016, 309(1), 303-308.

176 K. L. Shi, X. L. Hou, J. X. Qiao, X. J. Sun, P. Roos and W. S. Wu, Anal. Chem., 2016, 88(23), 11931-11937.

177 F. Yang and G. Chen, Arab. J. Geosci., 2016, 9(5), 16.

178 J. Zheng, L. G. Cao, K. Tagami and S. Uchida, Anal. Chem., 2016, 88(17), 8772-8779.

179 C. D. B. Amaral, L. L. Fialho, F. P. R. Camargo, C. Pirola and J. A. Nobrega, Talanta, 2016, 160, 354-359.

180 D. Badocco, V. Di Marco, A. Piovan, R. Caniato and P. Pastore, Anal. Methods, 2016, 8(41), 7545-7551.

181 A. Durand, Z. Chase, A. T. Townsend, T. Noble, E. Panietz and K. Goemann, Int. J. Environ. Anal. Chem., 2016, 96(2), 119-136.

182 L. S. F. Pereira, M. F. Pedrotti, M. S. P. Enders, C. N. Albers, J. S. F. Pereira and E. M. M. Flores, Anal. Chem., 2017, 89(1), 980-987.

183 N. Limchoowong, P. Sricharoen, S. Techawongstien, S. Kongsri and S. Chanthai, J. Braz. Chem. Soc., 2017, 28(4), 540-546.

184 J. M. Matong, L. Nyaba and P. N. Nomngongo, Ecotox. Environ. Safe., 2017, 135, $152-$ 157.

185 S. M. Alvarez, N. E. Llamas, A. G. Lista, M. B. Alvarez and C. E. Domini, Ultrason. Sonochem., 2017, 34, 239-245.

186 D. J. Leao, M. M. Silva, J. B. Silva, D. A. F. de Oliveira, A. F. S. Queiroz and S. L. C. Ferreira, Anal. Methods, 2016, 8(35), 6554-6559.

187 Q. L. Fu, J. Z. He, H. Gong, L. Blaney and D. M. Zhou, J. Soils Sed., 2016, 16(5), 15571568.

188 E. A. Dayton, S. Whitacre and C. Holloman, Appl. Geochem., 2017, 78, 357-362.

189 J. P. Brady, I. Kinaev, A. Goonetilleke and G. A. Ayoko, Mar. Pollut. Bull., 2016, 106(1-2), 329-334. 
190 J. M. Garforth, E. H. Bailey, A. M. Tye, S. D. Young and S. Lofts, Chemosphere, 2016, 155, 534-541.

191 O. Acar, A. Tunceli and A. R. Turker, Food Anal. Meth., 2016, 9(11), 3201-3208.

192 L. Qi, Y. F. Zhang, Y. H. Ma, M. D. Chen, X. L. Ge, Y. Ma, J. Zheng, Z. Wang and S. Z. Li, Atmos. Pollut. Res., 2017, 7(3), 547-556.

193 I. Machado, I. Dol, E. Rodriguez-Arce, M. V. Cesio and M. Piston, Microchem. J., 2016, 128, 128-133.

194 A. D. Santos, R. A. Matos, E. M. J. Andrade, W. N. L. dos Santos, H. I. F. Magalhaes, F. D. Costa and M. Korn, J. Braz. Chem. Soc., 2017, 28(2), 376-384.

195 P. Masson and T. Dalix, Commun. Soil Sci. Plant Anal., 2016, 47(16), 1866-1874.

196 O. Jashnsaz and F. Nekouei, Commun. Soil Sci Plant Anal., 2016, 47(10), 1263-1274.

197 J. A. Tafur-Marinos, M. Ginepro, L. Pastero and V. Zelano, Anal. Lett., 2016, 49(11), $1722-1733$.

198 D. X. Guan, P. N. Williams, H. C. Xu, G. Li, J. Luo and L. Q. Ma, J. Hazard. Mater., 2016, 316, 69-76.

199 O. Hanousek, S. Mason, J. Santner, M. M. A. Chowdhury, T. W. Berger and T. Prohaska, Anal. Bioanal. Chem., 2016, 408(24), 6759-6767.

200 O. Hanousek, J. Santner, S. Mason, T. W. Berger, W. W. Wenzel and T. Prohaska, Anal. Bioanal. Chem., 2016, 408(29), 8333-8341.

201 C. Hoefer, J. Santner, S. M. Borisov, W. W. Wenzel and M. Puschenreiter, Anal. Chim. Acta, 2017, 950, 88-97.

202 M. A. Herrera, M. Rosende, M. A. Z. Arruda and M. Miro, Anal. Chim. Acta, 2016, 939, 1-9.

203 Y. H. Xu, J. H. Huang and H. Brandl, J. Environ. Sci., 2017, 53, 173-183.

204 A. Lock, D. Wallschlager, C. McMurdo, L. Tyler, N. Belzile and G. Spiers, Environ. Pollut., 2016, 219, 1102-1108.

205 B. Lesniewska, M. Krymska, E. Swierad, J. Wiater and B. Godlewska-Zylkiewicz, Environ. Sci. Pollut. Res., 2016, 23(24), 25093-25104.

206 M. Roushani, Y. M. Baghelani, S. Abbasi, S. Z. Mohammadi, M. Zahedifar and M. Mavaei, Commun. Soil Sci. Plant Anal., 2016, 47(10), 1207-1215.

207 V. N. Bulut, H. Demirci, D. Ozdes, A. Gundogdu, O. Bekircan, M. Soylak and C. Duran, Environ. Prog. Sustain. Energy, 2016, 35(6), 1709-1715.

208 R. Gurkan, N. Altunay and E. Yildirim, Food Anal. Meth., 2016, 9(11), 3218-3229.

209 X. J. Wang, G. L. Xu, P. Chen, X. Y. Liu, Y. Fang, S. Y. Yang and G. Z. Wang, RSC $A d v ., 2016,6(111), 110247-110254$.

210 L. A. Meira and F. D. Dias, Microchem. J., 2017, 130, 56-63.

211 A. Thongsaw, W. C. Chaiyasith, R. Sananmuang, G. M. Ross and R. J. AmpiahBonney, Food Chem., 2017, 219, 453-458.

212 O. Arslan, C. Karadas and D. Kara, J. AOAC Int., 2016, 99(5), 1356-1362.

213 M. Eftekhari, F. Javedani-Asleh and M. Chamsaz, Food Anal. Meth., 2016, 9(7), 19851992.

214 T. Voyslavov, S. Tsakovski and S. Ganeva, Turk. J. Chem., 2016, 40(6), 944-952.

215 J. Ali, M. Tuzen and T. G. Kazi, Water Air Soil Pollut., 2016, 227(6), 12.

216 N. Altunay, R. Gurkan and S. Korkmaz, Anal. Methods, 2016, 8(30), 5930-5939.

217 M. Tuzen, A. M. Shemsi and A. A. Bukhari, Food Anal. Meth., 2017, 10(1), 219-226.

218 P. Majumdar, D. Santra and M. Sarkar, J. Indian Chem. Soc., 2016, 93(7), 883-888.

219 M. Soylak and M. Karaca, At. Spectrosc., 2016, 37(3), 108-113.

220 M. Pouyan, G. Bagherian and N. Goudarzi, Microchem. J., 2016, 127, 46-51.

221 E. K. Varbanova, P. A. Angelov and V. M. Stefanova, Talanta, 2016, 160, 389-399.

222 S. Z. Chen, J. F. Li, D. B. Lu and Y. Zhang, Food Chem., 211, 741-747. 
223 X. F. He, L. X. Chen, X. Chen, H. M. Yu, L. X. Peng and B. J. Han, Sci Rep, 2016, 6, 8.

224 H. E. Bayrak, V. N. Bulut, M. Tufekci, H. Bayrak, C. Duran and M. Soylak, Toxicol. Environ. Chem., 2017, 99(4), 590-600.

225 Q. H. Wang, G. W. Deng, M. Yang, X. R. Li, B. K. Li and X. H. Li, Int. J. Environ. Anal. Chem., 2016, 96(10), 990-1002.

226 C. R. T. Tarley, K. M. Diniz, F. A. C. Suquila and M. G. Segatelli, RSC Adv., 2017, 7(31), 19296-19304.

227 Q. O. Santos, I. Moreno, L. Dos Santos, A. G. Santos, V. S. Souza and M. A. Bezerra, An. Acad. Bras. Cienc., 2016, 88(2), 791-799.

228 S. Tokalioglu, A. Papak and S. Kartal, Arab. J. Chem., 2017, 10(1), 19-23.

229 M. Tuzen, S. Sahiner and B. Hazer, Food Chem., 2016, 210, 115-120.

230 M. A. Habila, Z. A. Alothman, A. M. El-Toni and M. Soylak, Clean-Soil Air Water, 2016, 44(6), 720-727.

231 C. R. S. Santos, R. T. Yamaki, J. A. Barreto, C. S. A. Felix, R. M. Aguiar, L. A. Santos and M. A. Bezerra, Curr. Anal. Chem., 2016, 12(5), 417-424.

232 S. Baytak and V. T. Kasumov, Anal. Lett., 2017, 50(1), 105-116.

233 D. Trak, E. Kenduzler and Y. Arslan, Anal. Lett., 2016, 49(10), 1589-1599.

234 N. Ashouri, A. Mohammadi, M. Shekarchi, R. Hajiaghaee, N. Adib and B. AkbariAdergani, Desalin. Water Treat., 2016, 57(44), 20867-20876.

235 M. R. Pourjavid, M. Arabieh, S. R. Yousefi and A. A. Sehat, Microchem. J., 2016, 129, 259-267.

236 J. J. Wang, Y. J. Han, G. Zhao and X. H. Chen, Int. J. Environ. Anal. Chem., 2016, 96(14), 1341-1355.

237 S. Tokalioglu, E. Yavuz, H. Sahan, S. G. Colak, K. Ocakoglu, M. Kacer and S. Patat, Talanta, 2016, 159, 222-230.

238 M. M. Hassanien, W. I. Mortada, I. M. Kenawy and H. El-Daly, Appl. Spectmsc., 2017, 71(2), 288-299.

239 M. Krawczyk and E. Stanisz, Talanta, 2016, 161, 384-391.

240 B. Bitirmis, D. Trak, Y. Arslan and E. Kenduzler, Anal. Sci., 2016, 32(6), 667-671.

241 E. Yavuz, S. Tokalioglu, H. Sahan, A. Berberoglu and S. Patat, Microchimica Acta, 2017, 184(4), 1191-1198.

242 Y. H. Song, Y. Q. Chen, Y. Y. Fu, Y. F. Li, R. H. Zhou, S. H. Chen, J. F. Wu and L. Wang, J. Alloy. Compd., 2017, 703, 148-155.

243 Y. B. Cai, B. B. Chen, M. He, X. L. Liu and H. Bin, Spectrochim. Acta, Part B, 2017, 127, 56-63.

244 N. Ozbek and A. Baysal, Trac-Trends in Analytical Chemistry, 2017, 88, 62-76.

245 S. Aghabalazadeh, M. R. Ganjali and P. Norouzi, Spectrosc. Lett., 2016, 49(7), 491497.

246 A. C. M. Aleluia, F. A. de Santana, G. C. Brandao and S. L. C. Ferreira, Microchem. J., 2017, 130, 157-161.

247 D. V. Babos, A. I. Barros, E. C. Ferreira and J. A. G. Neto, Spectrochim. Acta, Part B, 2017, 130, 39-44.

248 A. R. Borges, D. N. Bazanella, A. T. Duarte, A. V. Zmozinski, M. G. R. Vale and B. Welz, Microchem. J., 2017, 130, 116-121.

249 M. Pozzatti, A. R. Borges, M. B. Dessuy, M. G. R. Vale and B. Welz, Anal. Methods, 2017, 9(2), 329-337.

250 W. Boschetti, M. Orlando, M. Dullius, M. B. Dessuy, M. G. R. Vale, B. Welz and J. B. de Andrade, J. Anal. At. Spectrom., 2016, 31(6), 1269-1277.

251 N. Ozbek and S. Akman, Food Chem., 2016, 211, 180-184. 
252 N. Ozbek and S. Akman, Food Anal. Meth., 2016, 9(10), 2925-2932.

253 F. V. Nakadi, M. da Veiga, M. Aramendia, E. Garcia-Ruiz and M. Resano, J. Anal. At. Spectrom., 2016, 31(7), 1381-1390.

254 B. L. Turner, A. W. Bielnicka, J. W. Dalling and J. A. Wolf, Commun. Soil Sci. Plant Anal., 2016, 47(21), 2378-2386.

255 K. Greda, K. Swiderski, P. Jamroz and P. Pohl, Anal. Chem., 2016, 88(17), 8812-8820.

256 T. Frentiu, S. Butaciu, E. Darvasi, M. Ponta, M. Frentiu and D. Petreus, Chemical Papers, 2017, 71(1), 91-102.

257 X. Liu, Z. F. Liu, Z. L. Zhu, D. He, S. Q. Yao, H. T. Zheng and S. H. Hu, Anal. Chem., 2017, 89(6), 3739-3746.

258 X. C. Duan, R. Sun and J. L. Fang, Spectrochim. Acta, Part B, 2017, 127, 11-16.

259 F. A. de Santana, L. A. Portugal, A. M. Serra, L. Ferrer, V. Cerda and S. L. C. Ferreira, Talanta, 2016, 156, 29-33.

260 M. M. Silva, L. A. Portugal, A. M. Serra, L. Ferrer, V. Cerda and S. L. C. Ferreira, Talanta, 2017, 165, 502-507.

261 B. A. Boughton, D. Thinagaran, D. Sarabia, A. Bacic and U. Roessner, Phytochem. Rev., 2016, 15(3), 445-488.

262 I. W. Croudace, B. C. Russell and P. W. Warwick, J. Anal. At. Spectrom., 2017, 32(3), 494-526.

263 J. R. Almirall and T. Trejos, Elements, 2016, 12(5), 335-340.

264 V. Lyubomirova, B. Todorov and R. Djingova, Comptes Rendus De L Academie Bulgare Des Sciences, 2016, 69(3), 275-282.

265 S. J. M. Van Malderen, B. Laforce, T. Van Acker, L. Vincze and F. Vanhaecke, J. Anal. At. Spectrom., 2017, 32(2), 289-298.

266 H. Lopez-Fernandez, G. D. Pessoa, M. A. Z. Arruda, J. L. Capelo-Martinez, F. FdezRiverola, D. Glez-Pena and M. Reboiro-Jato, J. Cheminform., 2016, 8, 10.

267 G. D. Pessoa, C. A. Lopes, K. C. Madrid and M. A. Z. Arruda, Talanta, 2017, 167, 317 324.

268 J. Saatz, H. Stryhanyuk, D. Vetterlein, N. Musat, M. Otto, T. Reemtsma, H. H. Richnow and B. Daus, Environ. Pollut., 2016, 216, 245-252.

269 R. F. Wei, Q. J. Guo, H. J. Wen, M. Peters, J. X. Yang, L. Y. Tian and X. K. Han, Anal. Sci., 2017, 33(3), 335-341.

270 R. C. Machado, C. D. B. Amaral, D. Schiavo, J. A. Nobrega and A. R. A. Nogueira, Microchem. J., 2017, 130, 271-275.

271 A. Virgilio, R. S. Amais, D. Schiavo, J. A. G. Neto and J. D. A. Nobrega, Anal. Lett., 2017, 50(5), 842-852.

272 X. Q. Hu, Z. Y. Cao, W. H. Sun, H. Yang, P. Xu and Z. W. Zhu, Anal. Methods, 2016, 8(32), 6150-6157.

273 C. D. B. Amaral, R. C. Machado, A. Virgilio, D. Schiavo, A. R. A. Nogueira and J. A. Nobrega, J. Anal. At. Spectrom., 273, 31(6), 1179-1184.

274 A. Mestrot, Y. Ji, S. Tandy and W. Wilcke, Environ. Chem., 2016, 13(6), 919-926.

275 P. Flis, L. Ouerdane, L. Grillet, C. Curie, S. Mari and R. Lobinski, New Phytologist, 2016, 211(3), 1129-1141.

276 S. Le Roux, P. Baker and A. Crouch, 2016, South African Journal of Chemistry-SuidAfrikaanse Tydskrif Vir Chemie, 69, 124-131.

277 W. J. Gui, C. X. Tian, Q. Q. Sun, S. Y. Li, W. Zhang, J. Tang and G. N. Zhu, Water Res., 2016, 95, 185-194.

278 E. Resongles, P. Le Pape, L. Fernandez-Rojo, G. Morin, S. Delpoux, J. Brest, S. Guo and C. Casiot, Anal. Methods, 2016, 8(40), 7420-7426. 
279 P. Y. Shuai, X. J. Yang, Z. Q. Qiu, X. H. Wu, X. Zhu, G. R. Pokhrel, Y. Y. Fu, H. M. Ye, W. X. Lin and G. D. Yang, J. Sep. Sci., 2016, 39(16), 3239-3245.

280 X. F. Mao, Y. Zhang, J. X. Liu, M. Wang, Y. Z. Qian, Z. W. Zhang, Y. H. Qi and C. L. Gao, RSC Adv., 2016, 6(54), 48699-48707.

281 A. Praetorius, A. Gundlach-Graham, E. Goldberg, W. Fabienke, J. Navratilova, A. Gondikas, R. Kaegi, D. Gunther, T. Hofmann and F. von der Kammer, Environ.-Sci. Nano, 2017, 4(2), 307-314.

282 J. Y. Peng, F. Liu, F. Zhou, K. L. Song, C. Zhang, L. H. Ye and Y. He, Trac-Trends in Analytical Chemistry, 2016, 85, 260-272.

283 G. S. Senesi and N. Senesi, Anal. Chim. Acta, 2016, 938, 7-17.

284 C. H. Chen, Q. Shi, S. Wang, Q. Y. Lin and Y. X. Duan, J. Anal. At Spectrom., 2016, 31(7), 1527-1533.

285 A. Khumaeni, Z. S. Lie, K. H. Kurniawan and K. Kagawa, J. Appl. Spectrosc., 2017, 83(6), 1061-1067.

286 T. A. Labutin, S. M. Zaytsev, A. M. Popov and N. B. Zorov, J. Anal. At. Spectrom., 2016, 31(11), 2223-2226.

287 R. X. Yi, J. M. Li, X. Y. Yang, R. Zhou, H. W. Yu, Z. Q. Hao, L. B. Guo, X. Y. Li, X. Y. Zeng and Y. F. Lu, Anal. Chem., 2017, 89(4), 2334-2337.

288 G. C. Y. Chan, I. Choi, X. L. Mao, V. Zorba, O. P. Lam, D. K. Shuh and R. E. Russo, Spectrochim. Acta, Part B, 2016, 122, 31-39.

289 R. Hedwig, K. Lahna, Z. S. Lie, M. Pardede, K. H. Kurniawan, M. O. Tjia and K. Kagawa, Appl. Opt., 2016, 55(32), 8986-8992.

290 S. Zivkovic, M. Momcilovic, A. Staicu, J. Mutic, M. Trtica and J. Savovic, Spectrochim. Acta, Part B, 2017, 127, 22-29.

291 P. C. Han, D. M. Dong, X. F. Du, L. Z. Jiao and X. D. Zhao, Anal. Methods, 2016, 8(37), 6705-6710.

292 C. J. Zhao, D. M. Dong, X. F. Du and W. G. Zheng, Sensors, 2016, 16(10), 13.

293 K. Q. Yu, Y. R. Zhao, F. Liu and Y. He, Sci Rep, 2016, 6, 10.

294 D. S. Meng, N. J. Zhao, M. J. Ma, Y. H. Gu, Y. Yu, L. Fang, Y. Y. Wang, Y. Jia, W. Q. Liu and J. G. Liu, Spectrosc. Spectr. Anal., 2017, 37(1), 241-246.

295 J. Y. Peng, K. L. Song, H. Y. Zhu, W. W. Kong, F. Liu, T. T. Shen and Y. He, Sci Rep, 2017, 7, 9 .

296 M. M. Tamboli, V. K. Unnikrishnan, R. Nayak, P. Devangad, K. M. M. Shameem, V. B. Kartha and C. Santhosh, J. Instrum., 2016, 11, 21.

297 G. Y. Zhao, M. Lian, Y. Y. Li, Z. Duan, S. M. Zhu, L. Mei and S. Svanberg, Appl. Opt., 2017, 56(5), 1506-1516.

298 J. N. Kunz, D. V. Voronine, B. A. Ko, H. W. H. Lee, A. Rana, M. V. Bagavathiannan, A. V. Sokolov and M. O. Scully, J.Mod. Opt., 2017, 64(9), 942-947.

299 J. N. Kunz, D. V. Voronine, H. W. H. Lee, A. V. Sokolov and M. O. Scully, Opt. Express, 2017, 25(7), 7251-7262.

300 H. A. Castillo-Michel, C. Larue, A. E. P. del Real, M. Cotte and G. Sarret, Plant Physiol. Biochem., 2017, 110, 13-32.

301 M. Rouillon and M. P. Taylor, Environ. Pollut., 2016, 214, 255-264.

302 K. G. Mejia-Pina, M. A. Huerta-Diaz and O. Gonzalez-Yajimovich, Talanta, 2016, 161, 359-367.

303 P. Sarala, Geochem.Explor. Env. Anal., 2016, 16(3-4), 181-192.

304 G. E. M. Hall, M. B. McClenaghan and L. Page, Geochem.Explor. Env. Anal., 2016, 16(1), 62-84.

305 E. Frahm, G. F. Monnier, N. A. Jelinski, E. P. Fleming, B. L. Barber and J. B. Lambon, J. Archaeol. Sci., 2016, 75, 115-138. 
306 T. H. Dao, Comput. Electron. Agric., 2016, 129, 84-90.

307 S. Chakraborty, D. C. Weindorf, G. J. Michaelson, C. L. Ping, A. Choudhury, T. Kandakji, A. Acree, A. Sharma and W. Dandan, Pedosphere, 2016, 26(4), 549-560.

308 V. Cardelli, D. C. Weindorf, S. Chakraborty, B. Li, M. De Feudis, S. Cocco, A. Agnelli, A. Choudhury, D. P. Ray and G. Corti, Geoderma, 2017, 288, 130-142.

309 S. M. O'Rourke, B. Minasny, N. M. Holden and A. B. McBratney, Soil Sci. Soc. Am. $J ., 2016,80(4), 888-899$.

310 H. Gallardo, I. Queralt, J. Tapias, L. Candela and E. Margui, Chemosphere, 2016, 156, 294-301.

311 R. Hohner, S. Tabatabaei, H. H. Kunz and U. Fittschen, Spectrochim. Acta, Part B, 2016, 125, 159-167.

312 R. Dalipi, E. Margui, L. Borgese and L. E. Depero, Food Chem., 2017, 218, 348-355.

313 I. Ramos, I. M. Pataco, M. P. Mourinho, F. Lidon, F. Reboredo, M. F. Pessoa, M. L. Carvalho, J. P. Santos and M. Guerra, Spectrochim. Acta, Part B, 2016, 120, 30-36.

314 H. Gallardo, I. Queralt, J. Tapias, M. Guerra, M. L. Carvalho and E. Margui, J. Food Compost. Anal., 2016, 50, 1-9.

315 E. D. Berezhnaya and A. V. Dubinin, Geochem. Int., 2017, 55(2), 218-224.

316 D. S. Macholdt, K. P. Jochum, S. A. Wilson, L. M. Otter, B. Stoll, U. Weis and M. O. Andreae, Geostand. Geoanal. Res., 2016, 40(4), 493-504.

317 M. A. W. Marks, M. A. Kendrick, G. N. Eby, T. Zack and T. Wenzel, Geostand. Geoanal. Res., 2017, 41(1), 107-122.

318 P. P. Zhao, J. Li, L. Zhang, Z. B. Wang, D. X. Kong, J. L. Ma, G. J. Wei and J. F. Xu, Geostand. Geoanal. Res., 2016, 40(2), 217-226.

319 C. Z. Yao, S. T. Yu, X. Q. Li, Z. Wu, J. J. Liang, Q. Q. Fu, W. Xiao, T. J. Jiang and Y. Tang, Anal. Bioanal. Chem., 2017, 409(4), 1093-1100.

320 S. Chen, Y. C. Liu, J. Y. Hu, Z. F. Zhang, Z. H. Hou, F. Huang and H. M. Yu, Geostand. Geoanal. Res., 2016, 40(3), 417-432.

321 L. P. Feng, L. Zhou, L. Yang, D. J. DePaolo, S. Y. Tong, Y. S. Liu, T. L. Owens and S. Gao, Geostand. Geoanal. Res., 2017, 41(1), 93-106.

322 J. Kimura, Q. Chang, T. Ishikawa and T. Tsujimori, J. Anal. At. Spectrom., 2016, 31(11), 2305-2320.

323 M. Carpentier, A. Gannoun, C. Pin and O. Sigmarsson, Geostand. Geoanal. Res., 2016, 40(2), 239-256.

324 H. L. Yuan, W. T. Yuan, Z. A. Bao, K. Y. Chen, F. Huang and S. G. Liu, Geostand. Geoanal. Res., 2017, 41(1), 77-84.

325 T. X. Ren, J. Wang, H. Lu, T. Zhou and Y. J. Zhou, Geostand. Geoanal. Res., 2016, 40(2), 227-238.

326 C. Archer, M. B. Andersen, C. Cloquet, T. M. Conway, S. Dong, M. Ellwood, R. Moore, J. Nelson, M. Rehkamper, O. Rouxel, M. Samanta, K. C. Shin, Y. Sohrin, S. Takano and L. Wasylenki, J. Anal. At. Spectrom., 2017, 32(2), 415-419.

327 P. Onuk, F. Melcher, R. Mertz-Kraus, H.-E. Gäbler and S. Goldmann, Geostand. Geoanal. Res., 2017, 41(2), 263-272.

328 D. M. Chew, M. G. Babechuk, N. Cogne, C. Mark, G. J. O'Sullivan, I. A. Henrichs, D. Doepke and C. A. McKenna, Chem. Geol., 2016, 435, 35-48.

329 A. M. Cruz-Uribe, R. Mertz-Kraus, T. Zack, M. D. Feineman, G. Woods and D. E. Jacob, Geostand. Geoanal. Res., 2017, 41(1), 29-40.

330 A. Cadoux, G. Iacono-Marziano, A. Paonita, E. Deloule, A. Aiuppa, G. N. Eby, M. Costa, L. Brusca, K. Berlo, K. Geraki, T. A. Mather, D. M. Pyle and I. Di Carlo, Chem. Geol., 2017, 452, 60-70. 
331 N. M. W. Roberts, E. T. Rasbury, R. R. Parrish, C. J. Smith, M. S. A. Horstwood and D. J. Condon, Geochem. Geophys. Geosyst., 2017, 18(7), 2807-2814.

332 C. J. Wall, J. S. Scoates and D. Weis, Chem. Geol., 2016, 436, 54-71.

333 L. Nasdala, F. Corfu, J. W. Valley, M. J. Spicuzza, F. Y. Wu, Q. L. Li, Y. H. Yang, C. Fisher, C. Muenker, A. K. Kennedy, P. W. Reiners, A. Kronz, M. Wiedenbeck, R. Wirth, C. Chanmuang, M. Zeug, T. Vaczi, N. Norberg, T. Haeger, A. Kroener and W. Hofmeister, Geostand. Geoanal. Res., 2016, 40(4), 457-475.

334 Y. T. Tian, P. Vermeesch, M. Danisik, D. J. Condon, W. Chen, B. Kohn, J. Schwanethal and M. Rittner, Chem. Geol., 2017, 454, 80-92.

335 C. LaFlamme, L. Martin, H. Jeon, S. M. Reddy, V. Selvaraja, S. Caruso, T. H. Bui, M. P. Roberts, F. Voute, S. Hagemann, D. Wacey, S. Littman, B. Wing, M. Fiorentini and M. R. Kilburn, Chem. Geol., 2016, 444, 1-15.

336 J. Hammerli, A. I. S. Kemp, N. Barrett, B. A. Wing, M. Roberts, R. J. Arculus, P. Boivin, P. M. Nude and K. Rankenburg, Chem. Geol., 2017, 454, 54-66.

337 L. Chen, K. Y. Chen, Z. Bao, P. Liang, T. T. Sun and H. L. Yuan, J. Anal. At. Spectrom., 2017, 32(1), 107-116.

338 M. S. A. Horstwood, J. Kosler, G. Gehrels, S. E. Jackson, N. M. McLean, C. Paton, N. J. Pearson, K. Sircombe, P. Sylvester, P. Vermeesch, J. F. Bowring, D. J. Condon and B. Schoene, Geostand. Geoanal. Res., 2016, 40(3), 311-332.

339 T. B. Coplen and Y. Shrestha, Pure Appl. Chem., 2016, 88(12), 1203-1224.

340 E. Helmeczi, Y. Wang and I. D. Brindle, Talanta, 2016, 160, 521-527.

341 R. Henrique-Pinto, S. J. Barnes, D. Savard and S. Mehdi, Geostand. Geoanal. Res., 2017, 41(1), 41-62.

342 J. Sikdar and V. K. Rai, J. Anal. At. Spectrom., 2017, 32(4), 822-833.

343 L. Strnad, O. Sebek, M. Fayadova and J. Vrba, Geostand. Geoanal. Res., 2016, 40(2), 257-266.

344 A. S. Dubenskiy, I. F. Seregina, Z. K. Blinnikova, M. P. Tsyurupa, L. A. Pavlova, V. A. Davankov and M. A. Bolshov, Talanta, 2016, 153, 240-246.

345 C. F. Li, X. C. Wang, J. H. Guo, Z. Y. Chu and L. J. Feng, J. Anal. At. Spectrom., 2016, 31(5), 1150-1159.

346 W. J. Li, C. L. Wang, B. Y. Gao, Y. T. Wang, X. D. Jin, L. C. Zhang and P. A. Sakyi, Microchem. J., 2016, 127, 237-246.

347 X. L. Cui, F. J. Tang, C. L. Li, Y. Zhang, P. Wang, S. Y. Li and X. S. Ye, Energy Technol., 2017, 5(4), 549-556.

348 S. Kagami and T. Yokoyama, Anal. Chim. Acta, 2016, 937, 151-159.

349 C. Pin and A. Gannoun, Anal. Chem., 2017, 89(4), 2411-2417.

350 B. Tibari, A. Vacherat, M. Stab, R. Pik, D. Yeghicheyan and P. Hild, Geostand. Geoanal. Res., 2016, 40(3), 365-375.

351 M. H. Huyskens, S. Zink and Y. Amelin, Chem. Geol., 2016, 438, 25-35.

352 K. E. Watts, M. A. Coble, J. A. Vazquez, C. D. Henry, J. P. Colgan and D. A. John, Chem. Geol., 2016, 439, 139-151.

353 C. X. Zhang, Z. C. Hu, W. Zhang, Y. S. Liu, K. Q. Zong, M. Li, H. H. Chen and S. H. Hu, Anal. Chem., 2016, 88(20), 10088-10094.

354 B. Stoll, K. P. Jochum, K. Herwig, M. Amini, M. Flanz, B. Kreuzburg, D. Kuzmin, M. Willbold and J. Enzweiler, Geostand. Geoanal. Res., 2008, 32(1), 5-26.

355 F. Nehring, D. E. Jacob, M. G. Barth and S. F. Foley, Microchimica Acta, 2008, 160(1), 153-163.

356 Z. Bao, H. F. Zhang, H. L. Yuan, Y. Liu, K. Y. Chen and C. L. Zong, J. Anal. At. Spectrom., 2016, 31(11), 2261-2271. 
357 J. Xu, S. Y. Yang, Z. C. Hu, T. Luo and X. T. Huang, Spectrosc. Spectr. Anal., 2016, 36(11), 3683-3688.

358 D. Peters and T. Pettke, Geostand. Geoanal. Res., 2017, 41(1), 5-28.

359 F. Z. Teng, N. Dauphas and J. M. Watkins, in Non-Traditional Stable Isotopes, Vol. 82, ed. F. Z. Teng, J. Watkins, N. Dauphas, Mineralogical Soc Amer \& Geochemical Soc, Chantilly, 2017, pp. 1-26.

360 J. D. Barnes and Z. D. Sharp, Rev. Mineral. Geochem., 2017, 82(1), 345-378.

361 F. Moynier, D. Vance, T. Fujii and P. Savage, in Non-Traditional Stable Isotopes, Vol. 82, ed. F. Z. Teng, J. Watkins, N. Dauphas, Mineralogical Soc Amer \& Geochemical Soc, Chantilly, 2017, pp. 543-600.

362 L. P. Qin and X. L. Wang, in Non-Traditional Stable Isotopes, Vol. 82, ed. F. Z. Teng, J. Watkins, N. Dauphas, Mineralogical Soc Amer \& Geochemical Soc, Chantilly, 2017, pp. 379-414.

363 O. J. Rouxel and B. Luais, in Non-Traditional Stable Isotopes, Vol. 82, ed. F. Z. Teng, J. Watkins, N. Dauphas, Mineralogical Soc Amer \& Geochemical Soc, Chantilly, 2017, pp. 601-656.

364 S. Penniston-Dorland, X. M. Liu and R. L. Rudnick, in Non-Traditional Stable Isotopes, Vol. 82, ed. F. Z. Teng, J. Watkins, N. Dauphas, Mineralogical Soc Amer \& Geochemical Soc, Chantilly, 2017, pp. 165-217.

365 F. Z. Teng, in Non-Traditional Stable Isotopes, Vol. 82, ed. F. Z. Teng, J. Watkins, N. Dauphas, Mineralogical Soc Amer \& Geochemical Soc, Chantilly, 2017, pp. 219-287.

366 B. Kendall, T. W. Dahl and A. D. Anbar, in Non-Traditional Stable Isotopes, Vol. 82, ed. F. Z. Teng, J. Watkins, N. Dauphas, Mineralogical Soc Amer \& Geochemical Soc, Chantilly, 2017, pp. 683-732.

367 T. Elliott and R. C. J. Steele, Rev. Mineral.Geochem., 2017, 82(1), 511-542.

368 F. Poitrasson, in Non-Traditional Stable Isotopes, Vol. 82, ed. F. Z. Teng, J. Watkins, N. Dauphas, Mineralogical Soc Amer \& Geochemical Soc, Chantilly, 2017, pp. 289344.

369 N. Dauphas, S. G. John and O. Rouxel, in Non-Traditional Stable Isotopes, Vol. 82, ed. F. Z. Teng, J. Watkins, N. Dauphas, Mineralogical Soc Amer \& Geochemical Soc, Chantilly, 2017, pp. 415-510.

370 J. D. Blum and M. W. Johnson, in Non-Traditional Stable Isotopes, Vol. 82, ed. F. Z. Teng, J. Watkins, N. Dauphas, Mineralogical Soc Amer \& Geochemical Soc, Chantilly, 2017, pp. 733-757.

371 M. Chaussidon, Z. B. Deng, J. Villeneuve, J. Moureau, B. Watson, F. Richter and F. Moynier, in Non-Traditional Stable Isotopes, Vol. 82, ed. F. Z. Teng, J. Watkins, N. Dauphas, Mineralogical Soc Amer \& Geochemical Soc, Chantilly, 2017, pp. 127-164.

372 E. E. Stüeken, Rev. Mineral. Geochem., 2017, 82(1), 657-682.

373 S. G. Nielsen, M. Rehkamper and J. Prytulak, in Non-Traditional Stable Isotopes, Vol. 82, ed. F. Z. Teng, J. Watkins, N. Dauphas, Mineralogical Soc Amer \& Geochemical Soc, Chantilly, 2017, pp. 759-798.

374 M. B. Andersen, C. H. Stirling and S. Weyer, Rev.Mineral.Geochem., 2017, 82(1), 799850.

375 S. K. Aggarwal, Radiochimica Acta, 2016, 104(7), 445-455.

376 P. J. Sylvester and S. E. Jackson, Elements, 2016, 12(5), 307-310.

377 F. E. Jenner and R. D. Arevalo, Elements, 2016, 12(5), 311-316.

378 J. D. Woodhead, M. S. A. Horstwood and J. M. Cottle, Elements, 2016, 12(5), 317-322.

379 W. Muller and J. Fietzke, Elements, 2016, 12(5), 329-334.

380 Y. K. Shazzo and Y. A. Karpov, J. Anal. Chem., 2016, 71(11), 1069-1080.

381 M. Jarosova, P. Sulovsky and D. Milde, Chem. Listy, 2016, 110(11), 769-778. 
382 E. Bruand, M. Fowler, C. Storey and J. Darling, Am. Miner., 2017, 102(1-2), 75-84.

383 N. Cook, C. L. Ciobanu, L. George, Z. Y. Zhu, B. Wade and K. Ehrig, Minerals, 2016, 6(4), 34.

384 T. Wagner, T. Fusswinkel, M. Walle and C. A. Heinrich, Elements, 12(5), 2016, 323328.

385 M. Steele-MacInnis, J. Ridley, P. Lecumberri-Santhez, T. U. Schlegel and C. A. Heinrich, Earth-Sci. Rev., 2016, 159, 14-35.

386 A. V. Volzhenin, N. I. Petrova, N. S. Medvedev, D. S. Irisov and A. I. Saprykin, J. Anal. Chem., 2017, 72(2), 156-162.

387 N. B. Piperov, L. P. Ivanova and A. N. Aleksandrova, Anal. Methods, 2016, 8(15), 3183-3195.

388 A. H. Bachari, F. Jalali and G. Alahyarizadeh, Radiochimica Acta, 2017, 105(2), 95108.

389 M. Karadjov, N. Velitchkova, O. Veleva, S. Velichkov, P. Markov and N. Daskalova, Spectrochim. Acta, Part B, 2016, 119, 76-82.

390 T. Xu, Y. Zhang, M. Zhang, Y. He, Q. L. Yu and Y. X. Duan, Spectrochim. Acta, Part $B, 2016,121,28-37$.

391 Y. Cho, S. Sugita, Y. N. Miura, R. Okazaki, N. Iwata, T. Morota and S. Kameda, Planet Space Sci., 2016, 128, 14-29.

392 M. D. Dyar, C. I. Fassett, S. Giguere, K. Lepore, S. Byrne, T. Boucher, C. J. Carey and S. Mahadevan, Spectrochim. Acta, Part B, 2016, 123, 93-104.

393 R. B. Anderson, S. M. Clegg, J. Frydenvang, R. C. Wiens, S. McLennan, R. V. Morris, B. Ehlmann and M. D. Dyar, Spectrochim. Acta, Part B, 2017, 129, 49-57.

394 M. D. Dyar, S. Giguere, C. J. Carey and T. Boucher, Spectrochim. Acta, Part B, 2016, 126, 53-64.

395 J. A. Aguilera and C. Aragon, J. Anal. At. Spectrom., 2017, 32(1), 144-152.

396 C. Lefebvre, A. Catala-Espi, P. Sobron, A. Koujelev and R. Leveille, Planet Space Sci., 2016, 126, 24-33.

397 G. S. Senesi, G. Tempesta, P. Manzari and G. Agrosi, Geostand. Geoanal. Res., 2016, 40(4), 533-541.

398 J. Klus, P. Mikysek, D. Prochazka, P. Porizka, P. Prochazkova, J. Novotny, T. Trojek, K. Novotny, M. Slobodnik and J. Kaiser, Spectrochim. Acta, Part B, 2016, 123, 143 149.

399 R. S. Harmon, R. R. Hark, C. S. Throckmorton, E. C. Rankey, M. A. Wise, A. M. Somers and L. M. Collins, Geostand. Geoanal. Res., 2017, n/a-n/a.

400 B. Connors, A. Somers and D. Day, Appl. Spectmsc., 2016, 70(5), 810-815.

401 O. Marincas, V. Floare-Avram, I. Feher, D. Lazar, C. Voica and I. Grosu, Anal. Lett., 2016, 49(16), 2659-2670.

402 S. Richter, S. Konegger-Kappel, S. F. Boulyga, G. Stadelmann, A. Koepf and H. Siegmund, J. Anal. At. Spectrom., 2016, 31(8), 1647-1657.

403 S. Chen, X. H. Wang, Y. L. Niu, P. Sun, M. Duan, Y. Y. Xiao, P. Y. Guo, H. M. Gong, G. D. Wang and Q. Q. Xue, Science Bulletin, 2017, 62(4), 277-289.

404 L. Whitty-Leveille, K. Turgeon, C. Bazin and D. Lariviere, Anal. Chim. Acta, 2017, 961, 33-41.

405 B. Hattendorf, B. Gusmini, L. Dorta, R. S. Houk and D. Gunther, ChemPhysChem, 2016, 17(17), 2640-2644.

406 B. Hattendorf, B. Gusmini, L. Dorta, R. S. Houk and D. Gunther, Anal. Chem., 2016, 88(14), 7281-7288.

407 S. Gilbert, P. Olin, J. Thompson, E. Lounejeva and L. Danyushevsky, J. Anal. At. Spectrom., 2017, 32(3), 638-646. 
408 V. Warter and W. Muller, Paleogeogr. Paleoclimatol. Paleoecol., 2017, 465, 362-375.

409 H. J. Wang, S. C. Zhang, Y. T. Ye, X. M. Wang, W. X. Zhou and J. Su, Chin. J. Anal. Chem., 2016, 44(11), 1665-1669.

410 T. Raimondo, J. Payne, B. Wade, P. Lanari, C. Clark and M. Hand, Contrib. Mineral. Petrol., 2017, 172(4), 22.

411 J. Parnell, S. Spinks and D. Bellis, Terra Nova, 2016, 28(3), 221-227.

412 M. Petrelli, K. Laeger and D. Perugini, Geosci. J., 2016, 20(6), 851-863.

413 M. L. Warburton, M. R. Reid, C. H. Stirling and G. Closs, Can. J. Fish. Aquat. Sci., 2017, 74(4), 572-581.

414 C. J. Kelly, D. A. Schneider, S. E. Jackson, T. Kalbfleisch and C. R. McFarlane, Chem. Geol., 2017, 449, 82-98.

415 K. J. Hogmalm, T. Zack, A. K. O. Karlsson, A. S. L. Sjoqvist and D. Garbe-Schonberg, J. Anal. At. Spectrom., 2017, 32(2), 305-313.

416 M. Ohata, Y. B. Zhu and N. Nonose, Anal. Sci., 2017, 33(3), 375-380.

417 C. D. Coath, T. Elliott and R. C. Hin, Chem. Geol., 2017, 451, 78-89.

418 N. Krabbe, T. S. Kruijer and T. Kleine, Chem. Geol., 2017, 450, 135-144.

419 D. Clases, M. Birka, M. Sperling, A. Faust and U. Karst, J. Trace Elem. Med Biol., 2017, 40, 97-103.

420 C. Cordier, C. Chauvel and C. Hemond, Geochim. Cosmochim. Acta, 2016, 189, 236250.

421 M. N. Dai, Z. A. Bao, K. Y. Chen, C. L. Zong and H. L. Yuan, J. Earth Sci., 2017, 28(1), 92-102.

422 W. X. Tang, J. Bin, W. Fan, Z. M. Zhang, Y. H. Yun and Y. Z. Liang, Anal. Methods, 2016, 8(27), 5475-5486.

423 H. Obayashi, M. Tanaka, K. Hattori, S. Sakata and T. Hirata, J. Anal. At. Spectrom., 2017, 32(3), 686-691.

424 K. Hattori, S. Sakata, M. Tanaka, Y. Orihashi and T. Hirata, J. Anal. At. Spectrom., 2017, 32(1), 88-95.

425 E. Marillo-Sialer, J. Woodhead, J. M. Hanchar, S. M. Reddy, A. Greig, J. Hergt and B. Kohn, Chem. Geol., 2016, 438, 11-24.

426 M. Guillong, J. T. Sliwinski, A. Schmitt, F. Forni and O. Bachmann, Geostand. Geoanal. Res., 2016, 40(3), 377-387.

427 J. Thompson, S. Meffre, R. Maas, V. Kamenetsky, M. Kamenetsky, K. Goemann, K. Ehrig and L. Danyushevsky, J. Anal. At. Spectrom., 2016, 31(6), 1206-1215.

428 C. C. Wohlgemuth-Ueberwasser, C. Tegner and V. Pease, Am. Miner., 2017, 102(3), 571-579.

429 L. Courtney-Davies, Z. Y. Zhu, C. L. Ciobanu, B. P. Wade, N. J. Cook, K. Ehrig, A. R. Cabral and A. Kennedy, Minerals, 2016, 6(3), 17.

430 C. R. M. McFarlane, Chem. Geol., 2016, 438, 91-102.

431 M. Willbold and T. Elliott, Chem. Geol., 2017, 449, 253-268.

432 M. Willbold, K. Hibbert, Y. J. Lai, H. Freymuth, R. C. Hin, C. Coath, F. Vils and T. Elliott, Geostand. Geoanal. Res., 2016, 40(3), 389-403.

433 D. Malinovsky, P. J. H. Dunn and H. Goenaga-Infante, J. Anal. At. Spectrom., 2016, 31(10), 1978-1988.

434 X. F. Chen, L. Zhang, G. J. Wei and J. L. Ma, J. Anal. At. Spectrom., 2016, 31(12), 2410-2417.

435 J. R. Farmer, B. Honisch and J. Uchikawa, Chem. Geol., 2016, 447, 173-182.

436 J. Irrgeher, P. Galler and T. Prohaska, Spectrochim. Acta, Part B, 2016, 125, 31-42.

437 M. Willmes, L. Kinsley, M. H. Moncel, R. A. Armstrong, M. Aubert, S. Eggins and R. Grun, J. Archaeol. Sci., 2016, 70, 102-116. 
438 J. A. M. Nanne, M. A. Millet, K. W. Burton, C. W. Dale, G. M. Nowell and H. M. Williams, J. Anal. At. Spectrom., 2017, 32(4), 749-765.

439 L. Y. Zhu, Y. S. Liu, T. T. Ma, J. Lin, Z. C. Hu and C. Wang, J.Anal. At. Spectrom., 2016, 31(7), 1414-1422.

440 C. Kato, F. Moynier, J. Foriel, F. Z. Teng and I. S. Puchtel, Chem. Geol., 2017, 448, 164-172.

441 W. Yuan, J. B. Chen, J. L. Birck, Z. Y. Yin, S. L. Yuan, H. M. Cai, Z. W. Wang, Q. Huang and Z. H. Wang, Anal. Chem., 2016, 88(19), 9606-9613.

442 X. Y. Zheng, B. L. Beard, S. Lee, T. R. Reddy, H. F. Xu and C. M. Johnson, Chem. Geol., 2017, 450, 235-247.

443 S. M. Chernonozhkin, M. Costas-Rodriguez, P. Claeys and F. Vanhaecke, J. Anal. At. Spectrom., 2017, 32(3), 538-547.

444 M. Oelze, J. A. Schuessler and F. von Blanckenburg, J. Anal. At. Spectrom., 2016, 31(10), 2094-2100.

445 D. A. Frick, J. A. Schuessler and F. von Blanckenburg, Anal. Chim. Acta, 2016, 938, 33-43.

446 Y. Hu, M. D. Harrington, Y. Sun, Z. Yang, J. Konter and F. Z. Teng, Rapid Commun. Mass Spectrom., 2016, 30(19), 2123-2132.

447 A. Quemet, M. Maloubier and A. Ruas, Int. J. Mass Spectrom., 2016, 404, 35-39.

448 J. F. Wotzlaw, Y. Buret, S. J. E. Large, D. Szymanowski and A. von Quadt, J. Anal. At. Spectrom., 2017, 32(3), 579-586.

449 R. Fukai, T. Yokoyama and S. Kagami, Int. J. Mass Spectrom., 2017, 414, 1-7.

450 C. F. Li, L. J. Feng, X. C. Wang, Z. Y. Chu, J. H. Guoa and S. A. Wilde, J. Anal. At. Spectrom., 2016, 31(12), 2375-2383.

451 H. L. Zhu, Z. F. Zhang, G. Q. Wang, Y. F. Liu, F. Liu, X. Li and W. D. Sun, 2016, Geostand. Geoanal. Res., 40(2), 185-194.

452 Y. Fukami, M. Tobita, T. Yokoyama, T. Usui and R. Moriwaki, J. Anal. At. Spectrom., 2017, 32(4), 848-857.

453 H. Vollstaedt, K. Mezger, T. Nagler, I. Leya and A. Trinquier, Int. J. Mass Spectrom., 2016, 401, 55-63.

454 K. van Zuilen, T. F. Nagler and T. D. Bullen, Geostand. Geoanal. Res., 2016, 40(4), 543-558.

455 J. Lin, Y. S. Liu, X. R. Tong, L. Y. Zhu, W. Zhang and Z. C. Hu, J. Anal. At. Spectrom., 2017, 32(4), 834-842.

456 E. A. Worsham, R. J. Walker and K. R. Bermingham, Int. J. Mass Spectrom., 2016, 407, 51-61.

457 J. Liu, H. J. Wen, Y. X. Zhang, H. F. Fan and C. W. Zhu, J. Anal. At. Spectrom., 2016, 31(6), 1287-1297.

458 N. S. Saji, D. Wielandt, C. Paton and M. Bizzarro, J. Anal. At.Spectrom., 2016, 31(7), 1490-1504.

459 M. Ek, A. C. Hunt and M. Schonbachler, J. Anal. At. Spectrom., 2017, 32(3), 647-656.

460 R. Liu, L. Hu and M. Humayun, Meteorit. Planet. Sci., 2017, 52(3), 479-492.

461 K. R. Bermingham, R. J. Walker and E. A. Worsham, Int. J. Mass Spectrom., 2016, 403, 15-26.

462 T. Hopp, M. Fischer-Godde and T. Kleine, J. Anal. At. Spectrom., 2016, 31(7), 15151526.

463 O. Hanousek, M. Brunner, D. Profrock, J. Irrgeher and T. Prohaska, Anal. Methods, 2016, 8(42), 7661-7672.

464 Z. Y. Zhu, S. Y. Jiang, C. L. Ciobanu, T. Yang and N. J. Cook, Chem. Geol., 2017, 450, 223-234. 
465 S. Wakaki and T. Tanaka, Int. J. Mass Spectrom., 2016, 407, 22-28.

466 M. Schulze, M. Ziegerick, I. Horn, S. Weyer and C. Vogt, Spectrochim. Acta, Part B, 2017, 130, 26-34.

467 M. Pfeifer, N. S. Lloyd, S. T. M. Peters, F. Wombacher, B. M. Elfers, T. Schulz and C. Munker, J. Anal. At. Spectrom., 2017, 32(1), 130-143.

468 C. D. Williams, P. E. Janney, R. R. Hines and M. Wadhwa, Chem. Geol., 2016, 436, 110.

469 S. Schuth, I. Horn, A. Bruske, P. E. Wolff and S. Weyer, Ore Geology Reviews, 2017, 81, 1271-1286.

470 G. J. Archer, A. Mundl, R. J. Walker, E. A. Worsham and K. R. Bermingham, Int. J. Mass Spectrom., 2017, 414, 80-86.

471 D. L. Cook and M. Schonbachler, J.Anal. At. Spectrom., 2016, 31(7), 1400-1405.

472 J. L. Hao, W. Yang, Y. Luo, S. Hu, Q. Z. Yin and Y. T. Lin, J. Anal. At. Spectrom., 2016, 31(12), 2399-2409.

473 M. E. Regier, R. L. Hervig, M. L. Myers, K. Roggensack and C. J. N. Wilson, Chem. Geol., 2016, 447, 27-39.

474 G. G. Kenny, M. J. Whitehouse and B. S. Kamber, Geology, 2016, 44(6), 435-438.

475 C. M. Wang, Y. P. Liu, W. B. Zhang, S. Hong, S. D. Hur, K. Lee, H. X. Pang and S. G. Hou, Ann. Glaciol., 2016, 57(71), 265-272.

476 R. C. J. Steele, V. S. Heber and K. D. McKeegan, Geochim. Cosmochim. Acta, 2017, 201, 245-259.

477 Y. D. Sun, M. Wiedenbeck, M. M. Joachimski, C. Beier, F. Kemner and C. Weinzierl, Chem. Geol., 2016, 440, 164-178.

478 M. G. Sliwinski, K. Kitajima, R. Kozdon, M. J. Spicuzza, J. H. Fournelle, A. Denny and J. W. Valley, Geostand. Geoanal. Res., 2016, 40(2), 157-172.

479 M. G. Sliwinski, K. Kitajima, R. Kozdon, M. J. Spicuzza, J. H. Fournelle, A. Denny and J. W. Valley, Geostand. Geoanal. Res., 2016, 40(2), 173-184.

480 A. Audétat, D. Garbe-Schönberg, A. Kronz, T. Pettke, B. Rusk, J. J. Donovan and H. A. Lowers, Geostand. Geoanal. Res., 2015, 39(2), 171-184.

481 S. Seitz, L. P. Baumgartner, A. S. Bouvier, B. Putlitz and T. Vennemann, Geostand. Geoanal. Res., 2017, 41(1), 69-75.

482 A. Didier, B. Putlitz, L. P. Baumgartner, A. S. Bouvier and T. W. Vennemann, Chem. Geol., 2017, 450, 199-209.

483 F. M. Deegan, M. J. Whitehouse, V. R. Troll, D. A. Budd, C. Harris, H. Geiger and U. Halenius, Chem. Geol., 2016, 447, 1-10.

484 C. Fabrega, D. Parcerisa, J. M. Rossell, A. Gurenko and C. Franke, J. Anal. At. Spectrom., 2017, 32(4), 731-748.

485 M. G. Sliwinski, K. Kitajima, R. Kozdon, M. J. Spicuzza, A. Denny and J. W. Valley, IJGGC, 2017, 57, 116-133.

486 R. Tartese, M. Chaussidon, A. Gurenko, F. Delarue and F. Robert, Geochim. Cosmochim. Acta, 2016, 182, 24-39.

487 M. Manzini, A. S. Bouvier, J. D. Barnes, M. Bonifacie, E. F. Rose-Koga, P. Ulmer, N. Metrich, G. Bardoux, J. Williams, G. D. Layne, S. Straub, L. P. Baumgartner and T. John, Chem. Geol., 2017, 449, 112-122.

488 R. Sharpe and M. Fayek, Rapid Commun. Mass Spectrom., 2016, 30(13), 1601-1611.

489 X. X. Ling, Q. L. Li, Y. Liu, Y. H. Yang, G. Q. Tang and X. H. Li, J. Anal. At. Spectrom., 2016, 31(8), 1680-1687.

490 X. X. Ling, M. H. Huyskens, Q. L. Li, Q. Z. Yin, R. Werner, Y. Liu, G. Q. Tang, Y. N. Yang and X. H. Li, Mineralogy and Petrology, 2017, 111(2), 163-172. 
491 J. J. Bellucci, M. J. Whitehouse, A. A. Nemchin, J. F. Snape, R. T. Pidgeon, M. Grange, S. M. Reddy and N. Timms, Chem. Geol., 2016, 438, 112-122.

492 L. Ruzie-Hamilton, P. L. Clay, R. Burgess, B. Joachim, C. J. Ballentine and G. Turner, Chem. Geol., 2016, 437, 77-87.

493 C. Welte, L. Wacker, B. Hattendorf, M. Christl, J. Fohlmeister, S. F. M. Breitenbach, L. F. Robinson, A. H. Andrews, A. Freiwald, J. R. Farmer, C. Yeman, H. A. Synal and D. Gunther, Anal. Chem., 2016, 88(17), 8570-8576.

494 T. Stephan, R. Trappitsch, A. M. Davis, M. J. Pellin, D. Rost, M. R. Savina, R. Yokochi and N. Liu, Int. J. Mass Spectrom., 2016, 407, 1-15.

495 A. J. Schauer, J. Kelson, C. Saenger and K. W. Huntington, Rapid Commun. Mass Spectrom., 2016, 30(24), 2607-2616.

496 X. Wang, L. L. Cui, Y. Y. Li, X. F. Huang, J. X. Zhai and Z. L. Ding, Int. J. Mass Spectrom., 2016, 403, 8-14.

497 J. Goedert, F. Fourel, R. Amiot, L. Simon and C. Lecuyer, Rapid Commun. Mass Spectrom., 2016, 30(18), 2002-2008.

498 W. N. Han, L. J. Feng, H. W. Li and W. Liu, Rapid Commun. Mass Spectrom., 2017, 31(1), 16-20.

499 E. D. Hoegg, C. J. Barinaga, G. J. Hager, G. L. Hart, D. W. Koppenaalb and R. K. Marcus, J. Anal. At. Spectrom., 2016, 31(12), 2355-2362.

500 E. D. Hoegg, C. J. Barinaga, G. J. Hager, G. L. Hart, D. W. Koppenaal and R. K. Marcus, J. Am. Soc. Mass Spectrom., 2016, 27(8), 1393-1403.

501 S. Uhlig, R. Mockel and A. Plessow, X-Ray Spectrom., 2016, 45(3), 133-137.

502 V. Chubarov, A. Amosova and A. Finkelshtein, X-Ray Spectrom., 2016, 45(6), 352356.

503 V. Chubarov, T. Aisueva and A. Finkelshtein, Anal. Lett., 2016, 49(13), 2099-2107.

504 A. Younis, Z. Ahmadi, M. G. Adams and A. Iqbal, X-Ray Spectrom., 2017, 46(1), 6976.

505 J. J. Huang, L. Lowemark, Q. Chang, T. Y. Lin, H. F. Chen, S. R. Song and K. Y. Wei, Geochem. Geophys. Geosyst., 2016, 17(4), 1558-1566.

506 Q. Chen, C. Kissel, A. Govin, Z. F. Liu and X. Xie, Geochem. Geophys. Geosyst., 2016, 17(5), 1925-1934.

507 A. Rahman, G. Timms, M. S. Shahriar, C. Sennersten, A. Davie, C. A. Lindley, A. D. Hellicar, G. Smith, D. Biggins and M. Coombe, IEEE Sens. J., 2016, 16(11), 45554565.

508 K. E. Young, C. A. Evans, K. V. Hodges, J. E. Bleacher and T. G. Graff, Appl. Geochem., 2016, 72, 77-87.

509 K. Mauriohooho, S. L. L. Barker and A. Rae, Geothermics, 2016, 64, 125-134.

510 A. E. Steiner, R. M. Conrey and J. A. Wolff, Chem. Geol., 2017, 453, 35-54.

511 S. C. Lynch, A. J. Locock, M. J. M. Duke and A. W. Weber, J. Radioanal. Nucl. Chem., 2016, 309(1), 257-265.

512 B. J. Burnett, N. J. Lawrence, J. N. Abourahma and E. B. Walker, Appl. Spectmsc., 2016, 70(5), 826-828.

513 J. G. Ryan, J. W. Shervais, Y. Li, M. K. Reagan, H. Y. Li, D. Heaton, M. Godard, M. Kirchenbaur, S. A. Whattam, J. A. Pearce, T. Chapman, W. Nelson, J. Prytulak, K. Shimizu, K. Petronotis and I. E. S. Team, Chem. Geol., 2017, 451, 55-66.

514 Y. H. Cao, R. L. Linnen, D. J. Good, I. M. Samson and R. Epstein, Geochem. Explor. Env. Anal., 2016, 16(3-4), 193-212.

515 Y. A. Uvarova, M. F. Gazley, J. S. Cleverley, A. Baensch, D. Lawie and M. leGras, J. Geochem. Explor., 2016, 170, 1-9.

516 A. Bourke and P. S. Ross, Geochem. Explor. Env. Anal., 2016, 16(2), 147-157. 
517 N. M. McLean, J. F. Bowring and G. Gehrels, Geochem. Geophys. Geosyst., 2016, 17(7), 2480-2496.

518 J. R. Reimink, J. Davies, J. W. F. Waldron and X. Rojas, J. Geol.Soc., 2016, 173(4), 577-585.

519 R. Gonzalez-Guzman, B. Weber, M. D. Tazzo-Rangel and L. Solari, Revista Mexicana De Ciencias Geologicas, 2016, 33(2), 254-269.

520 S. A. Mischel, R. Mertz-Kraus, K. P. Jochum and D. Scholz, Rapid Commun. Mass Spectrom., 2017, 31(13), 1079-1087.

521 V. Mouchi, Q. G. Crowley and T. Ubide, Appl. Geochem., 2016, 75, 44-53.

522 D. De Vleeschouwer, A. G. Dunlea, G. Auer, C. H. Anderson, H. Brumsack, A. de Loach, M. Gurnis, Y. Huh, T. Ishiwa, K. Jang, M. A. Kominz, C. Marz, B. Schnetger, R. W. Murray, H. Palike and S. Expedition, Geochem. Geophys Geosyst., 2017, 18(3), 1053-1064. 